\title{
Deconstruction and Design for Disassembly: Analyzing Building Material Salvage and Reuse
}

by

Taylor Martin Highet Balodis

A thesis submitted to the Faculty of Graduate and Postdoctoral Affairs in partial fulfillment of the requirements for the degree of

Master of Architecture

Carleton University

Ottawa, Ontario

(C) 2017

Taylor Martin Highet Balodis 


\section{ABSTRACT}

Building construction and demolition waste contribute greatly to the total mass found in landfills. While the traditional linear building model demands new materials for new projects, adopting cyclical models of reclamation and reuse will provide a more resourceful and sustainable future.

This thesis proposes designing a building for disassembly by reusing salvaged materials in the Vanier neighbourhood of Ottawa. As the last major area near downtown that has yet to be developed, Vanier is a model that represents places where aging structures provide an opportunity for material evolution among the existing urban fabric, and where land value is beginning to outweigh the value in rehabilitating obsolete buildings situated on it.

Utilizing digital workflows, this thesis project will examine deconstructing derelict buildings and structures found on several Vanier properties as the base material palette for designing a new addition to an existing commercial structure with the ability to be methodically disassembled.

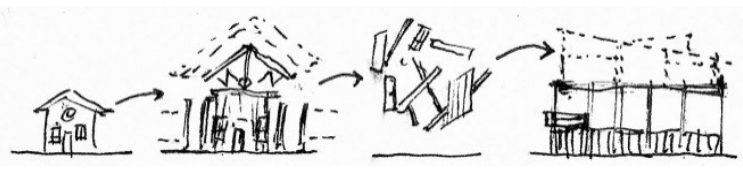

Figure 1: Conceptual sketch of project idea. 


\section{ACKNOWLEDGMENTS}

Thank you to my advisor, Stephen Fai, for his ideas and support throughout the development of this thesis. His guidance helped form what was initially a scrambled overlap of my interests into a focused subject that I became passionate about and will influence decisions I will take forward in my career.

I would also like to thank Sheryl Boyle for her course on recycling architecture that enhanced my knowledge on the subject of material salvage and adaptive reuse. Her contributions regarding the importance of art programs and artistic events in areas of urban decline proved valuable towards the development of the proposed programming.

Lastly my thanks to Susan Ross who, with spirited discussions on material salvage and reuse, brought to light the unique heritage values associated with our built environment. 


\section{TABLE OF CONTENTS}

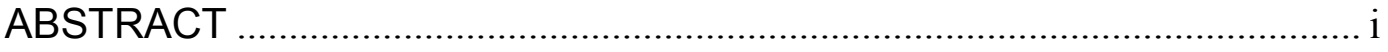

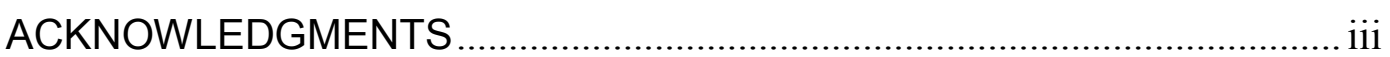

TABLE OF CONTENTS …………............................................................. iv

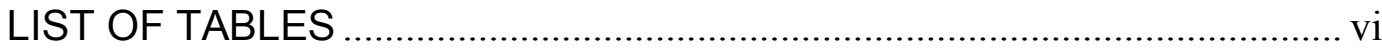

LIST OF ILLUSTRATIONS ....................................................................... vii

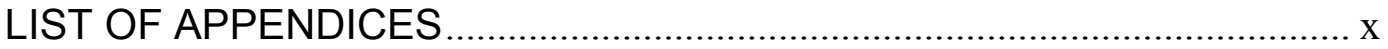

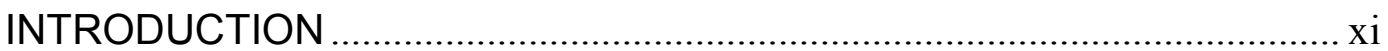

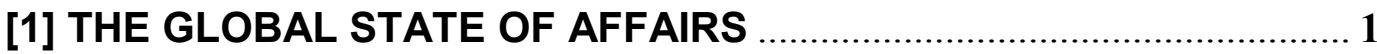

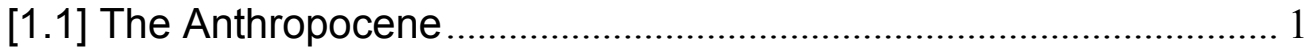

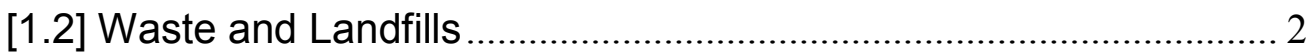

[1.3] Production and Consumption ........................................................... 5

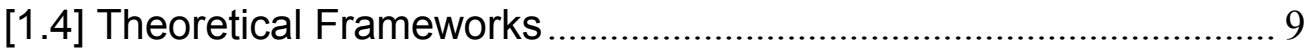

[1.5] Public and Private Initiatives.......................................................... 15

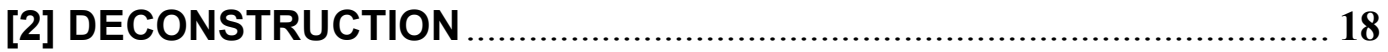

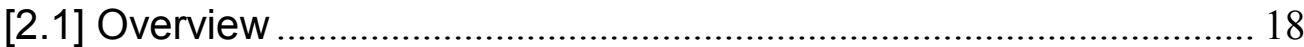

[2.2] Economic and Environmental Benefits ........................................ 19

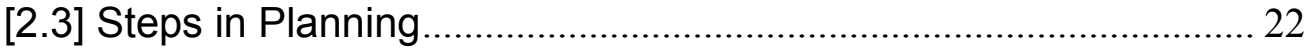

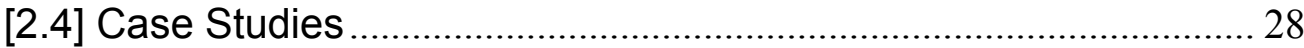

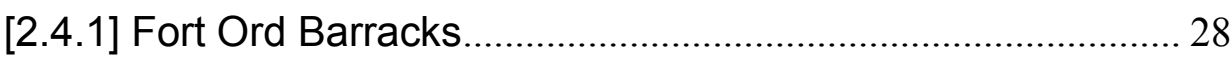

[2.4.2] Riverdale Village Apartments.............................................. 30

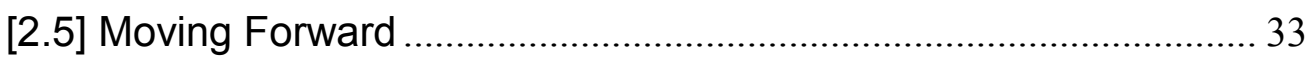

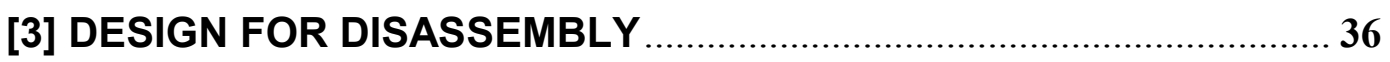

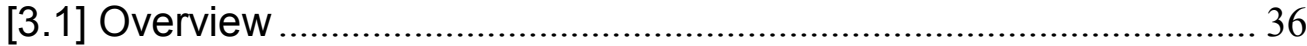

[3.2] Economic and Environmental Benefits ........................................... 37

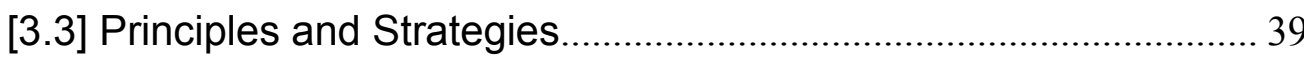

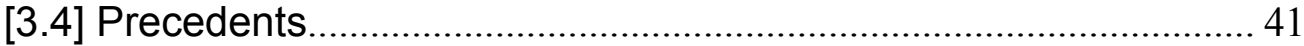

[3.4.1] Mountain Equipment Co-op Store ........................................ 41

[3.4.2] Woodward Avenue Environmental Laboratory..................... 43 


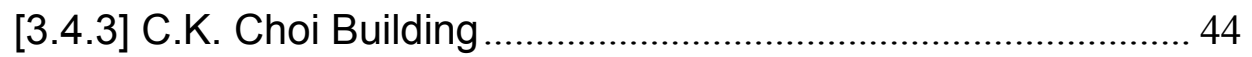

[3.4.4] Chartwell School ..................................................................... 46

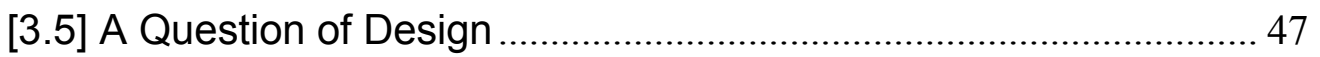

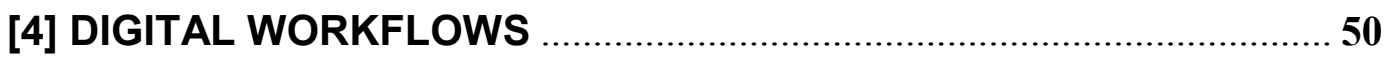

[4.1] Building Documentation and Assessment...................................... 50

[4.2] Enhanced Coordination ..................................................................... 54

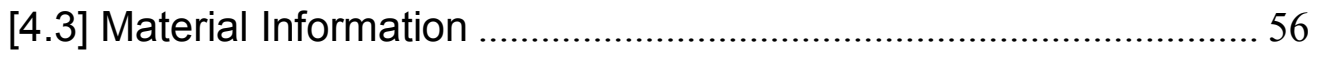

[4.4] Record Model and Manuals ............................................................ 59

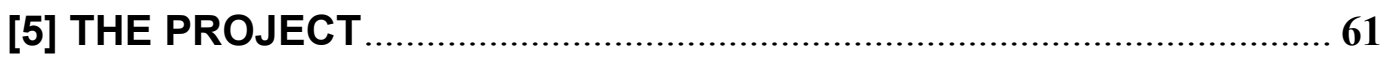

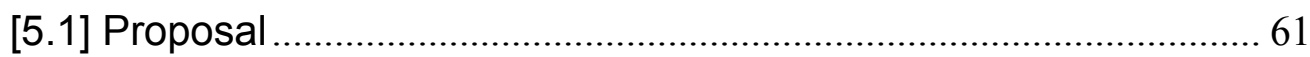

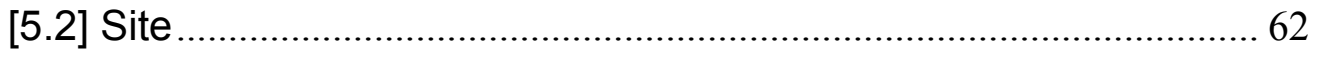

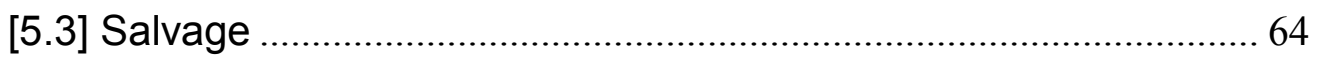

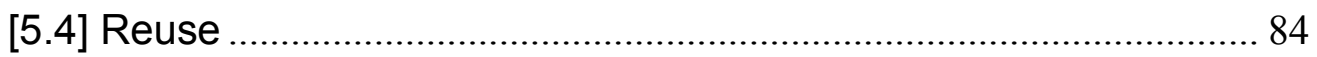

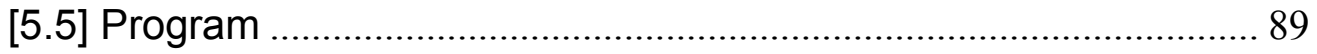

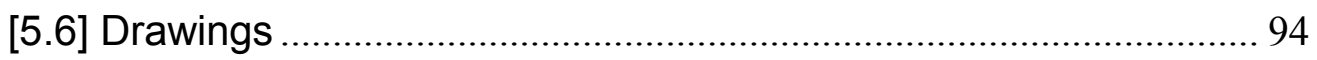

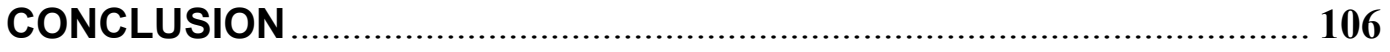

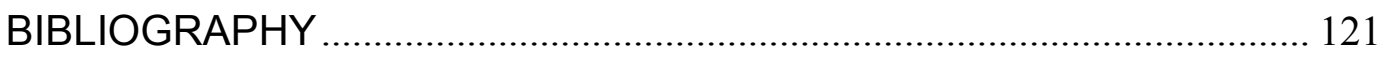

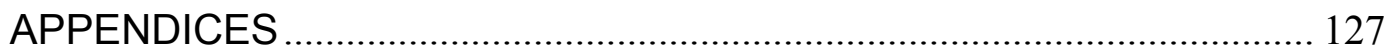

[A.1] Public and Private Initiatives ........................................................ 127 


\section{LIST OF TABLES}

Table 1: Time required per task category of deconstruction.

(Source: NAHB, 1997)

Table 2: Material diversion rates.

(Based on NAHB, 1997)

Table 3: Results of Riverdale Site Sale.

(Source: NAHB, 1997)

Table 4: Comparison of Deconstruction and Demolition Costs: Overall Project

(Source: NAHB, 1997).

Table 5: Riverdale Case Study quantities of salvaged materials

(Adapted from: NAHB, 1997)

Table 6: 234 Montreal Road - BIM structural framing calculations.

Table 7: 234 Montreal Road - estimated lumber amounts per type after deductions.

Table 8: 234 Montreal Road - estimated quantity of pieces per type by length.

Table 9: 270 Montreal Road - BIM structural framing calculations.

Table 10: 270 Montreal Road - estimated lumber amounts per type after deductions.

Table 11: 270 Montreal Road - estimated quantity of pieces per type by length.

Table 12: $329-331$ Lajoie Street - BIM structural framing calculations.

Table 13: 329-331 Lajoie Street - estimated lumber amounts per type after deductions.

Table 14: 329-331 Lajoie Street - estimated quantity of pieces per type by length.

Table 15: 315 Savard Avenue - BIM structural framing calculations.

Table 16: 315 Savard Avenue - estimated lumber amounts per type after deductions.

Table 17: 315 Savard Avenue - estimated quantity of pieces per type by length.

Table 18: 189 Carillon Street - BIM structural framing calculations.

Table 19: 189 Carillon Street - estimated lumber amounts per type after deductions.

Table 20: 189 Carillon Street - estimated quantity of pieces per type by length.

Table 21: Comparing estimated lumber amounts of subject properties.

Table 22: Comparing estimated lumber quantities to building area of existing properties

Table 23: Proposed Design - BIM structural framing calculations.

Table 24: Comparing existing and proposed building statistics.

Table 25: Comparing two-thirds adjusted existing building statistics to the proposed design. 


\section{LIST OF ILLUSTRATIONS}

All images by author unless otherwise noted.

For figures grouped as a series: $L=$ left, $C=$ centre, $R=$ right

Figure 3: The Think chair by Steelcase is $95 \%$ recyclable by weight. Disassembly takes just

five minutes with ordinary tools.

Steelcase. Title unknown. Photograph. 2016. Retrieved from https://www.steelcase.com/content/uploads/2015/02/thinkbrochure.pdf

Figure 4: Biological and technical nutrient cycles in the Cradle-to-Cradle design

framework.

Zhiying Lim. Biological and Technical Cycles. Illustration. 2012. Retrieved from https://en.wikipedia.org/wiki/Cradle-to-cradle_design\#/media/File:

Biological_and_technical_nutrients_(C2C).jpg

Figure 6: Stewart Brand's "six S's" diagram of time-related building layers.

Donald Ryan. Shearing Layers of Change. Illustration. Scanned from Brand, Stewart. How Buildings Learn: What Happens After They're Built. New York, NY: Viking, 1994.

Figure 7: Deconstruction Rapid Assessment Tool Action Framework illustrates how access

to materials and their market value can help with decision-making.

US EPA. DRAT Action Framework. Illustration. 2015. Retrieved from https://www.epa.gov/sites/production/files/2015-07/documents/dratinstructions.pdf

Figure 8: Images showing process of deconstructing Fort Ord Barracks; roof removal,

raised work areas, deboarding techniques, denailing and planing stations.

All images US EPA. Fort Ord Barracks Deconstruction. Photograph. 2006. Retrieved from https://www.epa.gov/sites/production/files/201511/documents/designfordeconstrmanual.pdf.

Figure 9: This mobile lead based paint remover is air-tight with negative pressure that captures any shavings created when wood passes through the built-in planer.

All images US EPA. Fort Ord Barracks Deconstruction. Photograph. 2006. Retrieved from https://www.epa.gov/sites/production/files/201511/documents/designfordeconstrmanual.pdf. 
Figure 10: The Riverdale Village Apartment deconstruction made important observations

about labour requirements and activities, job training, diversion rates, salvage

values, and cost comparisons.

L Author unknown. Disassembly of $1 x 6$ pine roof deck. Photograph. Date unknown.

Retrieved from

http://www3.epa.gov/epawaste/conserve/imr/cdm/pubs/decon_br.pdf.

$C$ Author unknown. Floor system disassembly. Photograph. Date unknown.

Retrieved from

http://www3.epa.gov/epawaste/conserve/imr/cdm/pubs/decon_br.pdf.

$R$ Author unknown. Stair removal - Riverdale Village. Photograph. Date unknown. Retrieved from

http://www3.epa.gov/epawaste/conserve/imr/cdm/pubs/decon_br.pdf.

Figure 11: MEC Ottawa employs DfD strategies such as a standard structural grid, exposed connections, minimal interior finishes, and suspended utility raceways.

L Ewald Richter Photography Ltd. Mountain Equipment Coop Store. Photograph.

Date unknown. Retrieved from

https://www.canadianarchitect.com/features/designing-for-disassembly/

$C$ Author unknown. Title unknown. Photograph. Date unknown. Retrieved from http://www.smartarchitecture.com/commercial-mec.html

$R$ Author unknown. Title unknown. Photograph. Date unknown. Retrieved from http://www.smartarchitecture.com/commercial-mec.html

Figure 12: MEC Ottawa employs DfD strategies such as a standard structural grid, exposed connections, minimal interior finishes, and suspended utility raceways.

All images Insite Photography. Title unknown. Photograph. 2008. Retrieved from http://www.sabmagazine.com/blog/2008/10/17/wastewater-testing/

Figure 13: C.K. Choi building showing exterior reclaimed brick cladding, reclaimed timber structure, exposed connections, and simplicity of finishes.

$L$ The University of British Columbia. Title Unknown. Photograph. Date unknown. Retrieved from http://iar.ubc.ca/about/c-k-choi-building/sustainabilityfeatures/

C Mike Sherman. Title unknown. Photograph. Date unknown. Retrieved from http://www.aiatopten.org/node/206

$R$ Susan Ross. C.K. Choi Building, University of British Columbia campus, interior showing timber reclaimed from Armory in use as new structural elements. Photograph. Date unknown. 
Figure 14: Exposed structural systems and utilities in classrooms allow students to learn

how buildings come together.

L Josh Partee. The multipurpose McMahan Building welcomes teachers and students to the Chartwell School. Photograph. 2009. Retrieved from http://www.usgbc.org/Docs/Archive/General/Docs8824.pdf.

C Josh Partee. The Multipurpose Room. Photograph. 2009. Retrieved from http://www.usgbc.org/Docs/Archive/General/Docs8824.pdf.

$R$ Josh Partee. The Classroom. Photograph. 2009. Retrieved from http://www.usgbc.org/Docs/Archive/General/Docs8824.pdf.

Figure 25: Property bird's eye.

Google Maps. Map Data: Google. 2016. Retrieved from https://www.google.ca/maps/@45.4363325,75.6616696,56a,35y,187.91h,44.86t/data=!3m1!1e3?hl=en

Figure 30: Property bird's eye.

Google Maps. Map Data: Google. 2016. Retrieved from https://www.google.ca/maps/@45.4367391,$75.6607063,56 \mathrm{a}, 35 \mathrm{y}, 112.27 \mathrm{~h}, 46.3 \mathrm{t} / \mathrm{data}=! 3 \mathrm{~m} 1 ! 1 \mathrm{e} 3 \mathrm{hl}=\mathrm{en}$

Figure 35: Property bird's eye.

Google Maps. Map Data: Google. 2016. Retrieved from https://www.google.ca/maps/@45.4340518,$75.658778,59 \mathrm{a}, 35 \mathrm{y}, 46.65 \mathrm{~h}, 41.74 \mathrm{t} / \mathrm{data}=! 3 \mathrm{ml} ! 1 \mathrm{e} 3 ? \mathrm{hl}=\mathrm{en}$

Figure 40: Property bird's eye.

Google Maps. Map Data: Google. 2016. Retrieved from https://www.google.ca/maps/@45.4335604,$75.6639819,54 \mathrm{a}, 35 \mathrm{y}, 101.46 \mathrm{~h}, 45.85 \mathrm{t} / \mathrm{data}=! 3 \mathrm{~m} 1 ! 1 \mathrm{e} 3 ? \mathrm{hl}=\mathrm{en}$

Figure 45: Property bird's eye.

Google Maps. (2016). Map Data: Google. Retrieved from https://www.google.ca/maps/@45.4371748,$75.6653569,65 \mathrm{a}, 35 \mathrm{y}, 34 \mathrm{~h}, 34.29 \mathrm{t} / \mathrm{data}=! 3 \mathrm{~m} 1 ! 1 \mathrm{e} 3 ? \mathrm{hl}=\mathrm{en}$

Figure 49: Truss nomenclature and common truss shapes.

Canadian Wood Council. Truss Nomenclature and Common Truss Shapes. Illustration. Date unknown. Retrieved from http://cwc.ca/wpcontent/uploads/publications-IBS2_Wood_Trusses_SMC_v2.pdf.

Figure 50: Manufacture of Light Frame Trusses.

Canadian Wood Council. Manufacture of Light Frame Trusses. Illustration. Date unknown. Retrieved from http://cwc.ca/wpcontent/uploads/publications-IBS2_Wood_Trusses_SMC_v2.pdf.

Figure 51: Bird's eye perspective of existing site conditions at 230 and 234 Montreal Road.

Google Maps. Map Data: Google. 2016. Edited from original. Retrieved from https://www.google.ca/maps/@45.4360693,$75.6633859,101 \mathrm{a}, 35 \mathrm{y}, 106.73 \mathrm{~h}, 50.14 \mathrm{t} / \mathrm{data}=! 3 \mathrm{~m} 1 ! 1 \mathrm{e} 3$ 


\section{LIST OF APPENDICES}

[A.1] Public and Private Initiatives ................................................ 127 


\section{INTRODUCTION}

This thesis explores how salvaged materials can be reused in new applications in lasting effort to offset our consumption of virgin resources and reduce associated pollution. The research also seeks means of situating a process for material quantification of existing conditions and redesign specifications that facilitate future reclamation. It is hence divided into the following chapters: The Global State of Affairs; Deconstruction; Design for Disassembly; Digital Workflows; and The Project.

Chapter one offers a general discussion of the current global state of affairs and how human beings have arrived at a point where economic and industrial advances are triggering major environmental repercussions for our planet. Our patterns of production and consumption are creating massive amounts of solid waste, putting enormous stress on natural resources and landfill capacities. However, as demand continues to grow, a variety of theoretical frameworks and initiatives have emerged that offer a shift toward a sustainable future.

Chapters two and three investigate the what, why, and how of deconstruction and design for disassembly. Deconstruction offers an alternative to traditional demolition that conserves raw materials and reduces landfill waste by considering buildings as untapped materials banks that provide provisions for the future. Similarly, design for disassembly also eases environmental burdens through key principles and strategies that facilitate endof-life recovery and reuse. The chapters are presented through a selection of case studies 
and precedents that review how buildings designed to be taken apart are significantly easier and more economical to deconstruct than those not originally intended to do so.

The digital workflows presented in chapter four considers the benefits of utilizing technology for building documentation and assessment, enhanced coordination, material information, and new design specifications. It examines the potential for photogrammetry and building information modelling to be used as a process for estimating salvaged material quantities of deconstruction candidates and calculating material quantities for new designs that integrate disassembly.

The final chapter of this thesis proposes a design project that considers all the processes and strategies of deconstruction and design for disassembly. It attempts to estimate the material quantities of existing Vanier structures for specification in a new building addition, with the intent that the collections of programs encourage a revitalization of the area. Ultimately, the proposal utilizes digital workflows to provide a practical framework that can be applied to actual projects for a wide range of scenarios. 


\section{[1] THE GLOBAL STATE OF AFFAIRS}

\section{[1.1] The Anthropocene}

Human beings have made an undeniable impact on the planet in our relatively short presence. Our population has exploded to over 7 billion people, consuming resources at an ever increasing rate and transforming the earth's landscape in the process by clearing fields, building cities, damming rivers, removing mountaintops, and digging craters in search of coal. The atmosphere has changed as a result of our actions, through carbon dioxide emissions generated since the industrial revolution related to manufacturing and transportation. Even if we were to stop releasing carbon dioxide, the gas we've already emitted into the atmosphere could still last for a number of years, ${ }^{1}$ as would the higher temperatures and rising sea levels it causes.

Our actions have affected other species as well, putting unprecedented stress on plant and animal populations around the world. In animals alone, we are witnessing extinction rates higher than ever before. We have caused so many changes to the planet so quickly that scientists have given this period its own name: the Anthropocene. The rise of fossil fuels as an energy source, the industrialization of agriculture, and the continued urbanization of the world's population are just some of the factors contributing to environmental affliction from growing human influence. Human beings alone are driving these recent changes, and more than ever before, we are aware that we are the cause.

1 "Overview of Greenhouse Gases," United States Environmental Protection Agency, accessed October 17, 2016, https://www.epa.gov/ghgemissions/overview-greenhouse-gases. 
In this age of global warming, resource depletion, deforestation, and loss of biodiversity, our mindset must shift to sustainability. Markets in the coming decades will need to adapt to renewed production models that will become more and more essential. The stress we are imposing on the planet has caused it to enter a vulnerable state which it cannot recover from if present rates of production and consumption continue. But how do we meet the growing demand for consumption while moderating the struggle for finite resources and alleviate the negative impact on the environment? We can determine what shape the future of our planet will take by acknowledging that we are intimately tied to it through our actions. As environmentally-conscious architect and designer William McDonough puts it: "How do we love all of the children of all species for all time?", It's up for us to decide.

\section{[1.2] Waste and Landfills}

For the purposes of this thesis, waste is defined as a material, substance, or by-product that is "eliminated or discarded as no longer useful or required after the completion of a process. ${ }^{3}$ It can be considered as anything discarded that is unusable, unwanted, or not fully utilized or appreciated. This falls under what would be considered municipal solid waste, garbage, or refuse in today's society. The definition captures physical material as waste but also the action to "use or expend carelessly, extravagantly, or to no purpose,", which reflects society's penchant for wasteful lifestyle choices and how we treat our natural and processed resources.

\footnotetext{
2 William McDonough. "Cradle to Cradle Design," TED video, 20:05, filmed February 2005, https://www.ted.com/talks/william_mcdonough_on_cradle_to_cradle_design?language=en.

3 "Waste," Oxford University Press, accessed October 8, 2016, https://en.oxforddictionaries.com/definition/waste.

4 lbid.
} 
A study on municipal solid waste management estimated the United States generated almost 390 million tons in 2008 , with $69 \%$ of it being landfilled. ${ }^{5}$ As older, smaller landfills near their capacities, communities often must redirect their waste to consolidated, larger, and more remote landfills. In addition to paying the associated transportation costs, an increased travel distance to further landfills results in increased emissions. Despite the fact that the number of active municipal solid waste landfills in the United States has decreased from roughly 7,900 in 1988 to 1,900 in 2009 , the overall volume of disposal capacity remains consistent. ${ }^{6}$ By some estimations, the average landfill has roughly 33 years left in capacity. ${ }^{7}$ In addition, it has been found that the more solid waste in landfills, the more anticipated greenhouse gases such as methane are likely to be released, ${ }^{8}$ further polluting the atmosphere and contributing to global warming. In sum, we are running out of space to put our garbage, it is becoming more expensive to manage, and landfills are contaminating our environment as more energy and emissions from transportation and processing methods become expended with time.

Construction and demolition (C\&D) materials are generated when constructing new structures or when existing structures are renovated or demolished. This includes all types of buildings, as well as streets, highways, bridges, pier, and dams. According to the U.S. Geological Survey, an estimated $60 \%$ of all materials flow in the United States is

\footnotetext{
${ }^{5}$ Nickolas Themelis, Rob van Haaren, and Nora Goldstein, "The State of Garbage in America," BioCycle Magazine, October, 2010, https://www.biocycle.net/images/art/1010/bc101016_s.pdf.

6 United States Environmental Protection Agency, Municipal Solid Waste Landfills (Washington, DC: US EPA, June, 2014), https://www3.epa.gov/ttnecas1/regdata/EIAs/LandfillsNSPSProposalEIA.pdf.

7 Laura Geggel, "US Dumps Twice as Much Trash as EPA Estimated," Live Science, September 22, 2015 , http://www.livescience.com/52261-landfill-waste-underestimated.html.

8 "Overview of Greenhouse Gases," US EPA.
} 
consumed by the construction industry. ${ }^{9}$ In addition, the U.S. Environmental Protection Agency has approximated that $92 \%$ of construction-related waste produced annually in the U.S. is the result of renovations and demolitions, with only $8 \%$ produced from new construction (see Figure 2). This waste from construction and demolition represents upwards of $30 \%$ of total solid-waste produced in the US. ${ }^{10}$ Industry is taking large steps to lessen its impact on the environment by goals and guidelines put forth by various governing building related associations, such as the Canadian Construction Association's standard document CCA 81-2001. ${ }^{11}$ These types of efforts have proven effective as there was a roughly $23 \%$ increase in the material recovery rate of construction and demolition debris in 2003 compared to $1996 .{ }^{12}$ However, over that same timeframe, there was also a $25 \%$ increase in the amount of that total waste generated in both residential and commercial applications. ${ }^{13}$ The increase of debris could be attributed to the growth in population and the economy resulting in increased development across industry sectors.

\footnotetext{
9 Lorie A. Wagner, "Materials in the economy, material flows, scarcity, and the environment," Vol. 1221, Geological Survey (USGS), 2002, https://pubs.usgs.gov/circ/2002/c1221/c1221-508.pdf.

${ }^{10}$ Franklin Associates, Characterization of Building-Related Construction and Demolition Debris in the United States (Washington, DC: US Environmental Protection Agency, EPA 530-R-98-010, June, 1998).

${ }^{11}$ Canadian Construction Association, CCA 81-2001: A best practices guide to solid waste reduction, 2001, http://www.cca-acc.com/wp-content/uploads/2016/10/PreviewCCA81.pdf.

12 United States Environmental Protection Agency, Estimating 2003 Building-Related Construction and Demolition Material Amounts (Washington, DC: US EPA, EPA530-R-09-002, March 2009), https://www.epa.gov/sites/production/files/2015-11/documents/cd-meas.pdf. 13 lbid.
} 

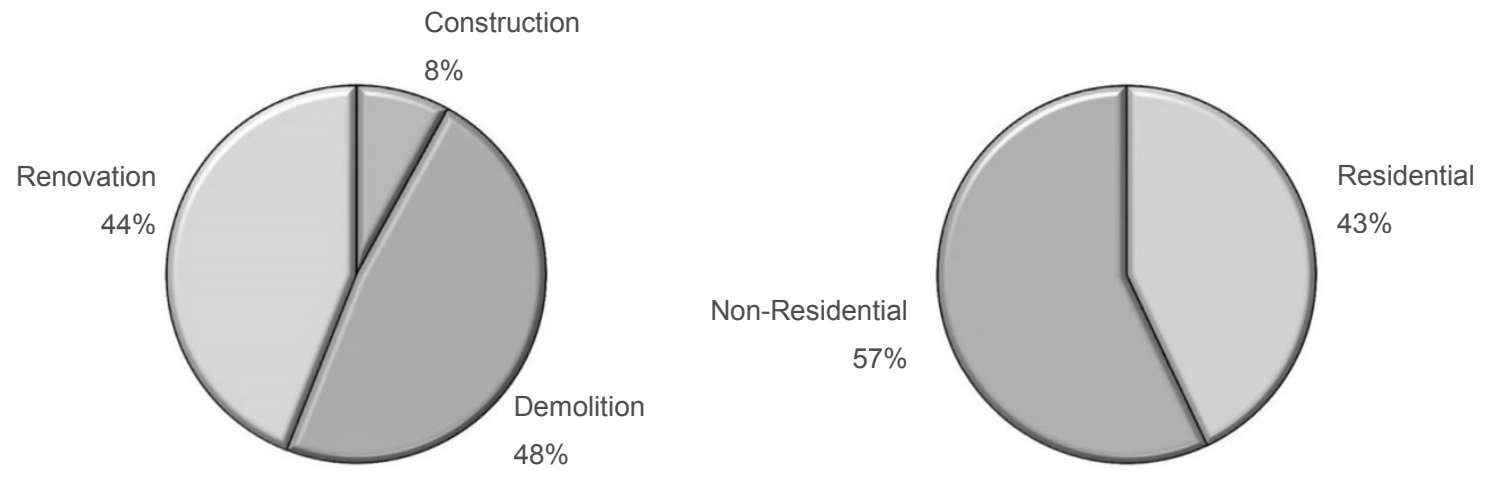

Figure 2: Building related construction and demolition waste in the United States (Source: US EPA, 1998).

Generally, an increasing population means an increase in demand of total built area for new construction or the replacement of our existing built environment. This translates to a huge mass of structures which can be viewed as either enormous sources of waste for upcoming generations, or hold great potential as material resources for the future. Society is becoming more educated and better at recovering materials, but we are also producing more of it. Overall, innovation and interest in green building should have a positive impact on the recovery rates of construction and demolition material.

\section{[1.3] Production and Consumption}

As human population continues to increase, so does the demand for the resources that support it. We are harvesting, extracting, consuming, and burning up natural resources more quickly than our planet can recover from. More than one-third of the planet's natural resource base has been consumed over the past four decades. ${ }^{14}$ Growing demand for more seafood has caused caches to plummet in traditional fishing grounds, pushing fishers into areas further away that are more sensitive and more susceptible to overfishing. Land for animals and crops cover millions of square kilometers around the

\footnotetext{
14 Paul Hawken, Amory Lovins and L. Hunter Lovins, Natural Capitalism: Creating the Next Industrial Revolution (New York: Little Brown and Company, 1999), 24.
} 
globe and require more and more space, but land already under cultivation for grains, cotton, and other crops has placed forests as the last major source of new farmland. ${ }^{15}$ Forests supply essential services such as filtering water, controlling runoff, protecting soil, cycling and storing nutrients, and providing habitat for vital species. They also help moderate climate by soaking up and storing carbon dioxide. Forests provide our most critical goods, such as timber and paper, but since the arrival of European settlers, the vast majority of original forests left in the United States have disappeared. Each year, the world has less forested area, and the forests that remain are of lesser quality. We have already harvested high quality old growth timber for our consumption, and reproduction of these losses will never hold the same biodiversity as natural old growth.

However, some natural resources have the potential for an infinite and abundant lifespan. In other words, they are completely renewable. As with energy, society needs to shift their focus to renewable sources, but with careful management and allocation to ensure a continuing and adequate supply. Society has become dependent on earth's other resources such as natural gas, coal, and crude oil, which are finite. Because of our dependence and growing demand, these finite caches are depleting. The closure of one site of extraction that has already exploited our natural resources only encourages new sites for further cutting, drilling, mining, hauling, and trashing. ${ }^{16}$ Throughout this process, the consistent dependence on fossil fuels, such as petroleum, will continue to have a

\footnotetext{
15 "The Human Condition," National Geographic Society, accessed December 10, 2016, http://www.nationalgeographic.com/earthpulse/human-impact.html.

${ }^{16}$ Annie Leonard, Dir. Louis Fox, Prod. Erica Priggen, "The Story of Stuff" (Berkeley, California: Free Range Studios, December 2007), Video, 21:24, http://storyofstuff.org/movies/story-of-stuff/.
} 
negative impact on the earth's biosphere and act as a major contributor to global warming.

The processes by which we design, produce, and distribute goods developed during a time when expending resources was considered economically advantageous, fuelled by modernization and automation. Many products used to be designed to endure and were built using durable materials, but with the growth of consumerism, disposability became a primary design parameter for products. With the government and corporations looking to boost the economies after World War 2, retail analyst and marketing consultant Victor Lebow wrote an accurate account of modern consumerism that developed and has become the norm:

"Our enormously productive economy demands that we make consumption our way of life, that we convert the buying and use of goods into rituals, that we seek our spiritual satisfaction, our ego satisfaction, in consumption.... We need things consumed, burned up, worn out, replaced, and discarded at an ever-increasing pace." ${ }^{17}$

Almost unknowingly, society stimulates consumer demand through strategies of planned obsolescence and perceived obsolescence. Planned (or built-in) obsolescence is intentionally designing a product that wears out or becomes obsolete after limited use. This is often achieved by frequent changes in design, unavailability of replacement parts, or the use of non-durable materials. There is also perceived obsolescence, which convinces consumers that they need an updated product, even if their existing product is

17 Victor Lebow, "Price competition in 1955," Journal of retailing 31, no. 1 (1955): 5-10. 
perfectly useful. From clothing to technology to cars, the styles of different things are always changing, and advertisements from media pressures society into thinking their items are unfashionable and out-dated. The amount of embodied energy that becomes invested in materials and products from extraction, transportation, processing, and manufacturing makes them too precious only to end up in landfills.

In terms of the built environment, we invest a huge percentage of our processed resources into buildings and infrastructure. Unlike planned and perceived obsolescence of our products, most buildings and structures are not intentionally designed to fail after a certain amount of time or become entirely unfashionable, even if they inevitably turn out to be. Our built environment is always in flux, and faces its own kind of obsolescence as a result. Due to rapid changes in family life, business, and global society, we experience faster changing functional demands on our buildings. Without the ability to adapt to changing needs, a building's actual service life is effectively reduced. ${ }^{18}$ Real estate market fluctuations also influence either sustained continuity or increased turnover in buildings. Increased turnover has negative environmental consequences at both ends of material flow, putting more pressure upstream on new raw materials and on downstream waste handling with limited landfill space. But what happens to the initial material investment when we consider these structures have reached their end of life? While conventional buildings typically have longer life spans and are not subjected to mass production in the same way as most consumer products, there is still a need to address the value that is embodied in our existing built environment for future reuse and recycling. Structures that are demolished and sent to landfill regardless of the technical quality of

${ }^{18}$ A.S. Nordby, "Salvageability of building materials," (PhD diss., NTNU, 2009), 14, http://www.divaportal.org/smash/get/diva2:225736/FULLTEXT02.pdf. 
their components are likely due to a potential second hand use not being feasible or financially profitable. ${ }^{19}$ Buildings can either be discarded as enormous culprits of waste or be viewed as valuable material banks, waiting to be re-harvested as materials for the future. Mine the city - not nature.

\section{[1.4] Theoretical Frameworks}

Industrial design and the manufacturing industry are addressing many of the issues related to the consumption of materials through their life-cycle stages. The field of industrial ecology (IE) is the study of material flows and energy and their effect on the environment in industrial and consumer activities. Working on the macro level of production systems, it aims to dissipate industrial outputs and create closed-loop ecosystems by enhancing metabolic pathways of material use. ${ }^{20}$ This need for managing end-of-life scenarios is driven by the increasing disposal of consumer goods, their pollutant impacts, and the lost embodied energy from pre-consumer processing.

An important methodology currently used in the industry is Life Cycle Assessment (LCA). Similar to industrial ecology, this approach analyzes environmental aspects and potential impacts over a product's complete life cycle, from raw material extraction through processing, manufacture, distribution, use, repair and maintenance, and finally disposal. ${ }^{21}$ However, the LCA's linear cradle-to-grave perspective does not effectively integrate potential reuse or recycling into its framework. ${ }^{22}$

\footnotetext{
${ }^{19}$ Nordby, Salvageability, 14.

20 Ibid., 18.

21 "Design for the Environment Life-Cycle Assessments," United States Environmental Protection Agency, accessed October 17, 2016, https://www.epa.gov/saferchoice/design-environment-life-cycle-assessments.

22 Nordby, Salvageability, 18.
} 


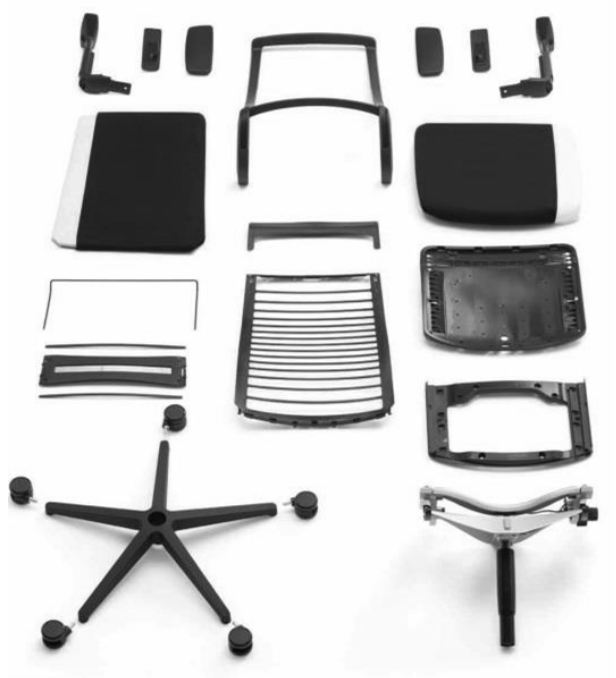

Figure 3: The Think chair by Steelcase is 99\% recyclable by weight. Disassembly takes just five minutes with ordinary tools.

Driven by the desire for economic progress and technological advancement, it is remarkable that modern society has continued to operate on this linear production model with little regard for the ecological impacts. However, writers in the field of environmental sustainability have offered enriched perspectives inspired by natural systems. Guided by the principle of "waste equals food," William McDonough and Michael Braungart published the book Cradle to Cradle: Remaking the Way We Make Things, where they explain how the characteristics in natural design cycles can be used as models for human designs. ${ }^{23}$ Similarly to the philosophy of industrial ecology, the theoretical framework of cradle-to-cradle is a biomimetic approach, taking nature itself as example for the design of products, buildings, and systems in a cyclical model for human industry. Their manifesto presents clear, accessible arguments that products can and should be designed from the outset so that their afterlife will provide sustenance for something new. They propose material flows which are divided into categories of

${ }^{23}$ William McDonough and Michael Braungart, Cradle to Cradle: Remaking the Way We Make Things (New York: North Point, 2002), 92-117. 
"biological nutrients" that can re-enter the natural environment (water and soil) without depositing harmful synthetic materials or toxins, and "technical nutrients" that circulate as valuable materials within closed-loop industrial cycles (see Figure 4). This principle not only looks at materials as nutrients, but also material reutilization, clean energy and water, and social fairness. ${ }^{24}$

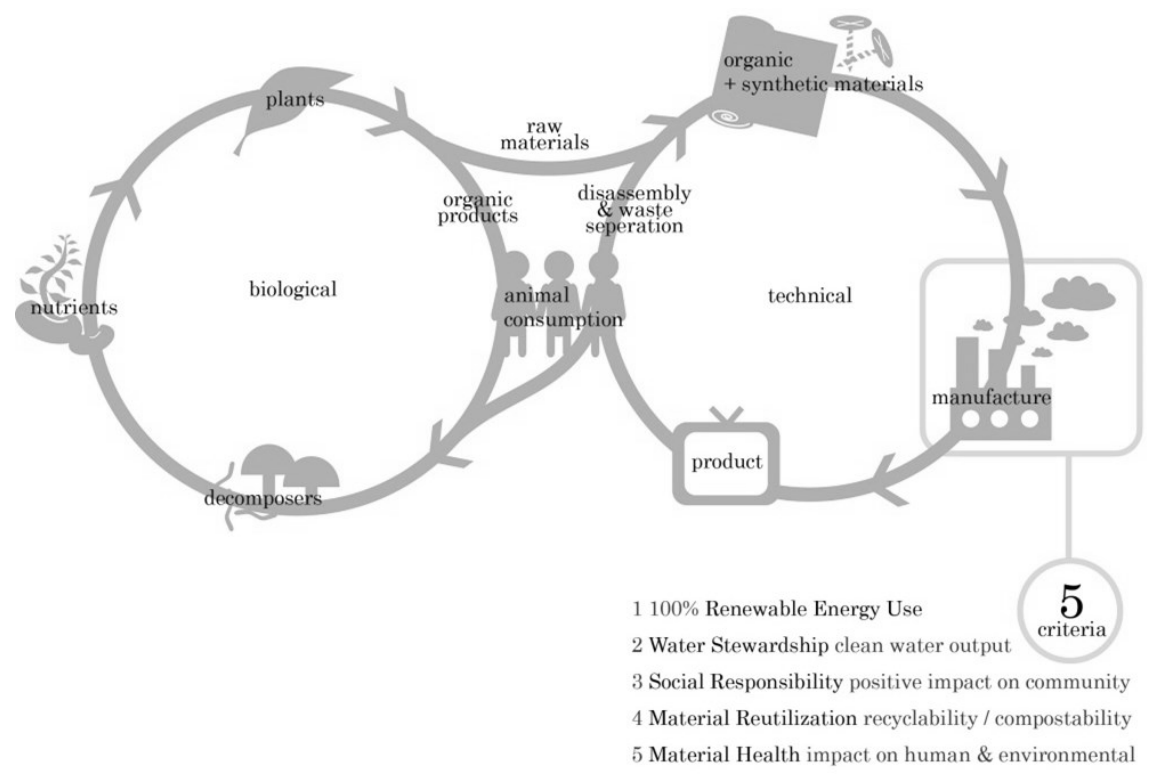

Figure 4: Biological and technical nutrient cycles in the Cradle-to-Cradle design framework.

McDonough and Braungart note that simply following the "reduce, reuse, recycle" pedagogy only maintains the one-way cradle-to-grave production model. The typical response to human impact has been to find a "less bad" approach (often through the terms reduce, avoid, minimize, sustain, limit) but still creates gargantuan amounts of waste and pollution and does not dig deep enough. ${ }^{25}$

Observing lessons from industrial ecology, the building industry can also incorporate similar systems of recycling hierarchy that address end-of-life scenarios of reclamation

${ }^{24}$ McDonough and Braungart, Cradle to Cradle, 45-67.

$25 \mathrm{lbid}$. 
and reuse. Although industrial ecology is taking steps in the right direction, incorporating these principles into designing building is a greater task. Much larger and complex, our built environment is always fluctuating between users and uses while in service, and should never be seen as static, fixed, or complete. The traditional model for consumption of materials in buildings is based on a linear, cradle-to-grave system over time that progress through a number of stages from design, construction, operation, demolition, and disposal. ${ }^{26}$ In order to reclaim the material in our buildings, the standard practice established by out-dated methodologies must be rearranged.

Comparing the proposed end-of-life scenarios of industrial designers with architects, such as the waste management hierarchyby Charles Kibert and Abdol Chini, Philip Crowther proposes closing the loop for end-of-life scenarios of our built environment following hierarchical principles. They include: building reuse or relocation, component reuse or relocation in a new building, material reuse in the manufacture of a new component, and material recycling into new materials. ${ }^{27}$ The significance of the hierarchy of end-of-life scenarios is the possibility to design buildings that facilitate environmentally advantageous or continued, alternative life cycles (see Figure5). ${ }^{28}$

${ }^{26}$ Philip Crowther, "Developing an Inclusive Model for Design for Deconstruction," in International Council for Research and Innovation in Building Construction Publication 266, edited by Abdol Chini (Wellington, New Zealand: CIB, 2001), http://eprints.qut.edu.au/2884/1/Crowther-TG39-2001.pdf.

${ }^{27}$ Crowther, "Developing an Inclusive Model for Design for Deconstruction."

28 lbid. 

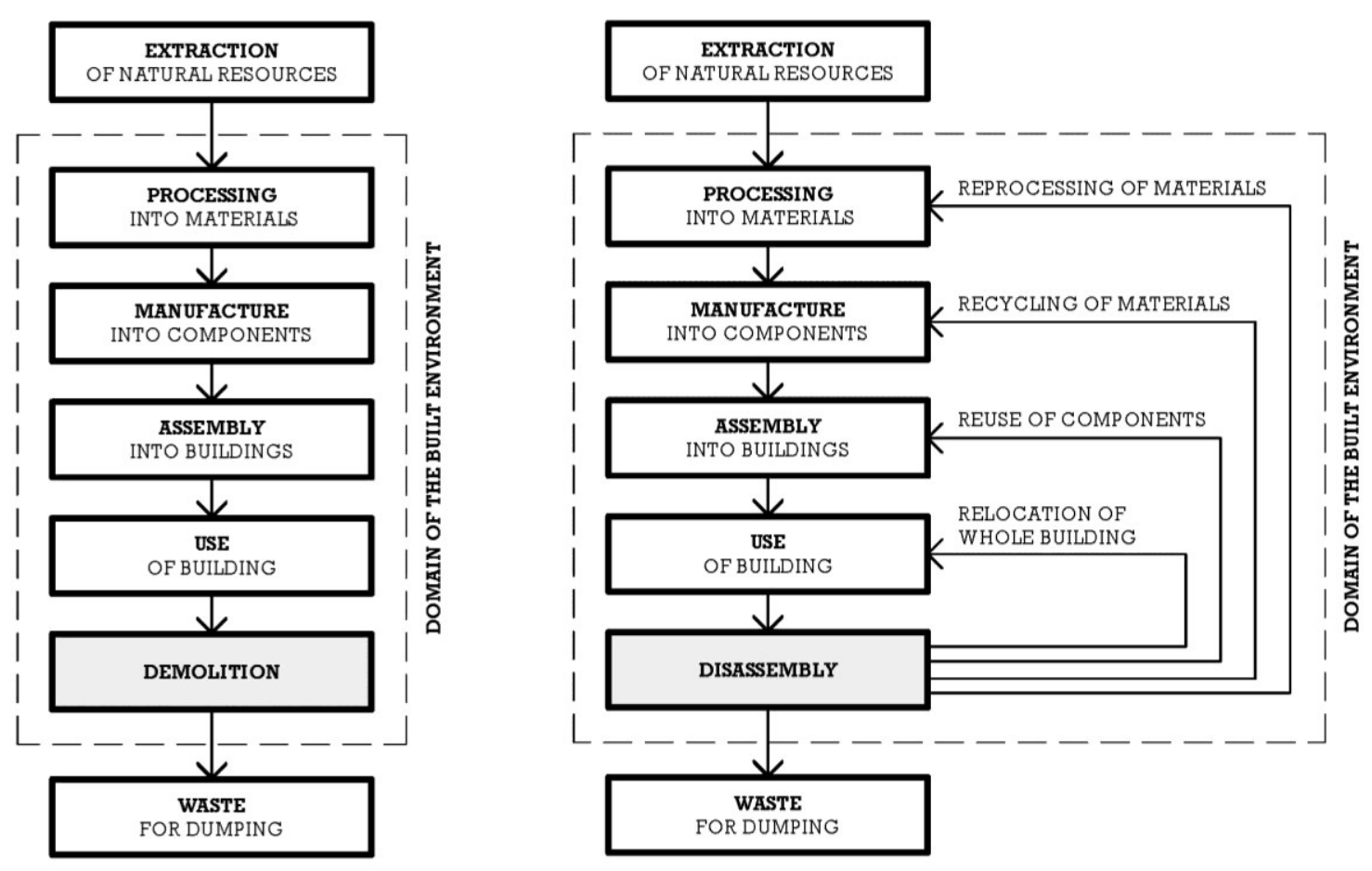

Figure 5: Dominant life cycle of the built environment (linear, cradle-to-grave) compared to possible end-of-life scenarios (cyclical, cradle-to-cradle).

(Based on Crowther, 2001)

In the hierarchy proposed by Crowther, reuse is more environmentally beneficial than material level recycling or disposal, in terms of the additional energy costs for processing. However, physical features and construction methods of a building affect which end-of-life scenarios are most feasible. As such, design considerations for a building should facilitate and encourage more environmentally preferable end-of-life opportunities. Structures and components that are designed for disassembly and reuse are viewed as beneficial across the entire recycling hierarchy and provide for adaptability, ease of maintenance, and ease of deconstruction. ${ }^{29}$

The separation of components into layers addresses the different life cycles of building systems and materials which is paramount in making a more technically and socially

${ }^{29}$ Crowther, "Developing an Inclusive Model for Design for Deconstruction." 
adaptable and responsible building. However, it wasn't until the 1960's that an expressed theoretical stance appeared on the issue of changes to buildings over time in a layered way. ${ }^{30}$ Building off previous theorists, Stewart Brand's work in How Buildings Learn offers an expanded analysis of the layers of buildings, assigning each with an expected service life. He proposes the "six S's" that explain the technical and social benefits of designing and constructing buildings in a layered manner: site, structure, skin, services, space plan, and stuff. ${ }^{31}$ This theory of time-related building layers (also known as shearing layers) permits the components and systems of a building to be broken down into segments with similar life expectancies. By planning for easy access and making materials or components with the shortest anticipated life cycle more accessible than longer ones, the generation of unnecessary waste will be reduced as a result of efficient replacements or upgrades.

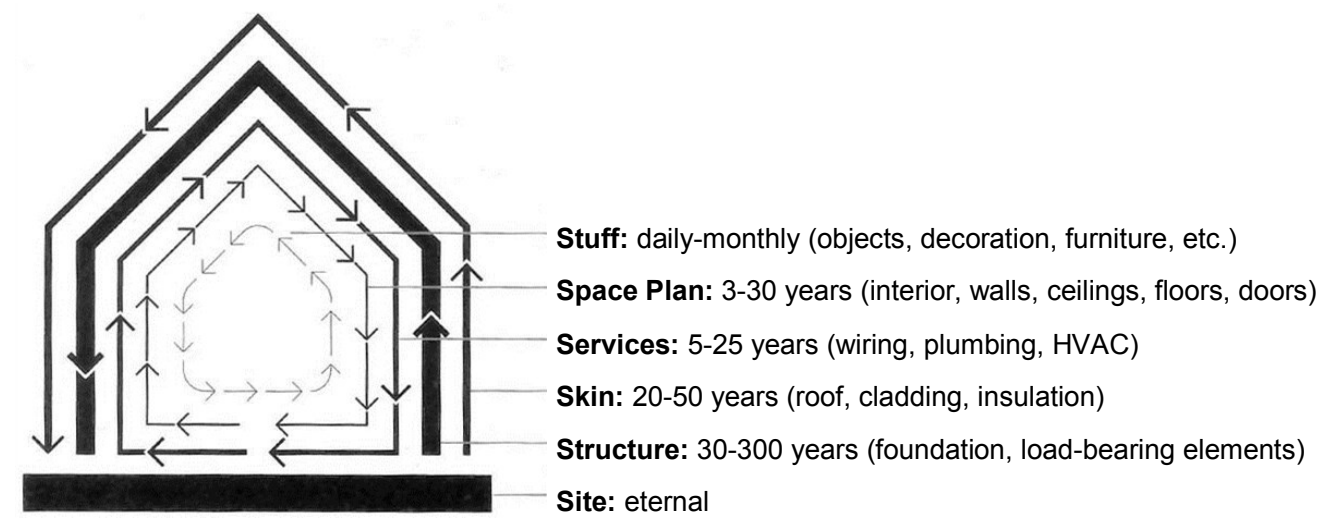

Figure 6: Stewart Brand's "six S's" diagram of time-related building layers (Source: Brand, 1994).

Brand also notes that a building designed to be adaptable and disassemble-able should be "scenario buffered." 32 This type of planning strategy leads to a more versatile building by developing potential occupant and life-cycle scenarios and plan resulting outcomes. "The

30 Crowther, "Developing an Inclusive Model for Design for Deconstruction."

31 Stewart Brand, How Buildings Learn: What Happens After They're Built (New York, NY: Viking, 1994), 12-13.

32 Ibid., 178-189. 
worst mistakes come not from wrong decisions but from not doing the right thing that never occurred to anybody to do." ${ }^{, 3}$ Scenario planning envisions multiple lives for a building for which design for disassembly strategies can easily be implemented to minimize the cost and impact of change between the original building and future alterations. $^{34}$

For supply to meet demand in the coming decades, an adjustment towards deconstruction and designing for disassembly offers economic and environmental benefits, while lowering the amount of C\&D waste established by the traditional linear building model. With an increasing population spreading across our finite terrain and densifying cities, Bradley Guy and Scott Shell accurately note in Design for Deconstruction and Materials Reuse: "If overall "sustainable development" necessitates an increase in the reuse and recycling of urban land and first generation suburbs, the trends towards renovation and rebuilding to use existing land and infrastructure will only increase." 35 Accordingly, it is critical that human beings minimize the consumption of raw materials and reduce the overall environmental impact of end-of-life building materials by adopting cyclical models and closing the loop.

\section{[1.5] Public and Private Initiatives}

Learning from industry, concepts about material flow can be applied to our built environment and rectify our patterns of consumption and production in a sustainable

\footnotetext{
33 Brand, How Buildings Learn, 185.

34 Bradley Guy and Nicholas Ciarimboli, Design for Disassembly in the Built Environment: $A$ Guide to Closed Loop in Design and Building (Seattle, WA: King County Solid Waste Division, accessed October 5, 2015), 12, http://your.kingcounty.gov/solidwaste/greenbuilding/documents/Design_for_Disassembly-guide.pdf.

35 Bradley Guy and Scott Shell, "Design for Deconstruction and Materials Reuse," in International Council for Research and Innovation in Building Construction Publication 272, edited by Abdol Chini (Karlsruhe, Germany: CIB, 2002). https://www.iip.kit.edu/downloads/CIB_Publication_272.pdf.
} 
manner. Society is becoming more familiar and recognizing the importance of processes that are environmentally responsible and resource-efficient throughout a building's lifecycle. For example, the notion of building green has come with a wave of acceptance for demonstrating benefits related to our overall environmental footprint. With the concern for energy conservation, resources, and waste, a range of initiatives in the built environment are being taken from both private and public entities. ${ }^{36}$

Of these in Canada, perhaps the most noteworthy for salvaging our building materials is in Vancouver, British Columbia, where home owners and property developers have followed new demolition waste recycling requirements under a Green Demolition Bylaw. Since coming into effect September, 2014, the bylaw establishes a minimum $75 \%$ reuse and recycling rate for building materials and demolition waste from pre-1940 one- and two- storey family houses. It has successfully resulted in a significant average diversion rate of $87 \%$, compared to the typical rate of $50 \%$ for residential demolitions. ${ }^{37}$ Proving to be an effective tool, the city intends to expand the by-law incrementally to include all houses regardless of year constructed by 2018 and will continue to work with industry on developing incentives while allowing time to adapt and implement new strategies. ${ }^{38}$ Vancouver is just one city taking necessary administrative steps toward reducing C\&D waste from landfills and in turn reducing our dependant consumption of raw materials.

Society should become active with salvaging and reusing building materials to provide the resources for new construction. The theory of time-related building layers should be

36 For further and more detailed analysis of public and private initiatives, see Appendix 1.

37 City of Vancouver, Green Demolition Program Update, November 16, 2015, http://council.vancouver.ca/20151216/documents/cfsc5.pdf.

$38 \mathrm{lbid}$. 
seen as a principal system that should be adopted by the construction industry. There should be no reason not to consider implementing measures such as take-back programs for producers of building materials and encourage cyclical building models. Regardless of the industry, location, or scale, changing the status quo will require cooperation and many people taking acting together under instruction from governing agencies. With the concern for the environment and our global resources, regulations such as the green demolition bylaw are likely to become more common. Fortunately, the process of deconstruction is a more resourceful alternative to demolition that inherently lends itself to achieving a high waste diversion rate that includes reclamation, reuse and source separation recycling. 


\section{[2] DECONSTRUCTION}

\section{[2.1] Overview}

Deconstruction is an alternate method of building removal that is gaining popularity as an environmentally-preferable way to save and reuse building material, offering a direct and measurable way to reduce the negative impact on the planet. As mentioned earlier, most buildings follow the traditional linear cradle-to-grave model and are not designed to eventually be taken apart. Modern construction has developed to be dependent on permanent, irreversible fixing methods or combinations of composite materials. Such practices are a major hindrance to successful deconstruction and often result in complete disposal of a building by way of destructive demolition. ${ }^{39}$

As resources become scarcer and more competitive, buildings should be thought of as untapped material banks. With a general need to decrease the current usage rates of new materials, deconstruction can yield high-quality materials and old growth lumber largely unavailable today while conserving raw resources. Many abandoned buildings have the potential to be deconstructed, and can apply to all buildings types, including residential homes, factories, barns, and industrial buildings. Engagement in deconstruction activities can be as simple as a single person following a simple process with basic tools on a small structure. It is also entirely scalable to larger buildings that require a bigger crew and heavier machinery to suit appropriate site specific conditions and available resources.

${ }^{39}$ Crowther, "Developing an Inclusive Model for Design for Deconstruction." 
Any degree of material salvage and reclamation is seen as beneficial, and while highquality materials can be salvaged in exchange for the invested effort, larger and more extensive projects can sometimes hold greater rewards.

\section{[2.2] Economic and Environmental Benefits}

As an alternative to demolishing a building and sending debris to the landfill, deconstruction is the ideal method in the recovery of existing processed materials for reuse. It also offers a number of environmental and economic benefits compared to traditional demolition that include lower building removal costs, reduced impact to site, conserved landfill space, revenue generation, and job creation. ${ }^{40}$

Deconstruction has the potential to offset incurred building removal costs through the value of material that is salvaged and saving money due to avoiding disposal tipping fees at landfills. Although separate costs can vary by region and hauler, in 2008 the average tipping fee in the United States was found to be $\$ 44$ per ton. ${ }^{41}$ Earlier research has also estimated an average waste generation rate of 4.39 pounds per square foot, but may not

represent all styles and regions across the country. ${ }^{42}$ Other benefits of deconstruction not reflected in standard costs are greater preservation to the local and surrounding sites compared to demolition. This includes reducing impacts in terms of dust generation, excessive noise, soil compaction, and loss of vegetation or ground cover.

\footnotetext{
40 NAHB Research Centre Inc., Deconstruction: Building Disassembly and Material Salvage, Brochure, accessed October 10, 2015, http://www3.epa.gov/epawaste/conserve/imr/cdm/pubs/decon_br.pdf.

41 Themelis, van Haaren, and Goldstein, "The State of Garbage in America."

42 US EPA, "Estimating 2003 Building-Related Construction and Demolition Material Amounts."
} 
Upwards of $90 \%$ of a building can be diverted into reuse or recycling streams. ${ }^{43}$ With high waste diversion rates that include reclamation, reuse, and recycling, deconstruction can conserve landfill space, reduce the strain on resources, and lessen emissions related to transportation and disposal. However, as some materials are not suited for reuse or difficult to recover, deconstruction can facilitate more careful source separation, handling, and disposal of more hazardous material, or recycling materials that cannot be sold or reused.

Although the process of salvaging materials typically expends a lot of time and labour, the items recovered from old buildings can be of much higher value or quality than those available on the market. Nearly every building has some degree of high-quality reusable materials, but some may be factually significant and have a greater value because of their origin. Materials in these buildings embody a heritage value associated with a particular social history or typology of vernacular architecture that can positively affect the perception or enthusiasm for reuse.

Salvaged building materials can also often be provided at lower costs than buying new. One case study sponsored by the U.S. EPA found that commodities such as framing lumber easily sold for about $50 \%$ of full, new retail value. It also found that more specific or finished materials such as windows or hardwood flooring have a lower value or market for resale. ${ }^{44}$ Much of this resale potential is based on local materials value specific to that geographical region and time of year. For example, due to the production or use of wood

\footnotetext{
43 US EPA, "Estimating 2003 Building-Related Construction and Demolition Material Amounts."

${ }^{44}$ NAHB Research Centre Inc., Deconstruction - Building Disassembly and Material Salvage: The Riverdale Case Study (Maryland: NAHB Research Centre, Inc., June 1997), http://www.lifecyclebuilding.org/docs/Riverdale\%20Case\%20Study.pdf.
} 
prevalent in British Columbia, it may be found framing lumber sells much easily with higher value versus Ontario, which could have a higher market demand for reused brick cladding.

Over the last 5 years, the city of Ottawa averaged 300 building demolitions annually. ${ }^{45}$ However, there are larger metropolises that experience more aggressive development and an even greater turnover of buildings. Vancouver recently introduced a Salvage and Abatement Permit that requires the removal of both hazardous and salvageable materials prior to demolition before any demolition work can commence. ${ }^{46}$ This is in accordance with the city's green initiatives of disposing buildings in a responsible manner, which is important for a place that issued approximately 820 demolition permits in $2016 .{ }^{47}$ With the amount of buildings slated for removal in urban areas, manual disassembly of buildings provides an opportunity to train and employ labourers ranging from the minimally-skilled to unionized apprentices in areas of building materials, construction sequence, and jobsite safety. ${ }^{48}$ Developing jobs and small business opportunities can be an important policy consideration for federal agencies or communities engaged in building removal to stimulate the economy.

Recognizing these benefits, local governments with active demolition have the opportunity to promote environmental stewardship and economic revitalization though deconstruction projects. Self-evaluation tools such as the Deconstruction Rapid

${ }^{45}$ City of Ottawa, 2015 Annual Development Report, April 2016, http://documents.ottawa.ca/sites/documents.ottawa.ca/files/2015_dev_rpt_en.pdf.

46 "Statistics on construction activity," City of Vancouver, accessed January 20, 2017, http://vancouver.ca/home-property-development/statistics-on-construction-activity.aspx.

${ }^{47}$ City of Vancouver, Demolition and Abatement Reporting Requirements, Bulletin 2015-008-EV, revised March 31, 2016, http://bulletins.vancouver.ca//2015/2015-008.pdf.

${ }^{48}$ NAHB Research Centre Inc., A Guide to Deconstruction (Maryland: NAHB Research Centre, Inc., February 2000), http://www3.epa.gov/epawaste/conserve/imr/cdm/pubs/decon_br.pdf. 
Assessment Tool provided by the U.S. EPA help identify candidates for deconstruction by examining information on the buildings condition and salvageable material inventory. The tool acknowledges and promotes the concern for building material reclamation by providing users with requisite information, including guidance on the process and terminology and how to assess candidates for deconstruction. ${ }^{49}$ The accessibility of this tool enables businesses and individuals to easily tackle evaluation and prioritize building stock slated for demolition.

\section{[2.3] Steps in Planning}

Given the stated potential economic and environmental benefits, it is obvious as to why one may choose to deconstruct instead of demolish. Although deconstruction can be thought as of as construction in reverse, the know-how of taking apart a building is different than putting one together. Organizations such as the Building Materials Reuse Association are just one of many sources that provide education to the industry and public through literature such as comprehensive training workbooks giving an extensive overview in carrying out deconstruction at different scales. ${ }^{50}$ There are also a variety of publications provided by the Canada Mortgage and Housing Corporation (CMHC), including manuals that aim to provide industry with a reference tool to assist in the economic feasibility assessment, planning, and supervision of deconstruction. ${ }^{51}$

Many stages and steps in planning in a deconstruction project need to be considered to make it successful. These include providing adequate time to deconstruct, perform

49 United States Environmental Protection Agency, Deconstruction Rapid Assessment Tool (Washington, DC: US EPA, March 2015), https://www.epa.gov/sites/production/files/2015-07/documents/drat-instructions.pdf 50 "Training," Building Materials Reuse Association, accessed February 08, 2017, https://bmra.org/training/. 51 Derek Badger, Residential Deconstruction Manual (Ottawa: Canada Mortgage and Housing Corporation, 1999). 
environmental assessments, acquire permits for procedure of the work, gather necessary equipment or labour, create a detailed building inventory, remove hazardous materials, and market the salvaged building elements. ${ }^{52}$

There are numerous other factors to consider when evaluating a building for deconstruction and salvage. These include health and safety standards for hazardous waste or dangerous conditions, the scale and extent of the project, what to do with the salvaged materials, how to store them, and handle the remaining debris. ${ }^{53}$ Not all buildings are good candidates for deconstruction, and may fall victim to being demolished depending on their specific evaluation regarding access to potential materials and their market value. (see Figure 7). Other issues determining feasibility and impacting decisions can include the cost of landfill tipping fees, the cost of labour and equipment, access to materials, the present market value of materials recovered, and time. ${ }^{54}$

52 NAHB, Deconstruction: Building Disassembly and Material Salvage.

${ }^{53}$ Robert H. Falk, and Brad Guy, Unbuilding: salvaging the architectural treasures of unwanted houses. (Newtown, CT: Taunton, 2007), 34.

${ }^{54}$ Scott Shell, Octavio Gutierrez, and Lynn Fisher, Design for Deconstruction: The Chartwell School Case Study, United States Environmental Protection Agency, accessed October 3, 2015, https://www.epa.gov/sites/production/files/2015-11/documents/designfordeconstrmanual.pdf. 


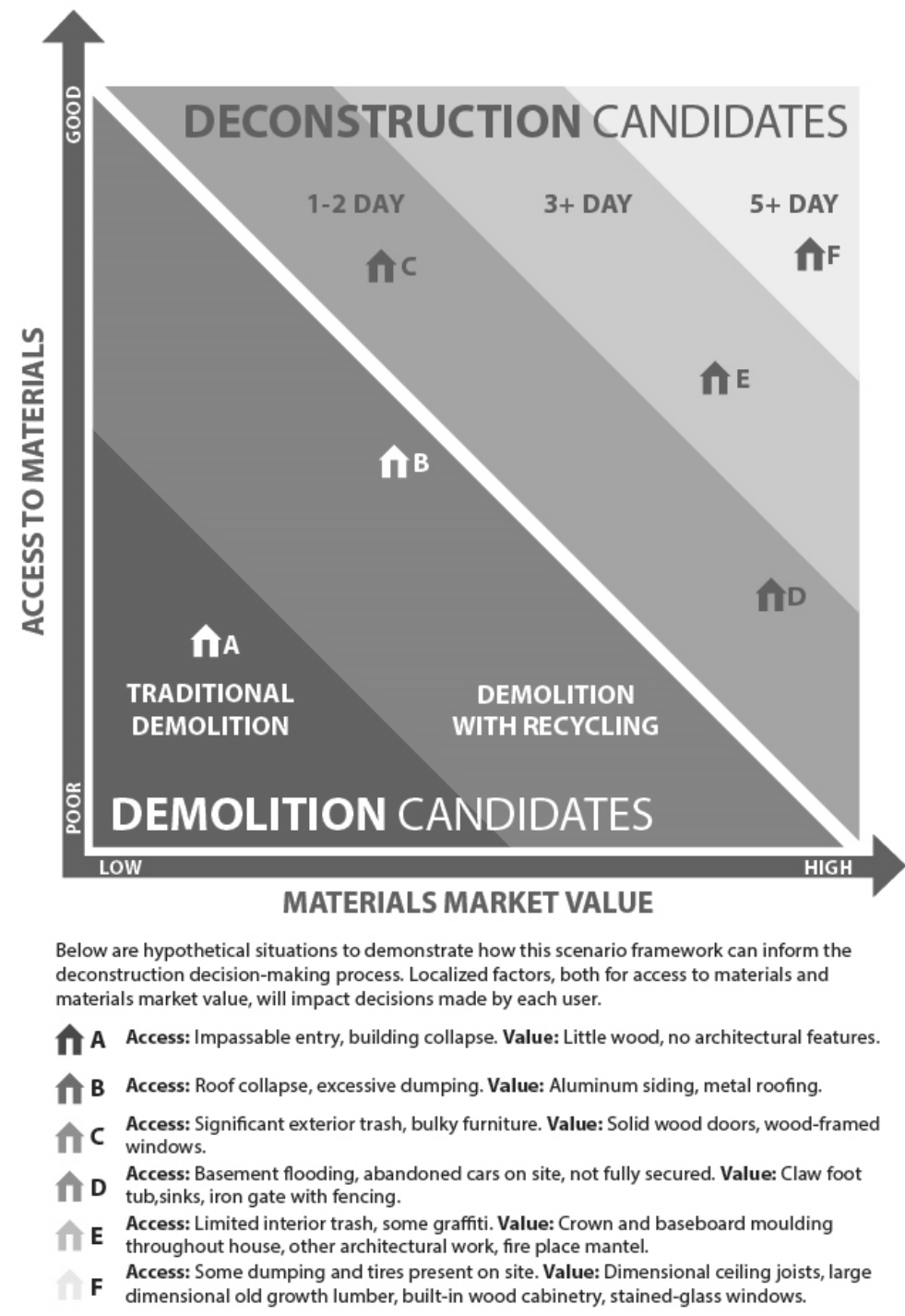

Figure 7: Deconstruction Rapid Assessment Tool Action Framework illustrates how access to materials and their market value can help with decision-making (Source: US EPA, 2015).

Undertaking deconstruction can take two to ten times longer than traditional demolition depending on the type of building and size of the working crew. ${ }^{55}$ This includes during analysis for feasibility, the planning phase, as well as removal and associated time to process, sort, stack, or recycle recovered materials. To increase time and cost performance, the deconstruction process can involve either manual disassembly of a building or in combination with mechanical methods to suit the scale and extent of the 
project. ${ }^{56}$ Permits that require the site to properly disconnect and abandon septic wells, water, and other utilities to comply with local acts and bylaws can also contribute to time required for deconstruction. While deconstruction can be a solo venture, the decisions on finding adequate labour and an organized team to perform deconstruction can mean the difference between a fruitful venture and disastrous outcome. In addition to range of knowledge that labourers can offer, an on-site crew would benefit if it included a job foreman or individual that has an understanding of demolition, construction, and flow of materials. The individuals involved need to understand their capabilities and approach to match the characteristics of the building, and determine cost-effectiveness of heavy machinery versus manual labour. Lastly, all participants should have an understanding of the material recovery goals of the project to successfully implement reuse or recycling strategies. ${ }^{57}$

Important to the process of deconstruction are environmental assessments that help identify hazardous materials and minimize liability in relation to site conditions by taking appropriate measures when proceeding with the work. Developing a project specific strategy will minimize disorganization and confusion can make for a slow, unsafe workplace. An importance piece of information to help with this is a site plan that communicates to all parties involved where various activities should take place, including equipment storage and material stockpiling. ${ }^{58}$ Organizing the site to minimize the movement and handling of materials between removal, processing (de-nailing, trimming, etc.), loading, and unloading is critical for time efficiency.

56 Falk and Guy, Unbuilding, 6.

57 lbid.

58 Ibid., 104. 
The evaluation of a potential project begins with an inspection of the underlying structural framing by way of exposed areas or invasive opening of walls and ceilings to determine its deconstruction feasibility. The main objective of the initial walkthrough is to identify potentially hazardous materials and take an inventory of all the materials and assembled components such as railings or trusses available in the building. A detailed building inventory is essential to estimating the quantity of material that can be salvaged. The extent of work to be completed can range from soft-stripping the readily accessible and non-structural items such as interior trim, windows, and doors, to more comprehensive whole-building deconstruction of framing and foundations. ${ }^{59}$ It is important to estimate the types and quantity of potential material for determining the overall salvage value, building condition, and level of effort required to justify undertaking the project. The assessment should ultimately identify construction methods, assemblies, connections, fasteners, quality, and hazardous materials. ${ }^{60}$

Building technologies are always changing, and the "correct" way 50 years ago no longer applies today. In addition, material types that were never analyzed for their long term effects were produced and used, including many which are now deemed unsafe or dangerous. This includes mercury, lead-based paints, or brands of products such as cement siding or vermiculite insulation that could contain asbestos. ${ }^{61}$ Many federal regulations now govern the management of these hazardous materials, and require different methods of hauling or disposal procedures that could require additional time or speciality equipment and trained workers.

\footnotetext{
59 Falk and Guy, Unbuilding, 35.

60 lbid.

61 lbid., 144-147.
} 
Ultimately, deconstruction requires salvaged materials to be marketed and sold or be able to be stored under proper conditions. There are many factors which determine the active market for a particular material and it is important to establish a marketing plan for all salvaged materials before a project begins. Factors that can affect the marketability or value of materials include the types of materials (from framing to finishes), the time of year, the condition of the local economy, retail material price costs, and overall condition, quality, and presentation of organized merchandise. ${ }^{62}$ Salvaged materials may be used on site for a subsequent construction project, stored on site for a site sale, or transferred to an intermediate location or retail center. ${ }^{63}$ From a business perspective, an important aspect to redirecting recovered materials is to develop a material inventory spreadsheet or database for potential customers. Tracking inventory and purchases help target sales of specific material, and maintaining a list of recurring customers to notify about readily available stock is the best way to quickly advertise and distribute new inventory.

While there are several methods of dealing with salvaged material, there is preference towards immediate specification in new construction or renovation projects, as every pound of material reused is more than a pound of extracted resources that do not need to be manufactured new. ${ }^{64}$

62 NAHB, "The Riverdale Case Study."

63 Ibid.

${ }^{64}$ Falk and Guy, Unbuilding, 5. 


\section{[2.4] Case Studies}

\section{[2.4.1] Fort Ord Barracks}

Monterey, California, USA - 2004

by Fort Ord Reuse Authority and Wood Waste Diversion

This case study took on straight deconstruction activities as a pilot project involving several decommissioned U.S. Army buildings to assess building removal feasibility for approximately 1,200 substandard buildings on the Monterey Bay base.$^{65}$ These one and two storey buildings had simple construction techniques, with few interior surface finish materials or adhesives, and evaluated as having high-value lumber content, making them suitable candidates for deconstruction.

The work performed by Wood Waste Diversion utilized a good balance of manual versus mechanical labour, and strategies that demonstrated efficient deconstruction activities and on-site innovations. In one instance, the building roof is removed in sections to the ground level using a forklift where it is safer and faster to deconstruct, and then is further separated into planes of rafters and sheathing. Elevated work platforms provide convenience and access for manual labour, while other activities for removing joists and studs from sheathing can be done from the ground using the drive-by method with a skid loader. $^{66}$

65 NAHB, "A Guide to Deconstruction."

${ }^{66}$ Shell, Gutierrez, and Fisher, Design for Deconstruction. 

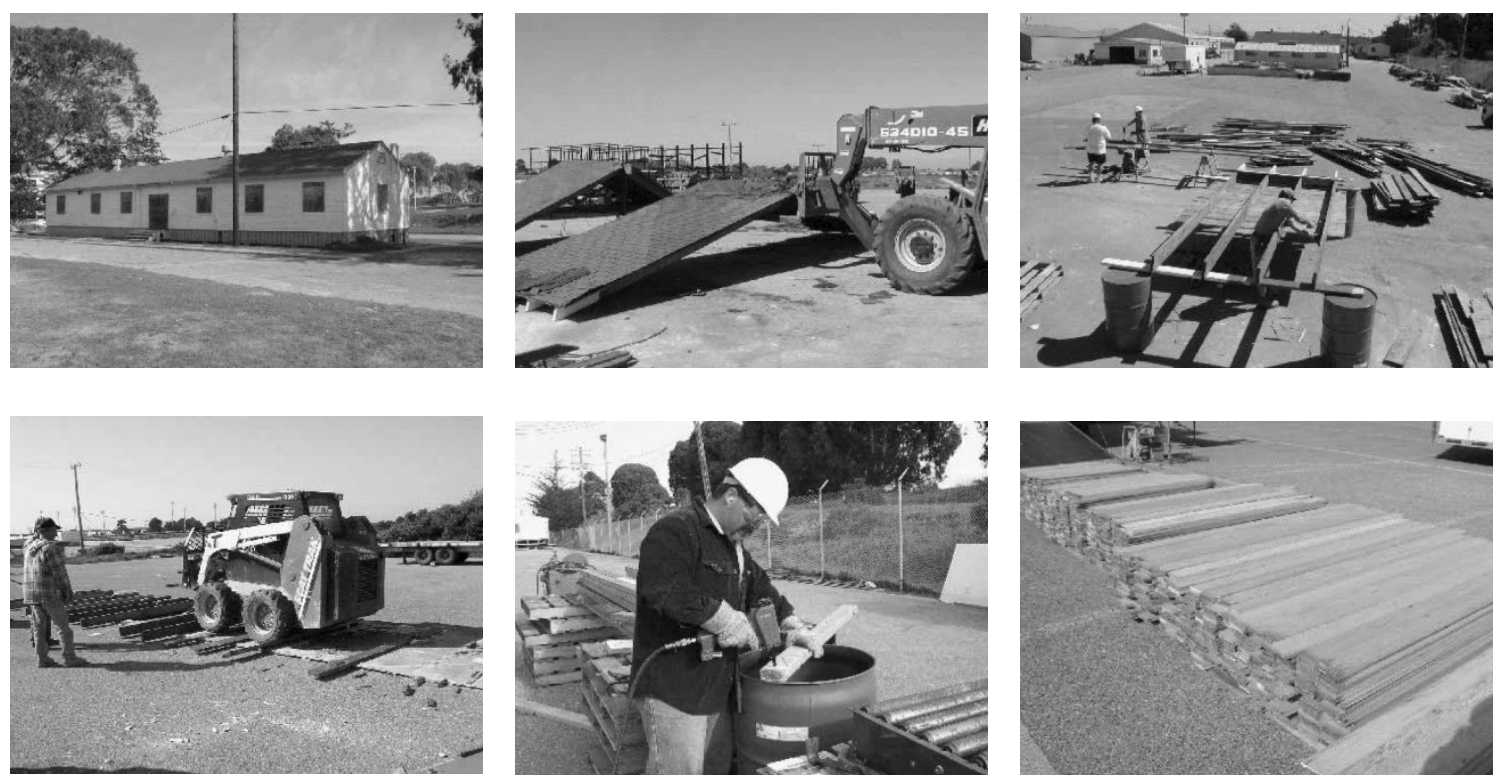

Figure 8: Images showing process of deconstructing Fort Ord Barracks; roof removal, raised work areas, deboarding techniques, denailing and planing stations.

Contaminant-free materials were sold onsite or donated, supplying the market with salvaged materials. Hazardous materials of asbestos and lead-based paint caused the biggest challenge, leading to the innovative creation of a mobile lead based paint removal system. ${ }^{67}$ This case study demonstrates effective, safe, economical tools and methods that are significant towards making deconstruction regular practice.
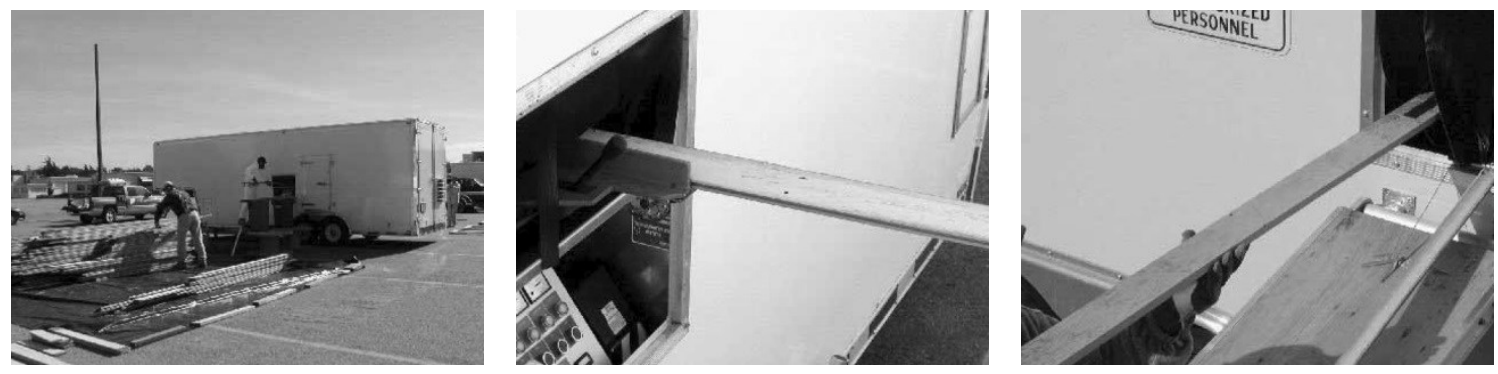

Figure 9: This mobile lead based paint remover is air-tight with negative pressure that captures any shavings created when wood passes through the built-in planer.

${ }^{67}$ Shell, Gutierrez, and Fisher, Design for Deconstruction. 


\section{[2.4.2] Riverdale Village Apartments}

\section{Riverdale, Maryland, USA - 1997 \\ by National Association of Homebuilders Research Center (NAHB)}

The deconstruction of this 2,000 square foot, two-storey 4-plex of masonry and wood is a case study analysis funded by the U.S. EPA. The comprehensive report of project results includes detailed labour analysis, a cost comparison to demolition, building material inventories, and environmental and regulatory recommendations for industry and practitioners in the field. ${ }^{68}$
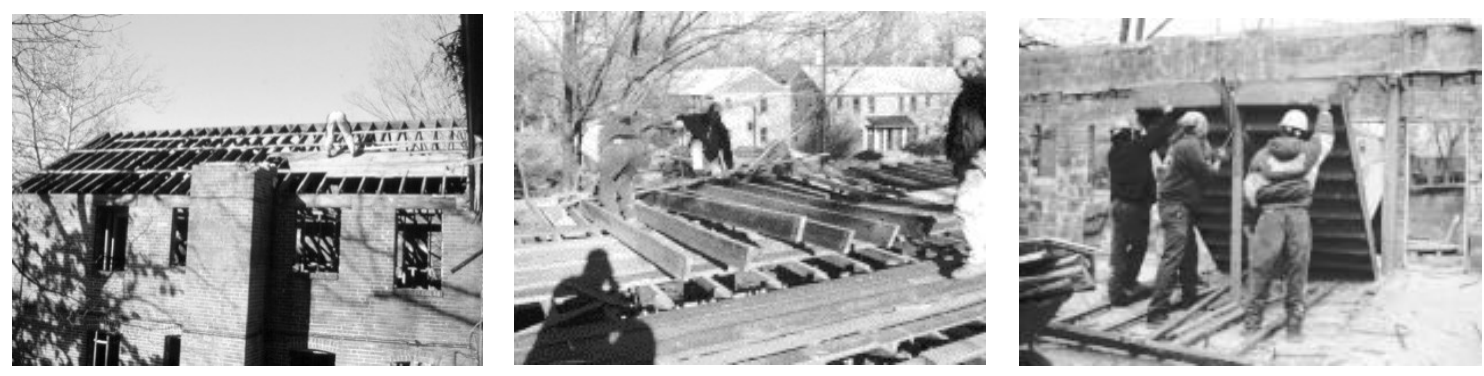

Figure 10: The Riverdale Village Apartment deconstruction made important observations about labour requirements and activities, job training, diversion rates, salvage values, and cost comparisons.

The study found that a high percentage of total labour hours were spent "processing" materials: de-nailing, sorting, and stacking (see Table 1). Being responsive to material flow and flexibility is vital to job site efficiency, and timely logistics such as service with waste haulers is critical to saving idle labour hours or moving materials more than once. ${ }^{69}$

\begin{tabular}{||l|c|}
\hline \multicolumn{1}{|c|}{ Task Category } & \% of Total Labour Hours \\
\hline Disassembly & $37 \%$ \\
\hline Production Support & $8 \%$ \\
\hline Processing & $55 \%$ \\
\hline
\end{tabular}

Table 1: Time required per task category of deconstruction (Source: NAHB, 1997).

68 NAHB, "The Riverdale Case Study."

69 lbid. 
The project results also show that a material diversion rate of approximately $70 \%$ by volume was achieved (see Table 2). This diversion from the landfill was accomplished by separating all materials into categories that were salvaged, reused, donated, recycled, or resold. Materials that are salvaged were divided into three quality categories based on their value compared to new equivalents, which affect marketability. ${ }^{70}$

\begin{tabular}{|c|c|}
\hline Item & Quantity \\
\hline Oak strip hardwood flooring & 950 square feet \\
\hline $\begin{array}{l}\text { Framing lumber: } \\
\text { 2x4s (avg 8' length) } \\
2 \times 8 \text { s (avg } 14 \mathrm{ft} \text { length) }\end{array}$ & $\begin{array}{l}400 \\
190\end{array}$ \\
\hline $\begin{array}{l}\text { Sheathing boards: } \\
1 \times 6 \text { (avg } 8 \text { ' length) }\end{array}$ & 475 \\
\hline Brick: red, flush & 5500 \\
\hline Windows: double glazed, aluminum & 24 \\
\hline $\begin{array}{l}\text { Metals: radiators, copper piping, } \\
\text { aluminum trim, gutters }\end{array}$ & 2.2 tons \\
\hline $\begin{array}{l}\text { Miscellaneous: } \\
\text { plumbing fixtures } \\
\text { oak stair treads } \\
\text { rubble (masonry) } \\
\text { asphalt shingles }\end{array}$ & $\begin{array}{c}12 \\
20 \\
62 \text { tons } \\
3.5 \text { tons }\end{array}$ \\
\hline $\begin{array}{l}\text { Total amount salvaged } \\
\text { (for reuse and recycling) } \\
\text { By weight } \\
\text { By volume }\end{array}$ & $\begin{array}{c}96.5 \text { tons } \\
192.5 \text { cubic yards }\end{array}$ \\
\hline $\begin{array}{l}\text { Total salvage rate } \\
\text { (as percentage of total generated) } \\
\text { By weight } \\
\text { By volume }\end{array}$ & $\begin{array}{l}76 \% \\
70 \%\end{array}$ \\
\hline
\end{tabular}

Table 2: Material diversion rates (Based on NAHB, 1997).

70 NAHB, "The Riverdale Case Study." 
Based on input of several building materials salvage firms, a range of estimated values of materials from the project were given to reflect a variation in quality or potential market fluctuations. After estimation and through an on-site sale, they found that commodity material such lumber and brick required little marketing to customers, selling for about half of the new retail price (See Table 3). Visitors to the site sale hesitant on purchasing more specific materials such as windows or doors commented on the need for an established retail set-up to tap a greater customer base. ${ }^{71}$

\begin{tabular}{||l|c|c|c||}
\hline \multicolumn{1}{|c|}{ Salvaged Material } & $\begin{array}{c}\text { \% of total amount } \\
\text { of item sold }\end{array}$ & $\begin{array}{c}\text { Sale price as a \% } \\
\text { of estimated retail }\end{array}$ & Income \\
\hline $\begin{array}{l}\text { Framing-2x4s } \\
\text { ("higher" quality) }\end{array}$ & $75 \%$ & $45 \%-50 \%$ & $\$ 300$ \\
\hline $\begin{array}{l}\text { Framing-2x4s } \\
\text { ("lower" quality) }\end{array}$ & $15 \%$ & $\sim 25 \%$ & $\$ 30$ \\
\hline $\begin{array}{l}\text { Framing-2x8s } \\
\text { ("higher" quality) }\end{array}$ & $50 \%$ & $45 \%-50 \%$ & $\$ 380$ \\
\hline $\begin{array}{l}\text { Framing-2x8s } \\
\text { ("lower" quality) }\end{array}$ & $40 \%$ & $\sim 25 \%$ & $\$ 175$ \\
\hline Sheathing-1x6 & $5 \%$ & NA & $\$ 6$ \\
\hline Brick & $100 \%$ & $45 \%-50 \%$ & $\$ 825$ \\
\hline Windows, doors, shutters & $25 \%$ & $\sim 10 \%$ & $\$ 154$ \\
\hline $\begin{array}{l}\text { Tubs, toilets, sinks, } \\
\text { radiators }\end{array}$ & $50 \%$ & $45 \%-50 \%$ & $\$ 70$ \\
\hline Hardwood flooring & $50 \%$ & & $\$ 2,440.00$ \\
\hline Total
\end{tabular}

Table 3: Results of Riverdale Site Sale (Source: NAHB, 1997).

Based on previous information, a cost analysis can compare the overall cost of deconstruction to conventional demolition, including offsetting values for salvaged

${ }^{71}$ NAHB, "The Riverdale Case Study." 
building materials and their avoided disposal costs. Factoring in all contractor and site specific considerations for this 2,000 square foot building, the study estimated the price of standard demolition at a cost of $\$ 3.50$ to $\$ 5.00$ USD per square foot, compared to deconstruction at $\$ 4.50$ to $\$ 5.40$ USD per square foot. ${ }^{72}$

\begin{tabular}{||c|c|c|}
\hline Costs/Premiums & Deconstruction & Demolition \\
\hline Labour (hours X rate) & $-\$ 11,443$ & \multirow{2}{*}{ Proprietary info: NA } \\
\hline Marketing & $-\$ 500$ & \\
\cline { 1 - 2 } Equipment & $\sim \$ 0$ & \\
\hline Disposal (\#pulls X rate) & $-\$ 900$ & \\
\cline { 1 - 2 } Recycling (\#pulls X rate) & $-\$ 1,000$ & \\
\hline Recycling Value (metals) & $+\$ 250$ & $\mathbf{- \$ 7 , 0 0 0}$ to $-\mathbf{\$ 1 0 , 0 0 0}$ \\
\hline $\begin{array}{c}\text { Estimated Value of } \\
\text { Salvaged Materials }\end{array}$ & $+\$ 2,791$ to $+\$ 4,572$ & \\
\hline Total & $\mathbf{- \$ 9 , 0 2 1}$ to $-\mathbf{\$ 1 0 , 8 0 2}$ & \\
\hline
\end{tabular}

Table 4: Comparison of Deconstruction and Demolition Costs: Overall Project (Source: NAHB, 1997).

While the project provides important key findings, it is important to remember that a single project cannot address all of the comparative issues involved with building removal decision making.

\section{[2.5] Moving Forward}

The deconstruction industry has gained popularity as completed projects exemplify the economic and environmental benefits compared to demolition. As the process of reclaiming materials becomes better understood and more common through advancing techniques and methodologies, the cost-competitiveness as a viable alternative to

72 NAHB, "The Riverdale Case Study." 
demolition will improve. Various how-to literature continue to be refined and expanded, while beneficial tools such as the Rapid Deconstruction Assessment by the U.S. EPA allow even non-professionals to pick up and engage in environmentally responsible deconstruction activities following a simple checklist and investigative steps.

A growing database for material inventory and warehousing of stock will increase the ability for contractors and builders to find used materials that are bounded by time, distance, and cost constraints. In addition to performing some degree of deconstruction activities, Habitat for Humanity Restores are just one example of an operation known for accepting donations of material stock, and selling these goods to benefit the public as well as their homebuilding efforts. Local online classifieds continue to be the most accessible platform for advertising merchandise, but frequently updated directories such as SalvoWEB also provide a wider-ranging gateway to marketplaces and dealers in architectural salvage and reclaimed materials. ${ }^{73}$

With greater experience among labourers comes greater proficiency and innovation. Specialty hand tools such as a wreckers adze, nail kicker, or double-clawed t-type wrecking bar have developed with the industry for deconstruction to operate more efficiently, while other innovations lie with change of practices or new methods to address a unique scenario. ${ }^{74}$ Dealing with a specific task, such as lead based paint removal, has also prompted innovators to develop more safe and efficient practices. This has resulted in inventions such as a mobile airtight trailer that captures hazardous lead

73 "About Us," Salvo Ltd, accessed March 2, 2017, http://www.salvoweb.com/aboutus.html.

${ }^{74}$ Falk and Guy, Unbuilding, 119-131. 
shavings from planed wood on-site. As a result of their success, these trailers are now being leased to large projects across the United States. ${ }^{75}$

As used materials become better understood with advancing techniques, many labour and time-saving strategies will develop that will embed greater efficiency in the process of deconstruction. Innovations such as the mobile lead-paint removal trailer suggest that there always will be a need filled as the industry continually looks for ways to become safer and more competitive than demolition.

${ }^{75}$ Shell, Gutierrez, and Fisher, Design for Deconstruction. 


\section{[3] DESIGN FOR DISASSEMBLY}

\section{[3.1] Overview}

Design for disassembly (DfD) "is the design of buildings to facilitate future change and the eventual dismantlement (in part or whole) for recovery of systems, components, and materials. The design process includes developing the assemblies, components, materials, construction techniques, and information and management systems to accomplish this goal. ${ }^{, 76}$ As discussed earlier, the intent of recovering materials is to maximize economic value and minimize environmental impacts of buildings through their subsequent reuse, repair, remanufacture, or recycling.

The idea of designing with disassembly in mind is an old concept. Circumstances of early human nomads called for shelter that would be mobile, repairable, and adaptable to suit required conditions. The Native American tipi, which tribes assembled and disassembled to accommodate migratory patterns, shows how DfD has been integrated throughout history. ${ }^{77}$ Another example is the craft-intensive architecture based in traditional Japanese culture. The earthquake-prone geography of Japan combined with mild climate conditions and readily available timber resulted in wood joinery that facilitated disassembly. ${ }^{78}$ The epitome of this practice is embodied in the Grand Shrine in the city of Ise. Here, the inner sanctum and supplementary access bridge have been dismantled and

\footnotetext{
${ }^{76}$ Bradley Guy and Nicholas Ciarimboli, Design for Disassembly in the Built Environment: A Guide to Closed Loop in Design and Building (Seattle, WA: King County Solid Waste Division, accessed October 5, 2015), 3 , http://your.kingcounty.gov/solidwaste/greenbuilding/documents/Design_for_Disassembly-guide.pdf.

77 Ibid., 4.

78 lbid.
} 
reconstructed every twenty years since the seventh century. ${ }^{79}$ Each time this cycle of rebuilding occurs, it passes down traditional carpentry skills to the next generation. It also instils a sustainability paradigm with immense symbolic and heritage value that carries throughout their culture. "This process includes the stewardship of the timber resource used to build each new iteration and the reuse and dispersal of the dismantled shrine to other shrines across the country." $\$ 0$

The International Style of architecture is a more recent example of how many concepts of design for disassembly are embodied through modernized materials and bolted connections. This movement sought to depress ornament and express materials, form, and structural assembly through their methods of connection. Utilizing pure materials such as metal, glass, stone, and concrete, buildings came with integral reuse and recycling capabilities, whether or not designers were thinking about the future in the spotlight. Design for disassembly principles have also become integral to exhibition pavilions or temporary structures requiring swift deployment or withdrawal in a variety of settings and conditions, and continue to provide valuable concepts and explorations for design of more permanent building types. ${ }^{81}$

\section{[3.2] Economic and Environmental Benefits}

Choosing DfD embodies a cyclical life for materials and components compared to the traditional linear cradle-to-grave building model that has little thought for what happens at the end of material life cycles. Deconstruction and DfD have primary objectives of

\footnotetext{
79 Kenneth Pletcher, "Ise Shrine," Encyclopaedia Britannica, Inc, accessed November 4, 2016 , https://www.britannica.com/topic/lse-Shrine.

80 Guy and Ciarimboli, Design for Disassembly, 4.

81 Ibid., 5.
} 
preventing unnecessary construction and demolition waste by closing the loop of resource use and, in turn, reducing the strain on our natural environment. DfD differs from deconstruction in that it attacks the problem of linear waste through early, collaborative design strategies. Buildings initially design to be dismantled permit greater recovery of material for reuse throughout their life stages. DfD also conserves the embodied energy invested building material, curtails the enormous solid-waste burden of demolished buildings, creates future cost savings from the end-of-life dismantling, and reduces potential future liability and waste disposal costs. ${ }^{82}$ The idea of material abundance through designing-out construction waste from outset and with return on investment is monumental.

DfD is a paradigm to build in an environmentally-responsible manner that generates fullcost accounting in the context of waste management, meaning it recognizes the entirety of expenses for the buildings life cycle from upfront, in operation, and end-of-life considerations. ${ }^{83}$ This includes scenario planning strategies that allow for flexible and convertible buildings to accommodate renovations that can add or subtract to meet owner, occupant, or market demands.

DfD buildings cost less to repair or upgrade over time because of their ease of maintenance thanks to the separation of building systems and materials. This separation also means materials can be removed and replaced before failure without destroying

82 Guy and Ciarimboli, Design for Disassembly, 9.

83 lbid. 
adjacent materials in the process. ${ }^{84}$ While there is usually an associated capital cost premium associated with planning and considerations for $\mathrm{DfD}$ buildings, there are further benefits and increased value resulting from the application of simple principles and strategies.

\section{[3.3] Principles and Strategies}

A vast majority of existing buildings are not designed to be spatially-adaptable or deconstruct easily to recover their materials for reuse and recycling in a cost-effective manner. A reason for this is the method by which buildings were constructed, with connections using nails, staples, and adhesives that can be difficult to take apart and inhibits disassembly. As discussed earlier, Brand's "six S's" and theory of time-related building layers identifies that the components and systems of a building should be grouped into segments with similar life expectancies. The concept of making these layers accessible reduces future maintenance costs and waste generation, and the theory provides a critical foundation when considering DfD strategies.

Buildings undergo design changes in their lifespan by the functional requirements of their users, and reducing the complexity of assembling building layers allows for a higher degree of flexibility. Adaptive design principles such as versatility, convertibility, and expandability are interrelated and affect the long-term functionality of a building through the design of structural systems and organization of space. ${ }^{85}$ For example, DfD provides a market for flexible spatial configurations or interior fit-outs that are valuable for

84 Vince Catalli, "Design for Disassembly: Early planning means an economic afterlife for buildings," Sustainable Architecture and Building Magazine, September/October 2009, 41-46.

$85 \mathrm{lbid}$. 
merchandising layouts in retail environments. DfD also permits the dismantlement of mechanical, electrical, and plumbing systems for ease of separate repair or replacement relative to their anticipated life cycle, thereby maintaining value in the reduced adaptation and removal costs incurred by a future owner.

In the comprehensive publication Design for Disassembly in the Built Environment, Bradley Guy and Nicholas Ciarimboli outline other key principles and strategies that facilitate the longevity of building resources and future adaptability. The documentation of materials, labelling of connections, and creation of manuals for future deconstruction are important steps in improving overall efficiency. They note it is critical to design visually, physically, and ergonomically accessible connections using standard bolted or screwed connections wherever possible while also minimizing or eliminating the specification of chemical adhesives. ${ }^{86}$ Additionally, simplifying structural systems and form to a modular grid or standard dimensions reduces the complexity of construction and potential clashing of various material types and building systems on site and among different trades. Further approaches to reduce complexity include using a minimal amount of interior finishes that are durable, low maintenance, and low impact environmentally that expose the 'guts' of the building, such as suspended utility raceways, heating, or plumbing.

Other strategies of design for disassembly include using high-quality durable or salvaged materials, minimizing the number of materials to reduce complexity and separation, and avoiding many different types of components, connections, or fasteners. Just as it is good practice to separate different layers of a building, the same mentality should be applied to

${ }^{86}$ Guy and Ciarimboli, Design for Disassembly, 6. 
the buildings materials themselves. Composite materials are common in the building supply market, but the nature of their design makes them extremely difficult to separate and recycle into proper waste streams. Following the principles and strategies of DfD, there are many successful precedents that have demonstrated a high degree of material reuse, adaptability, and sustainable design features.

\section{[3.4] Precedents}

\section{[3.4.1] Mountain Equipment Co-op Store}

Ottawa, Ontario, Canada - 2000

by Linda Chapman, Christopher Simmonds, Leslie Jones \& Associates

The Mountain Equipment Co-op in Ottawa is a two-story retail store designed by Linda Chapman and Christopher Simmonds in partnership with Leslie Jones \& Associates completed in June 2000. At a cost of \$2.9 million, the project used a design team of waste management and deconstruction consultants that co-ordinated as a group from the onset to map out the best solutions for design and construction and produce a more cost effective, energy efficient and environmentally favourable building.
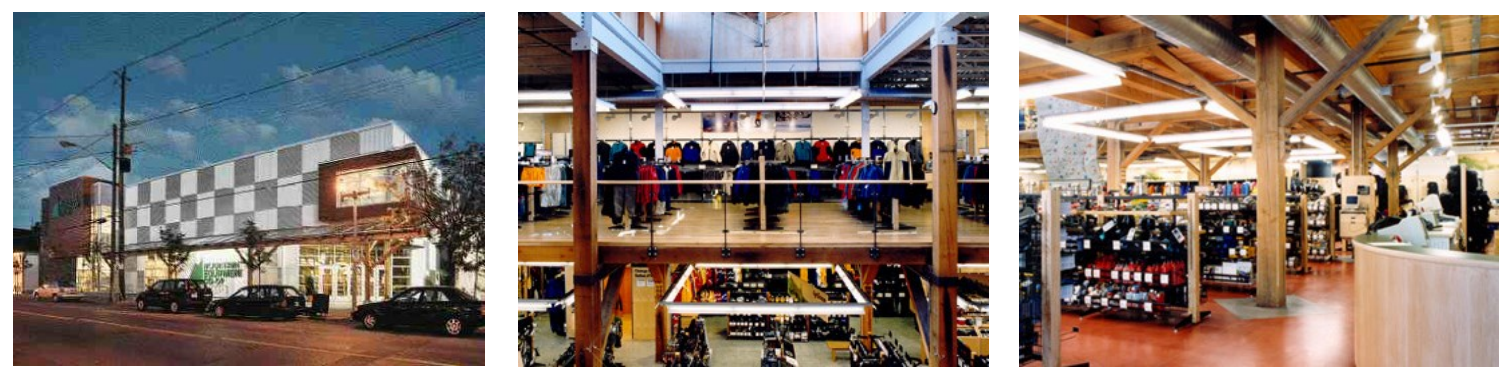

Figure 11: MEC Ottawa employs DfD strategies such as a standard structural grid, exposed connections, minimal interior finishes, and suspended utility raceways.

Reused materials were the main aspect of this project, with the team meticulously deconstructing the old MEC store location in Ottawa to relocate to a new site. When 
MEC purchased the property, they made the decision to salvage the existing 40-year-old one-storey commercial building on the proposed site, ultimately using the steel for the structure of the new building's second floor with bolted connections and screwed down timber decks. ${ }^{87}$ The first floor of the new build also utilized salvaged Douglas fir timbers from old log booms on the St. Lawrence River. Although the project was estimated to cost $13 \%$ more than a standard similar size retail store, it reused or recycled almost $90 \%$ of materials from both project sites. ${ }^{88}$ The materials not used on the project were sold to local contractors and the community, while materials that are recycled enter into biological or technical cycles and continue to serve another use downstream.

Other strategies implemented are reduction of interior finishes, demountable partition panels, and suspended utility raceways that minimize damage to material and allow spatial adaptability well suited for merchandising layouts in retail environments. The modular and versatile design also allowed for the easy expansion of the store eastward two bays in 2012 for a gain of 9,000 square feet with easy integration and minimal damage for the materials of the existing MEC store. ${ }^{89}$

MEC Ottawa and its notable features of salvaged heavy timbers, demountable partitions, modular design, and exposed connections embody the adaptive reuse and longevity of material through its design for disassembly strategies, thereby extending the lifespan of existing processed resources.

\footnotetext{
87 Linda Chapman, "Mountain Equipment Co-op Store," Linda Chapman Architect, accessed November 24, 2016, http://www.smartarchitecture.com/articles-2001spring.html.

88 Vince Catalli and Maria Williams, "Designing for Disassembly," Canadian Architect, January 1, 2001, https://www.canadianarchitect.com/features/designing-for-disassembly/.

$89 \mathrm{lbid}$.
} 


\section{[3.4.2] Woodward Avenue Environmental Laboratory}

\section{Hamilton, Ontario, Canada-2007 \\ by McCallum Sather Architects}

The Woodward Labs is an Operations Control Centre and wastewater testing facility for Hamtilton's municipal water supply. Receiving LEED Silver certification, the project consists of different components for laboratories, administration, operations, and regulations. ${ }^{90}$
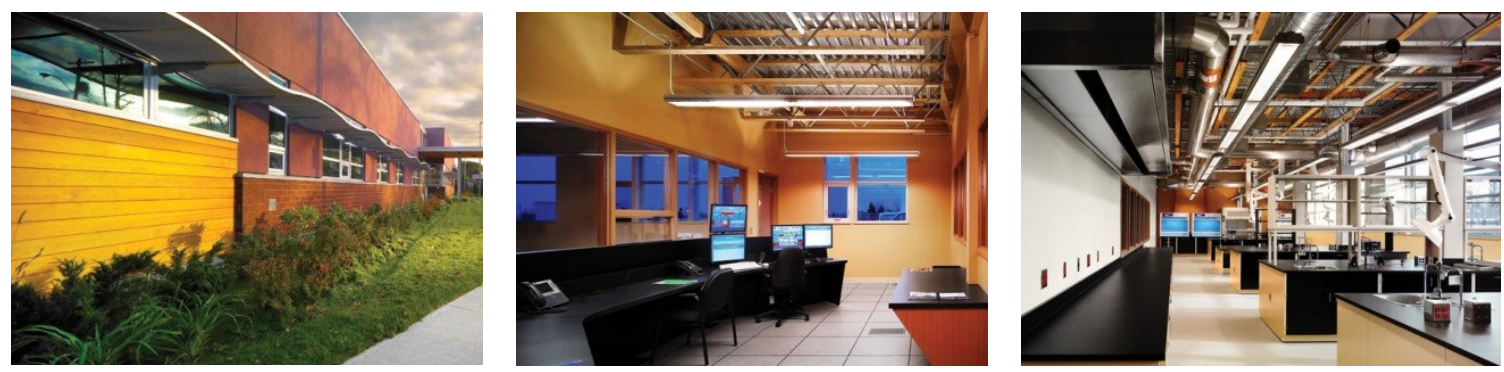

Figure 12: Exposed, mechanically fastened structure, fixtures, and utilities demonstrate that laboratory spaces do not have to fall victim to 'white-room' syndrome.

The project participated in extensive recycling during construction, reducing landfill emissions by almost $90 \%$. In addition, $25 \%$ of materials used were from local sources and $15 \%$ reused from recycled sources, reducing emissions related to transportation and manufacturing respectively. ${ }^{91}$

The entire structure is designed to be completely demountable and recyclable at the end of its life by taking advantage of bolted connections and screws. Open web steel joists incorporate hybrid wood chords that permit screw fastening of the metal deck, related assemblies, and building systems. ${ }^{92}$ On the exterior, sections of masonry veneer and

90 "Woodward Labs," McCallum Sather Architects Inc., accessed September 26, 2016, http://mccallumsather.com/projects/woodward-labs/.

91 Greg Sather, "Woodward Avenue Environmental Laboratory," Sustainable Architecture and Building Magazine, accessed September 26, 2016, http://www.sabmagazine.com/blog/2008/10/17/wastewater-testing/. 92 lbid. 
stucco panels are mechanically fastened to the structure, while reclaimed red cedar is fastened with clever screw details.

As a LEED certified lab, the building incorporates other sustainable green features, including stormwater management, efficient fixtures, high performance windows, and environmental sensors. ${ }^{93}$ Given these considerations, it is important to observe in projects such as this that incorporating design for deconstruction strategies do not impact the required conditions of more sensitive indoor environments.

\section{[3.4.3] C.K. Choi Building}

\section{Vancouver, British Columbia, Canada - 1996 by Matsuzaki Wright Architects Inc.}

This award winning building is home of the University of British Columbia's Institute for Asian Studies and is recognized for extensive material salvage and reuse, in addition to applying principles of DfD. ${ }^{94}$
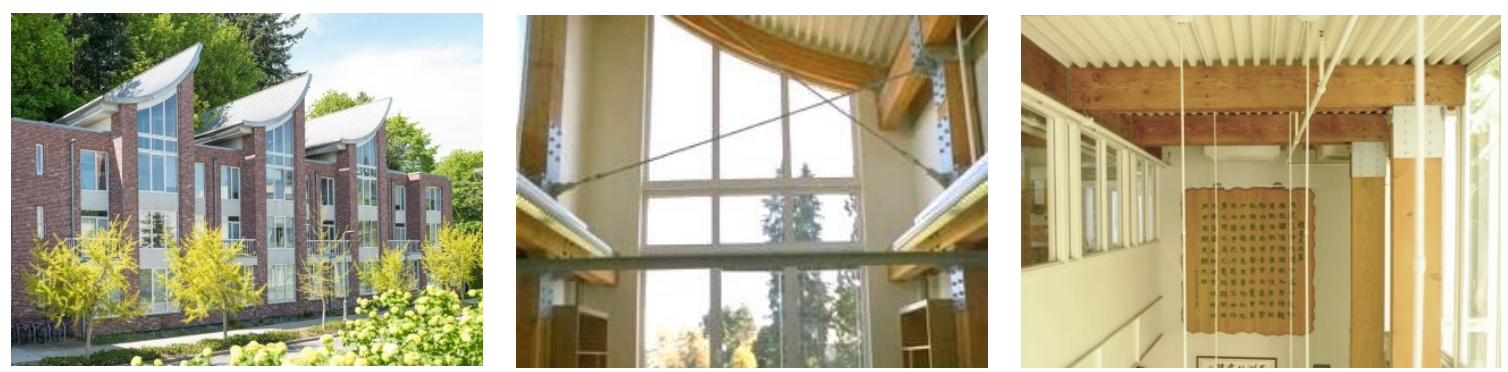

Figure 13: C.K. Choi building showing exterior reclaimed brick cladding, reclaimed timber structure, exposed connections, and simplicity of finishes.

A heavy focus on structural materials assessment of the adjacent university owned Armory building slated for demolition provided estimations of available base materials that influenced the design of the new building. However, this project also illustrates

93 Sather, "Woodward."

94 Susan Ross, "From Salvage to De-construction of Heritage Places: Rethinking Waste Values in Canadian Cities," What Does Heritage Change? (Montreal: UQAM/Association for Critical Heritage Studies (forthcoming), 2017). 
issues in symbolic value of connection between a source and the place of reuse. ${ }^{95}$ For example, the Armory building was built for campus-based military service training of wartime students. The history of expelling of Japanese Canadians and period of mistreatment in the Second World War and potential associated values pertaining to that building has become directed into the reclaimed timbers, seemingly ignoring this history in favour of evoking the protection and significance of forestry. ${ }^{96}$

In sum, the project resulted in salvaging heavy timbers for reuse that provided $60 \%$ of the primary wood structure. ${ }^{97}$ Over $50 \%$ material is reused or comes from recycled sources, such as the steel, plywood, framing timber, and doors. This includes over $100 \%$ of the exterior cladding reused from Vancouver buildings. ${ }^{98}$ The structure is built in modular bays with reusable components and avoids composite materials. For example, recycled aggregate is used in the concrete floors with a simple polish finish. The entire 34,400 square foot building reveals and celebrates exposed components and connections that facilitate design for disassembly. A comprehensive waste management plan was also developed prior to construction that implemented job site recycling and waste separation between different trades or subcontractors. ${ }^{99}$

${ }^{95}$ Susan Ross, "From Salvage to De-construction of Heritage Places"

96 Ibid.

97 "C.K. Choi Building," The American Institute of Architects, accessed October 1, 2016, http://www.aiatopten.org/node/206.

$98 \mathrm{lbid}$.

99 Ibid. 


\section{[3.4.4] Chartwell School}

Seaside, California, USA - 2006

by EHDD Architecture

Chartwell is the first LEED Platinum-certified school and integrates responsible resource stewardship and reduced environmental impact. This includes consideration for delivering a sustainable site, renewable energy, and providing a high level of indoor environmental quality for its occupants. Creating the best learning environment also aligned with the benefits of building a green school. Using the LEED rating system ensured that the building facilities perform as intended, with building system verification through ongoing commissioning and monitoring a key to operational goals and success. ${ }^{100}$

Demonstrating good practice of design for disassembly strategies, only essential finishes are introduced where required, leaving most of the structure, systems, and services exposed throughout the interior spaces while celebrating the true nature of material and construction. This, along with over-engineered bearing walls, non-structural partitions between classrooms, exposed structural connections, and suspended utility raceways, provide flexibility to accommodate the school's future needs. Roof-truss connections also use bolts instead of straps or nails, allowing the efficient end-of-life removal of structurally insulated panels. ${ }^{101}$

100 United States Green Building Council, LEED Stories From Practice: Case Study - Chartwell School (Washington, DC: USGBC, 2010), 9, http://www.usgbc.org/Docs/Archive/General/Docs8824.pdf. 101 lbid. 

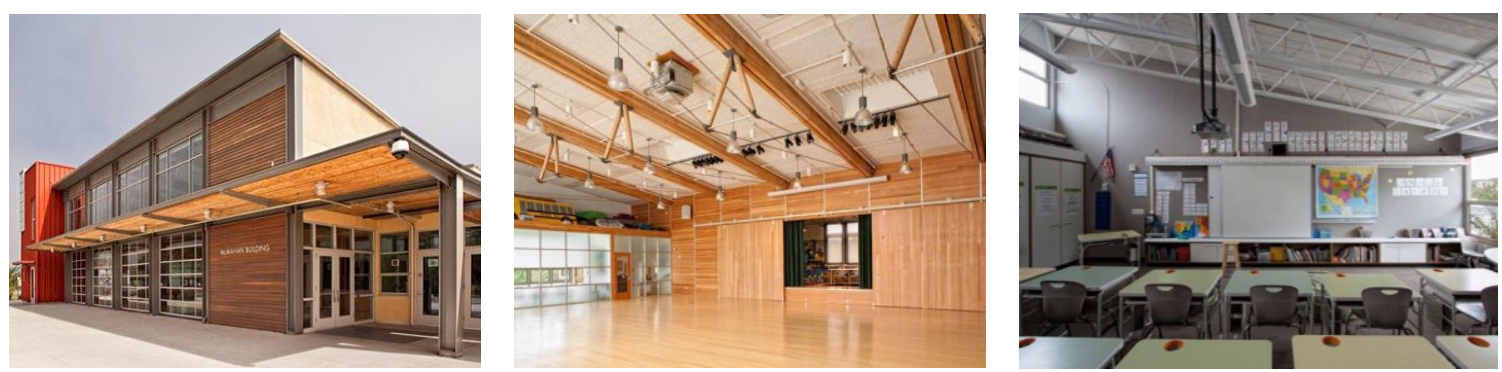

Figure 14: Exposed structural systems and utilities in classrooms allow students to learn how buildings come together.

The school's executive director conducted a visioning process to determine the school's overall education and economic goals that resulted in a program document to use the new school facilities as teaching tools and have its green building features and energyefficient systems integrated throughout the curriculum. ${ }^{102}$ Passive energy and resource generating systems such as photovoltaic panels and rainwater collection cisterns provide students with a direct connection to how landscape irrigation affects water supply and the warmth of radiant slab heating related to amount of sun in the sky. Allowing building occupants to understand how building systems operate and come together is an important concept when applied to a school environment. By constant exposure and daily integration of these green building features and DfD principles, students passively absorb a mindset based on sustainability that they will carry forward in their future careers.

\section{[3.5] A Question of Design}

Perhaps hoping to alter the way architects design buildings, Steward Brand suggests a categorization of different building typologies that can be considered Low Road, High Road, or No Road. He proposes that Low Road buildings (which are simple, low-cost, and easily modified) are vital to innovation and economic growth, whereas No Road

102 USGBC, LEED Stories - Chartwell School, 6. 
buildings (which are over-complicated, over-artistic, and inherently rigid) can be impressive but impractical and do not facilitate disassembly as easily as simple construction. ${ }^{103}$

Choosing whether or not to follow DfD principles or employ intelligent building strategies comes down to a question of design. Although financial benefits to DfD may be difficult to quantify throughout a buildings life-cycle, the environmental benefit related to waste is almost certain. If $\mathrm{DfD}$ strategies result in more adaptable, more easily renovated, durable buildings as well as greater resource-efficiency, then a small increase in initial materials or cost is worth the overall benefit. The traditional economic views of buildings only consider the initial structure, services, and space plans, but the changes within a building over time cost upwards of three times more than the original building. ${ }^{104}$ As DfD practices become more recognized and understood as common-place, the competitiveness to traditional construction methods and coordination will likely increase.

DfD occurs at both micro and macro levels, from developing new details for connections and component assemblies, to overall collaborative design strategies that involve all parties from the project onset. Technology has played a large part in the development of modern workflows that utilize $\mathrm{DfD}$, helping project teams become more efficient and communicate potential issues related to construction or systems sooner in the design process. This collaboration through digital modelling software assists in the process of assembling components and systems together that can be examined for potential clash

103 Brand, How Buildings Learn, 24-71.

104 Ibid., 13. 
detection. In turn, this could result in less change orders and site instructions during the construction phase, and better flow between consultants and contractors.

The incorporation of innovative technologies and digital workflows, such as the use of a building information model, has helped facilitate smoother project collaboration practices, building documentation, and commissioning in the industry. Taking into consideration all aspects of the current building industry, deconstruction, and design for disassembly, the following chapter proposes a process that utilizes digital workflows and acts as a foundation guiding the design project. 


\section{[4] DIGITAL WORKFLOWS}

\section{[4.1] Building Documentation and Assessment}

The amount of salvageable material contained in an existing building can be difficult to determine. Typically, this process would be done manually in person, surveying the building for its merits and inventory, which usually involves an invasive investigation into the structure and opening up walls and ceilings to provide an accurate evaluation on sizes of building components. However, being able to penetrate the finish surface is sometimes not permissible by the owner prior to a contract being awarded to proceed with deconstruction work, or as in the case of this thesis.

The process of deconstruction would prompt any responsible builder to request architectural drawings, blueprints, or any other details of how or when the building was constructed for review. ${ }^{105}$ Obtaining this information helps to understand how the building was put together, and in turn how to reverse the process for safer and more efficient deconstruction. However, as a property passes down to new owners, it is likely that corresponding documentation for the property does not and becomes lost during the transition. Without any reference information to associate findings, this leads to questioning what else can be done to appraise existing conditions without damage.

Photography plays a critical part in building documentation. It captures spaces and content in a digital frame, as an existing record in time. Photography also offers other

105 Falk and Guy, Unbuilding, 48. 
opportunities, and serves as the primary reference material for the proposed thesis project. In endeavouring to document an existing building digitally, one strategy that can be used is to rectify elevation-based photographs for use in creating 3D computer model of the existing building. This process involves using a single photo (or merge of photos) to use as reference for modelling each elevation digitally, set up in the model to the width and length dimensions of the building.

Through investigations into emerging digital workflows, photogrammetry techniques are another way to utilize the information contained in photographs. Similar to point-based laser scanning, photogrammetry uses technology that optimizes position-based photographs to implement 3D reconstruction and visualization. The resulting output of intelligent image processing is the same point cloud style recreation used by expensive laser scanning equipment, but extends further to allow creation of high quality meshes and textures (see Figure 15-16). Software such as Photoscan offer a fairly easy to use interface and linear procedure of automatically processing photos into a point cloud model within a few hours depending on setting preferences. 


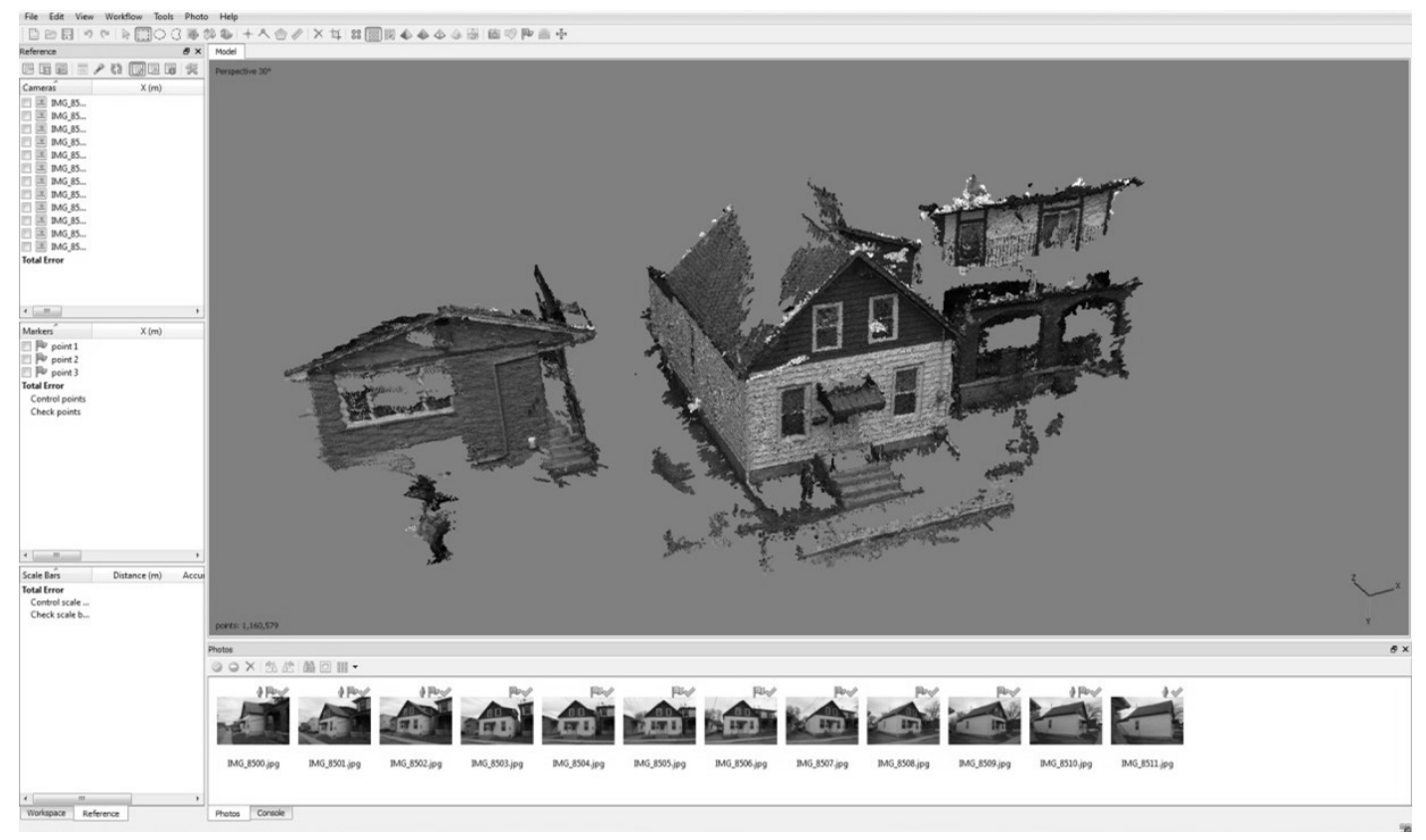

Figure 15: Screenshot of Photoscan software that converts position-based photographs into $3 D$ point cloud data.

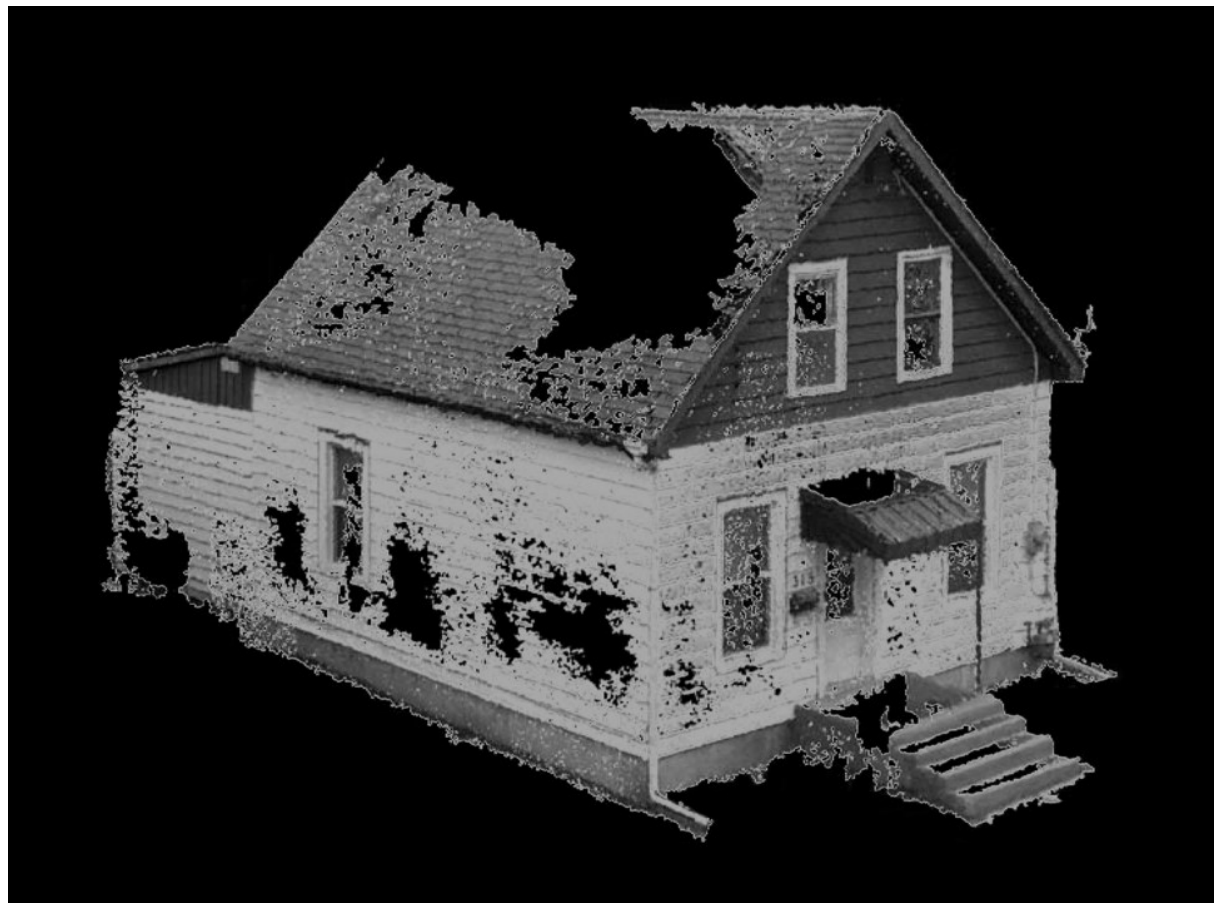

Figure 16: Resulting perspective of cleaned up point cloud model.

Having a digital point cloud model of millions of reference points in 3D space allows for accurate outlines and measurements of existing conditions by slicing plans or sections. 
The point cloud can then be linked into building information model (BIM) software such as Autodesk Revit and becomes a crucial starting point for documentation.
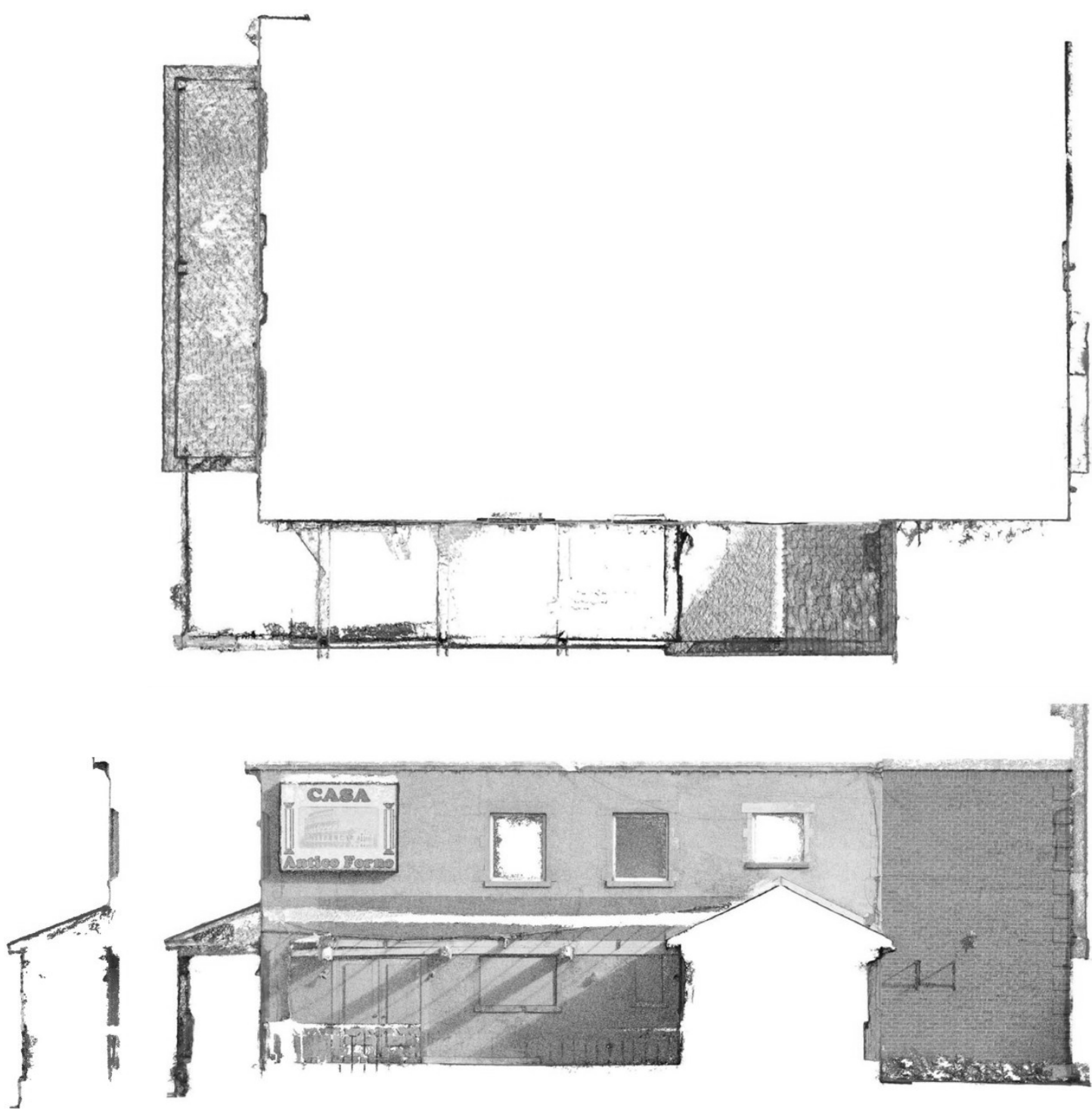

Figure 17: Plans and sections are easily created to reference building dimensions from point cloud model generated via photogrammetry

Utilizing the power of BIM, documenting this information digitally offers many advantages, but primarily the ability to quantify and inventory all building elements in organized schedules. Structural framing components are the most advantageous to quantify and schedule due to their high reuse potential, while certain exterior sidings like 
vinyl or stucco finish materials are less significant. These schedules then allow elements to be assigned unique mark identifiers with specific material properties that can locate where it was salvaged from the existing building, stored in warehousing, and specified for reuse in new projects.

\section{[4.2] Enhanced Coordination}

Just as project teams would get together for meetings to coordinate and discuss the status of the project, the same collaboration can occur through the more efficient digital interface found in BIM workflows. Building information modelling is the digital equivalent of design for disassembly that facilitates "disentanglement" of all the components and systems in a building. It integrates collaborative management tools that enable a project team to better communicate regarding the planning of different disciplines or design phases of a project. This includes software add-ons for automatic clash detection which identifies conflicts between different systems or components, and allows for correcting routing or connections before potential costly site issues during construction. 


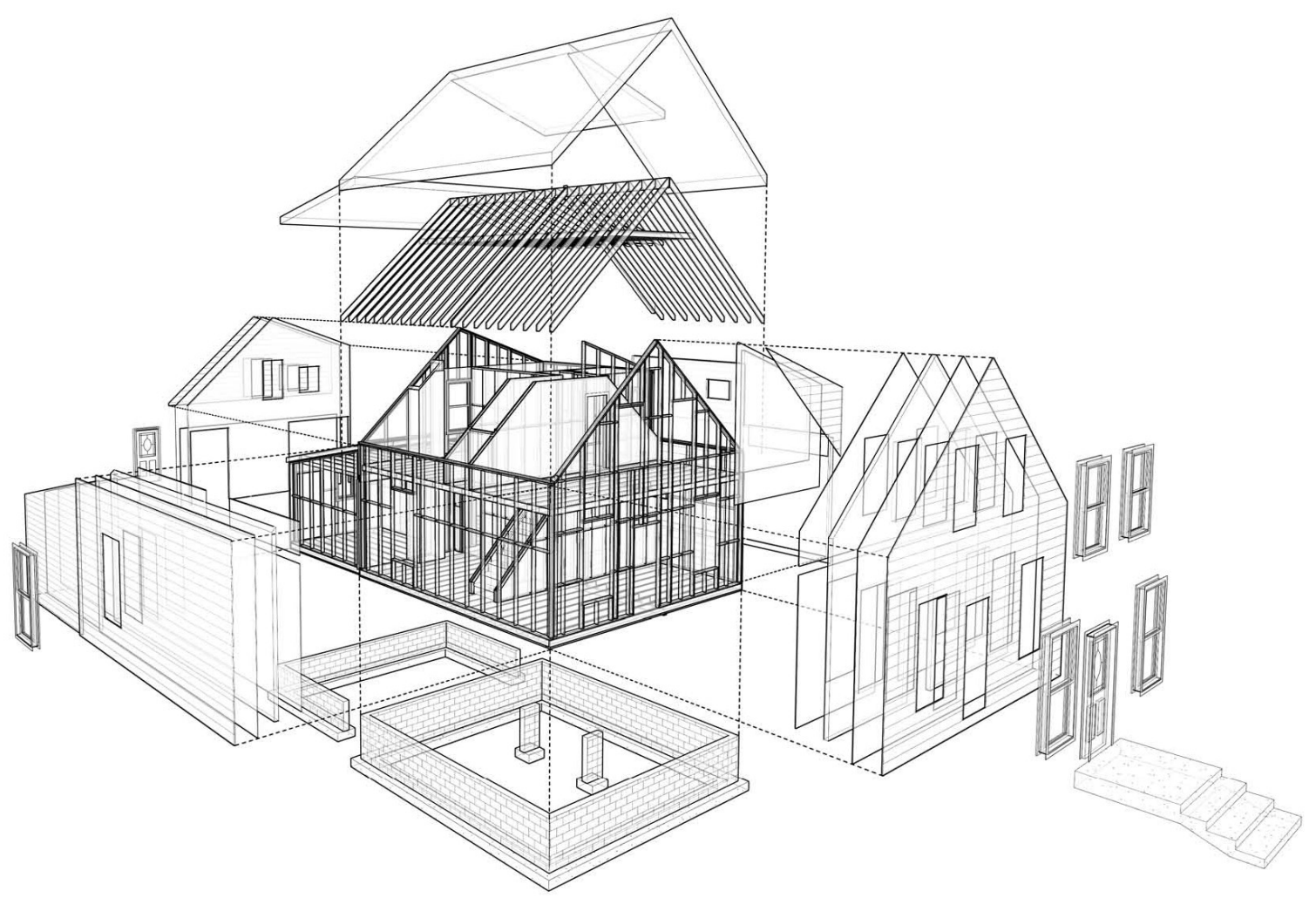

Figure 18: BIM enables the visual separation and understanding of how the different layers of materials and systems interact.

Utilizing BIM from the beginning of a project allows teams to perform massing and area studies, daylighting and energy simulations, as well as structural analysis of potential design options to find the solution that provides the best economic and environmental benefits. It also provides a platform to plan and manage the life-cycle of building layers, or for future phases or additions, with the ability to analyze the performance of its current or anticipated building systems for facilities management.

The potential of using BIM for deconstruction and to design for disassembly allows further insight into the life-cycle of building layers, methods of detailing adaptive components, and assessing economic and environmental challenges while considering the design and development of integrated workflows. 


\section{[4.3] Material Information}

As stated earlier, a Building Information Model through Autodesk Revit software offers many opportunities to specify unique material properties embedded in the model. While the primary advantage remains in its intelligent material scheduling, it also allows the prospect of entering a variety of user-defined parameters for evaluation and review.

The different major structural materials of wood, steel, and masonry are good candidates for end-of-life reuse potential, although masonry can be difficult to separate and salvage depending on the type of mortar used, and may yield a lower salvage rate. If diversion rate goals will be met based on volume or weight, concrete may also be worthwhile to include evaluating. These materials are easily scheduled as an itemized list through BIM to provide live material take-offs and quantities of each material element, or in the case of deconstruction, an estimated sum of structural members for salvage. The properties of elements in the model can include specifying a quality rating for each piece of material, or its composition, length, width, and height dimensions. This includes unique mark identifiers which can track elements for reuse locating or warehousing, and parameters for verification of element existence based on fact or just speculation. There is also builtin conditional formatting options that establish rules and colours of cells to help identify when a value may be in or out of a defined range. Figure 19 shows the potenital types of parameters and properties that can be set up in a schedule, with conditional formatting colours and different filtering options. Custom fields on the right round down each length of lumber to the nearest two-foot length section, reflecting how component reuse may be categorized or trimmed to modular dimensions. 


\begin{tabular}{|c|c|c|c|c|c|c|c|c|c|c|c|c|c|c|c|}
\hline \multicolumn{16}{|c|}{$<$ Structural Framing Schedule Properties $>$} \\
\hline A & B & C & $D$ & $\mathrm{E}$ & $\mathrm{F}$ & G & $\mathrm{H}$ & 1 & $\mathrm{~J}$ & $\mathrm{~K}$ & $\mathrm{~L}$ & $\mathrm{~m}$ & $\mathrm{~N}$ & 0 & $\bar{P}$ \\
\hline Family & Type & Length & Mark & $\begin{array}{l}\text { Structural Material } \\
\end{array}$ & $\mathrm{W} \times \mathrm{H}$ & Board Footage & Low Q. & Medium Q. & High Q. & $14.5^{\mathrm{m}} \mathrm{pic}$ & 2 piece & 4' pieces & $6^{\prime}$ piece: & 8 pieces & $10^{\prime}$ piece \\
\hline M_Dimension Lumber & $38 \times 90\left(2 \times 4^{\prime \prime}\right)$ & $2-51 / 2^{\prime \prime}$ & $W-10$ & Softwood (Spruce/Pine/Fir) & 8 & 1.63 & $\sqrt{1}$ & 同 & 同 & 12 & 1 & 5 & 0 & 0 & 0 \\
\hline M_Dimension Lumber & $38 \times 90\left(2 \times 4^{4}\right)$ & $2-51 / 2$ & W-11 & Softwood (Spruce/Pine/fir) & 8 & 1.63 & $\mathrm{~T}$ & 国 & 1 & 2 & 1 & 10 & 0 & 0 & 0 \\
\hline M_Dimension Lumber & $38 \times 90\left(2 \times 4^{\prime}\right)$ & $2-91 / 2^{2}$ & $W-12$ & Softwood (Spruce/Pine//Fir) & 8 & 1.86 & $\sqrt{v}$ & 而 & (1) & 2 & 1 & 10 & 0 & 0 & 0 \\
\hline M_Dimension Lumber & $38 \times 90\left(2 \times 4^{\prime \prime}\right)$ & $2-91 / 2^{\prime}$ & $N-37$ & Softwood (Spruce/Pine/Fir) & 8 & 1.86 & 7 & 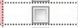 & 同 & 2 & 1 & 10 & 0 & 0 & 0 \\
\hline M_Dimension Lumber & $38 \times 90\left(2 \times 4^{\prime \prime}\right)$ & $2-91 / 2$ & $N-38$ & Softwood (Spruce/Pine//Fir) & 8 & 1.86 & 目 & 国 & $\sqrt{v}$ & 2 & 1 & 0 & 0 & 0 & 0 \\
\hline M_Dimension Lumber & $38 \times 90\left(2 \times 4^{\prime}\right)$ & $2-91 / 2$ & $N-39 a$ & Softwood (Spruce/Pine/Fir) & 8 & 1.86 & 7 & (1) & $\mathrm{v}$ & 2 & 1 & 0 & 0 & 0 & 0 \\
\hline M_Dimension Lumber & $38 \times 90\left(2 \times 4^{-1}\right)$ & $2-91 / 2^{2}$ & $N-39 b$ & Softwood (Spruce/Pine/fir) & 8 & 1.86 & $\sqrt{v}$ & 而 & 䡒 & 2 & 1 & 0 & 0 & 0 & 0 \\
\hline M_Dimension Lumber & $38 \times 90\left(2 \times 4^{4}\right)$ & $2-91 / 2^{m}$ & $N-40$ & Softwood (Spruce/Pine/fir) & 8 & 1.86 & 目 & $\nabla$ & 䣦 & 2 & 1 & 10 & 0 & 0 & 0 \\
\hline M_Dimension Lumber & $38 \times 90\left(2 \times 4^{\prime \prime}\right)$ & $2-10^{\prime \prime}$ & $N-41$ & Softwood (Spruce/Pine/Fir) & 8 & 1.88 & 国 & $\nabla$ & D & 2 & 1 & 10 & 0 & 0 & 0 \\
\hline M_Dimension Lumber & $38 \times 90\left(2 \times 4^{\prime}\right)$ & $2-10^{m}$ & S-6 6 & Softwood (Spruce/Pine//Fir) & 8 & 1.89 & 同 & $\mathrm{v}$ & (1) & 2 & 1 & 0 & 0 & 0 & 0 \\
\hline M_Dimension Lumber & $38 \times 90\left(2 \times 4^{\prime}\right)$ & $2^{\prime}-10^{m}$ & S-7 & Softwood (Spruce/Pine//Fir) & 8 & 1.88 & $\sqrt{7}$ & 10 & (1) & 2 & 1 & 0 & 0 & 0 & 0 \\
\hline M_Dimension Lumber & $38 \times 90\left(2 \times 4^{-1}\right)$ & $2-10^{\prime \prime}$ & $N-44$ & Softwood (Spruce/Pine/fir) & 8 & 1.88 & $\sqrt{1}$ & $\nabla$ & (1) & 2 & 1 & 0 & 0 & 0 & 0 \\
\hline M_Dimension Lumber & $38 \times 90\left(2 \times 4^{\prime}\right)$ & $2-1111 / 2$ & $N-45$ & Softwood (Spruce/Pine/fir) & 8 & 1.97 & $\sqrt{1}$ & 䓝 & (1) & 2 & 1 & 0 & 0 & 0 & 0 \\
\hline M_Dimension Lumber & $38 \times 90\left(2 \times 4^{-}\right)$ & $2^{2}-1111 / 2^{m}$ & $E-30$ & Softwood (Spruce/Pine//Fir) & 8 & 1.97 & $\sqrt{7}$ & 而 & 国 & 2 & 1 & 10 & 0 & 0 & 0 \\
\hline M_Dimension Lumber & $38 \times 90\left(2 \times 4^{\prime \prime}\right)$ & $3^{3}-0^{-\prime}$ & $E-38$ & Softwood (Spruce/Pine/fir) & 8 & 2.00 & $\sqrt{n}$ & $\nabla$ & (1) & 2 & 1 & 10 & 0 & 0 & 0 \\
\hline M_Dimension Lumber & $38 \times 90\left(2 \times 4^{\prime}\right)$ & $3^{\prime}-0^{-}$ & $E-45$ & Softwood (Spruce/Pine/Fir) & 8 & 2.00 & 网 & $\sqrt{7}$ & (1) & 2 & 1 & 0 & 0 & 0 & 0 \\
\hline M_Dimension Lumber & $38 \times 90\left(2 \times 4^{\prime}\right)$ & $3^{\prime}-2^{\prime}$ & $N-49$ & Softwood (Spruce/Pine/fir) & 8 & 2.11 & v & G & (1) & 2 & 1 & 10 & 0 & 0 & 0 \\
\hline M_Dimension Lumber & $38 \times 90\left(2 \times 4^{4}\right)$ & $3^{3}-2^{2}$ & $N-50$ & Softwood (Spruce/Pine//Fir) & 8 & 2.11 & $\sqrt{n}$ & 恶 & $\nabla$ & 2 & 1 & 10 & 0 & 0 & 0 \\
\hline M_Dimension Lumber & $38 \times 90\left(2 \times 4^{\prime}\right)$ & $3^{3}-2^{\prime \prime}$ & $N-51$ & Softwood (Spruce/Pine/Fir) & 8 & 2.11 & 同 & 国 & च & 2 & 1 & 0 & 0 & 0 & 0 \\
\hline M_Dimension Lumber & $38 \times 90\left(2 \times 4^{-}\right)$ & $3-31 / 2$ & $N-52$ & Softwood (Spruce/Pine//Fir) & 8 & 2.20 & a & 1 & $\frac{1}{7}$ & 2 & 1 & 0 & 0 & 0 & 0 \\
\hline M_Dimension Lumber & $38 \times 90\left(2 \times 4^{\prime \prime}\right)$ & $3^{\prime}-31 / 2$ & $N-53$ & Softwood (Spruce/Pine//Fir) & 8 & 2.20 & $\square$ & $\sqrt{7}$ & (1) & 2 & 1 & 0 & 0 & 0 & 0 \\
\hline M_Dimension Lumber & $38 \times 90\left(2 \times 4^{-1}\right)$ & $3^{3}-6^{\prime \prime}$ & $N-54$ & Softwood (Spruce/Pine/fir) & 8 & 2.32 & 同 & $\nabla$ & $\sqrt{1}$ & 2 & 1 & 0 & 0 & 0 & 0 \\
\hline M_Dimension Lumber & $38 \times 90\left(2 \times 4^{-1}\right)$ & $3^{3}-6^{\prime \prime}$ & $N-55$ & Softwood (Spruce/Pine/fir) & 8 & 2.32 & $\sqrt{v}$ & (1) & (1) & 2 & 1 & 10 & 0 & 0 & 0 \\
\hline M_Dimension Lumber & $38 \times 90\left(2 \times 4^{\prime \prime}\right)$ & $3^{3}-61 / 2^{\prime \prime}$ & $\mathrm{N}-88$ & Softwood (Spruce/Pine/Fir) & 8 & 2.37 & 国 & I. & $\mathrm{v}$ & 2 & 1 & 0 & 0 & 0 & 0 \\
\hline M_Dimension Lumber & $38 \times 90\left(2 \times 4^{\prime \prime}\right)$ & $3^{3}-61 / 2^{2}$ & $N-89$ & Softwood (Spruce/Pine//Fir) & 8 & 2.37 & 网 & 7 & 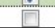 & 2 & 1 & 0 & 0 & 0 & 0 \\
\hline Grand total: 25 & & $75^{\prime}-01 / 2^{\prime \prime}$ & & & & 50.02 & & & & 50 & 25 & 0 & 0 & 0 & 0 \\
\hline
\end{tabular}

Figure 19: Sample Revit structural framing schedule filtering lengths of $2 x 4$ " lumber between 2'-0'” and 4- '0" long, with their respective properties.

In Revit, model elements are linked to live schedules and can become more effective when combined with built-in formula calculations. For example, calculated values can be customized to determine the amount of board feet of lumber, a common unit of measurement in North America (see Figure 20). The method for calculating cost for different sizes and shapes of lumber (softwoods or hardwoods) are often based on their total board feet, where one board foot $(\mathrm{BF})$ equals one square foot by one inch thick. It refers to the nominal thickness and width of lumber, calculated in principle on its size before drying and planning. It can be calculated using the following formulas depending on units used:

$$
\begin{aligned}
& \text { (width in inches * thickness in inches * length in feet) / } 12 \\
& \text { Board Footage = or } \\
& \text { (width in inches * thickness in inches * length in inches) / } 144
\end{aligned}
$$




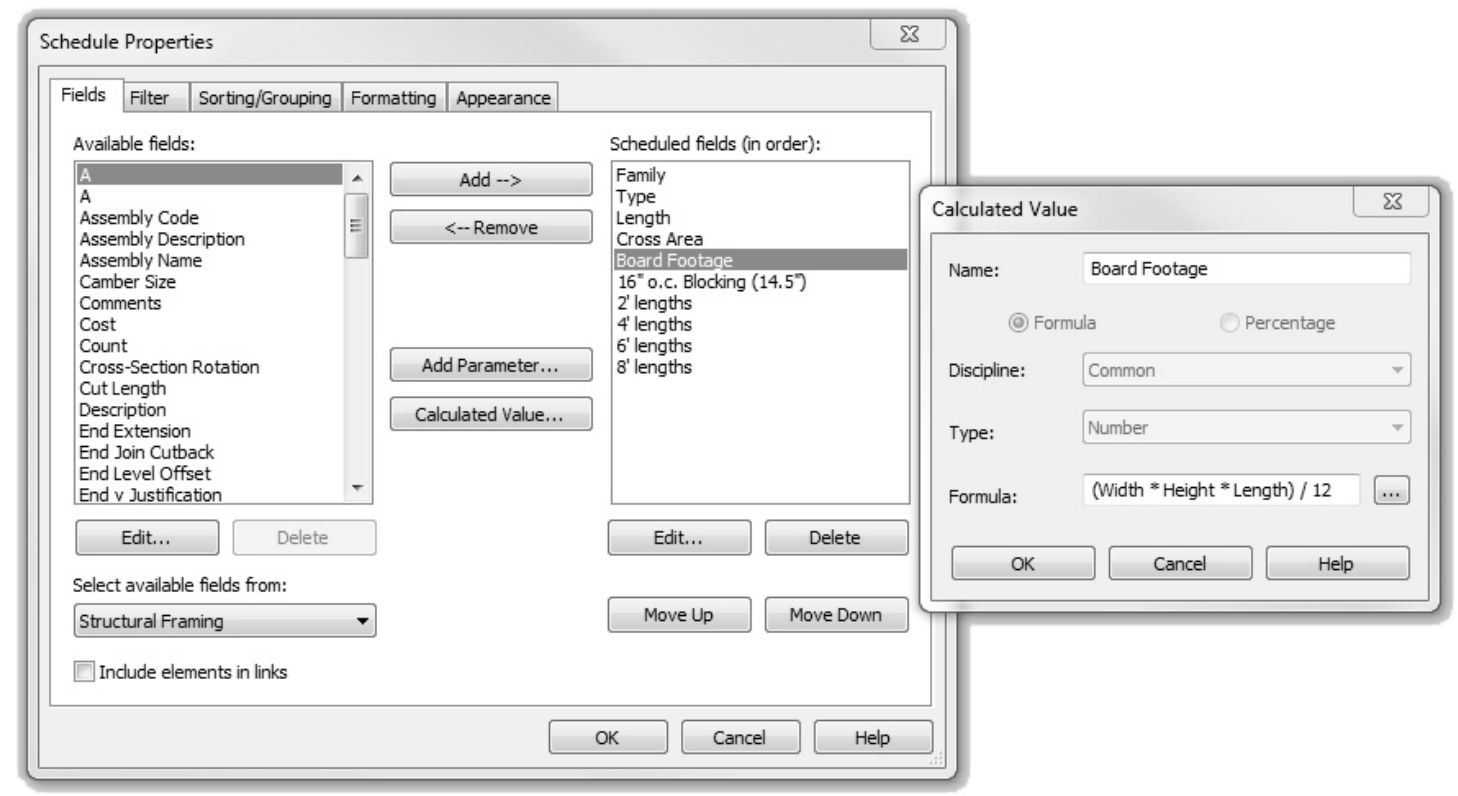

Figure 20: BIM customizable schedules allow for different fields, parameters, and calculated value formulas to assess and review different building elements as an itemized list.

This and other values delivered automatically by schedules can assist in evaluating statistics for board feet of lumber or other reclamation figures that assess feasibility or economics of the specific project. While there isn't as much freedom compared to fields of customizable cells found with Microsoft Excel spreadsheets, the benefit of BIM schedules is that they are interrelated to the model elements that exist in the project and ensure accurate counts and totals of materials automatically.

Concerning digital exploration of BIM and schedules, there is untapped potential for program add-ons that integrates more complex code scripting or algorithms. Such an example could be tools that automatically specify and relocate materials in new designs that currently exist in other building structures or are warehoused in inventory. This would allow project teams to quickly determine feasibility for new designs and put a cost value associated with reusing salvaged material at-hand to compare and offset the price of buying new. However regarding new designs, third-party BIM software add-ons are 
developing that give users a robust platform to automatically generate structural framing members based on user defined parameters and presets, and regenerate to match live design changes with the click of a button. ${ }^{106}$

Utilizing Revit BIM software for deconstruction projects allows material salvage quantities to be estimated. Equally, utilizing BIM for design for disassembly projects allows material quantity requirements to be calculated. Therefore, BIM becomes a sensible platform for the following thesis project of existing material quantity calculations for reuse. Once calculations are established, automatic scheduling becomes a tool that can inform the design or by which the design is informed by it.

\section{[4.4] Record Model and Manuals}

Similar to photographs, a building information model provides a record of the building in its current status, but also offers embedded documentation through different project phases of deconstruction or reconstruction of building elements in new designs. However, unlike photographs which only capture a point in time, a BIM can be continually developed and used to serve a variety of functions or purposes.

After a building has been modelled, it can be used as a communication tool for the project team through diagrams and site plans, as a visual aid outlining the stages of deconstruction and steps that will be implemented for that specific project. Site organization is critical for a smooth operating and efficient deconstruction project, and having different site plan options allows site accessibility to be analyzed and communicated prior to work beginning. The few hours invested in planning and

106 For an example of BIM add-on software, visit http://www.aga-cad.com/products/bim-solutions. 
systematizing activities will help execute efficiently and safely. This includes where equipment and tools are stored, materials are processed or stockpiled, delivery trucks are routed, site fencing is secured, and direct paths of travel. ${ }^{107} \mathrm{~A}$ BIM becomes especially useful in the event of deconstruction and rebuild occurring on the same site, as it also integrates survey data and records routing and connection points of below grade site services for future planning, and previously identified material for reuse will already have recorded documentation for reference or specification in new the project.

The BIM model could also be disseminated to act as a manual that illustrates best practices learned and carry forward to future projects. Depending on the type of building or mandate, it can also be leveraged to create maintenance manuals for building operations and as-built drawings or disassembly procedures for future owners and users.

Technology is continually advancing to make things more efficient, and new workflows are being discovered that assist in the process. With some familiarity, BIM acts as a multi-faceted tool that can greatly assist with deconstruction salvage estimates and site organization, and new design for disassembly projects that facilitate separation of building systems and enhanced coordination between parties involved over time.

107 Falk and Guy, Unbuilding, 104-113. 


\section{[5] THE PROJECT}

\section{[5.1] Proposal}

Compared to traditional demolition, deconstruction is a more resourceful alternative of building removal that provides economic and environmental benefits toward sustaining the processed materials contained in our built environment. Furthermore, designing for disassembly lends itself to take on a variety of strategies and characteristics that exemplify smart building design and facilitate material reuse.

Accordingly, this thesis takes on the challenge of using derelict buildings and structures found on several properties located in Vanier that are theoretically deconstructed in an attempt to determine their quantity of salvaged materials for reuse. These material estimations would act as the basis for designing a new mixed-use building addition, with the ability to be disassembled and further reused as a methodical, cyclical life for building components.

The key principles, strategies, and process of deconstruction and design for disassembly previously discussed will also serve as the platform for the subsequent project design. The project also proposes an exploration of digital workflows and capabilities through photogrammetry and building information modelling to explore their potential in providing quantity calculations and other benefits through the design process. 


\section{[5.2] Site}

This thesis proposes reusing salvaged materials and designing a building for disassembly in the Vanier neighbourhood of Ottawa. As an area close to downtown facing urban intensification, Vanier is an example of where aging structures provide an opportunity for material evolution among the existing urban fabric. Vanier can also be observed as a model that represents many urban neighbourhoods where land value is beginning to outweigh the value in rehabilitating obsolete buildings situated on it.

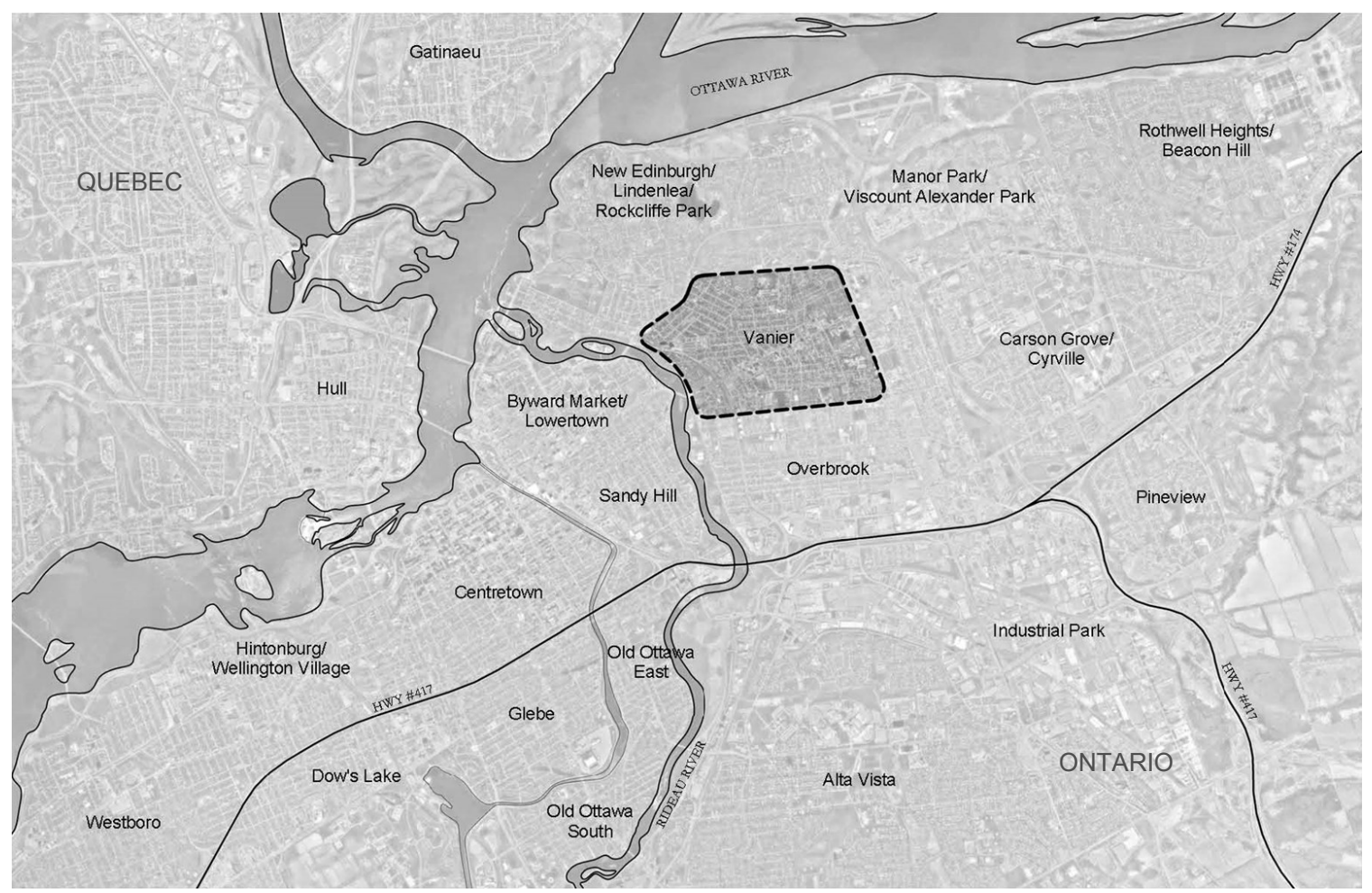

Figure 21: Context map of Ottawa neighbourhoods.

Over the past several years, the City of Ottawa has been reviewing the Official Plan and Zoning By-law that will guide development of downtown Vanier, primarily around the main thoroughfare of Montreal Road. Currently under a traditional main street zoning, the city aims to encourage mixed-use development through consolidation and revision to 
the variations of zoning along the street. ${ }^{108}$ More recently, the city undertook a transportation planning and functional design study of the Montreal Road corridor and presented findings at a public open house meeting that included stakeholders and members of the community. The results from the study will serve as the basis for the Montreal Road Infrastructure Renewal project, which seeks to revitalize the street as a destination that enhances quality of life as a well-balanced and connected transportation corridor that is also in accordance with the Official Plan and Transportation Master Plan. ${ }^{109}$

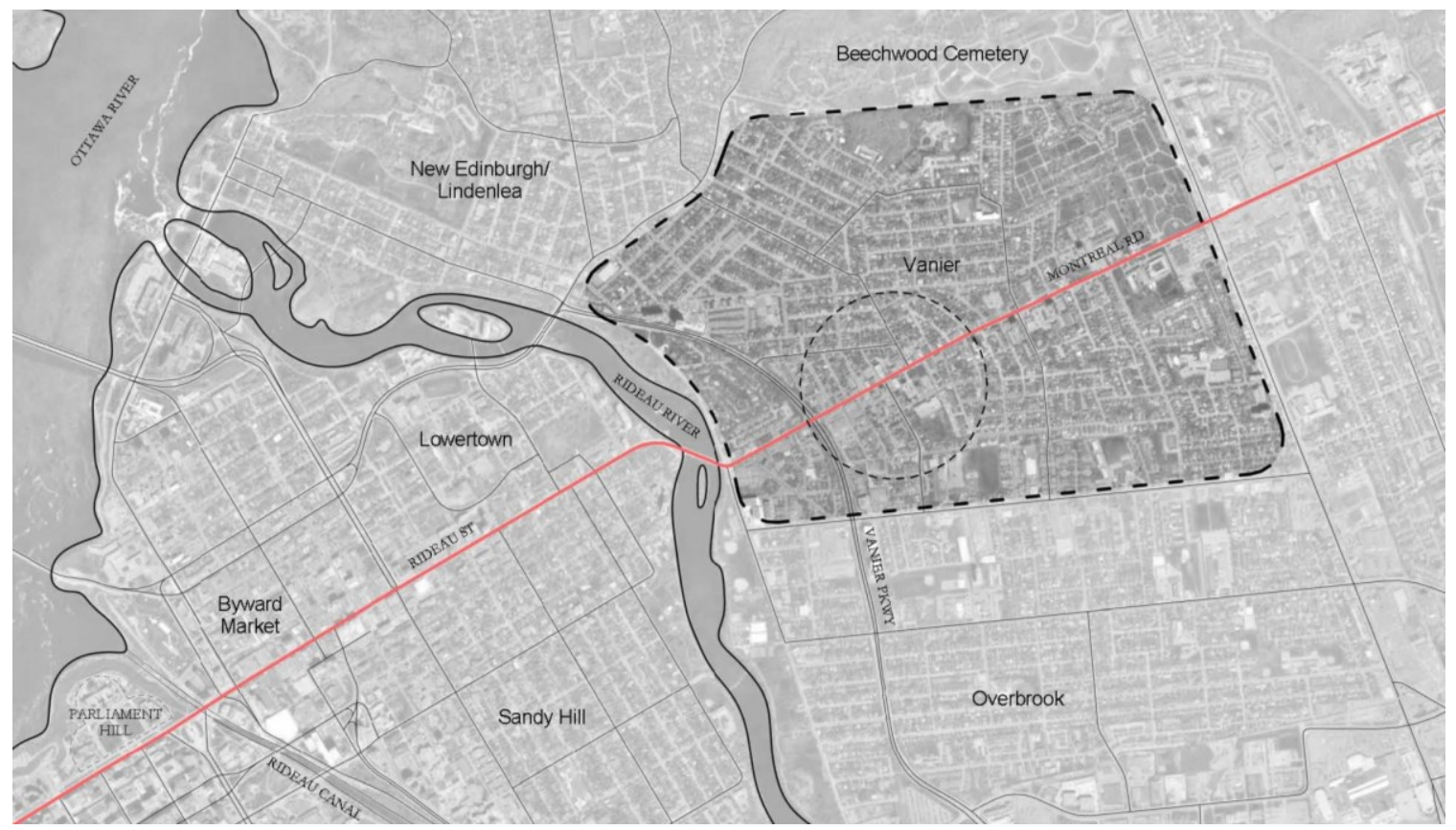

Figure 22: Vanier and surrounding neighbourhoods. The main thoroughfare of Montreal Road that continues into Rideau Street and connects to downtown is highlighted. The area of focus for the proposed project is circled.

108 Mike Bulthuis, "Planning (and building) Vanier's mainstreets: the revised Offician Plan," VanierNow, August 18, 2013, http://vaniernow.blogspot.ca/2013/08/planning-and-building-vaniers.html.

109 City of Ottawa, Montreal Road Transportation Planning and Functional Design Study, March 9, 2017, https://documents.ottawa.ca/sites/documents.ottawa.ca/files/montreal_road_pohboards_en.pdf. 
Montreal Road offers some buildings that are of a reasonable quality from more recent developments, but as a primary thoroughfare it also contains some of the first buildings in the area. Many of these buildings have been renovated to accommodate changing functions and programmatic requirements, either adding onto or subtracting as years pass. Several properties surrounding Montreal Road were found to have fairly decrepit or vacant buildings that qualify as good candidates for deconstruction, with aerial evidence of their original structure existing since before $1965 .{ }^{110}$

In terms an architectural intervention, an existing retail structure at 230 Montreal Road was chosen as the subject building to receive an addition because of its central location, simple modular bay construction, and flat, one-storey roof structure. While the initial idea for the project was to only deconstruct and reuse the building on the property adjacent to the site, a greater scope of property analysis was initiated to increase the potential base material quantities.

\section{[5.3] Salvage}

Taking a practical perspective, this thesis project has been approached with the prospect as a foundation for a potential business model. Accordingly, the analysis for properties with suitable buildings for deconstruction began with a search for local real estate on the market. As this thesis will not undertake the tangible procedure of deconstruction, this proved beneficial, as information such as photos, dimensions, and room areas are readily available in online adverts or have realtors that are more likely to share data to potential

110 For Ottawa aerial imaging and other datasets, visit http://maps.ottawa.ca/geoottawa/. 
buyers. The search identified five potential properties for deconstruction, varying in scale and use, within a 350 metre radius of the subject building site (see Figure 23).

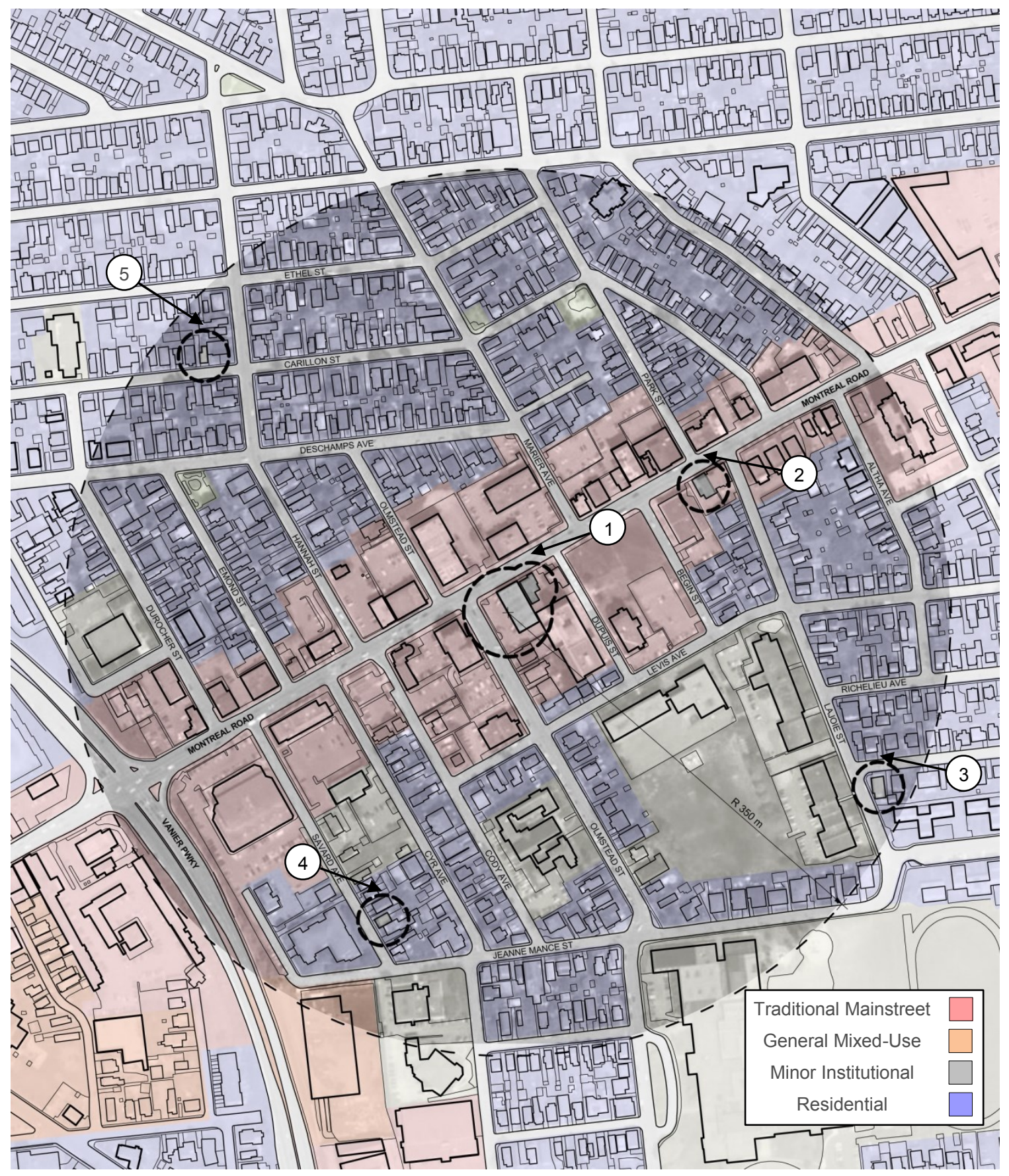

Figure 23: Vanier properties and zoning plan. While primarily lined with commercial buildings, many qualifying candidates for deconstruction are found off the adjacent streets. 
The idea of acquiring multiple properties to deconstruct comes with the intention that their quality materials would be salvaged, while others recycled or diverted into other waste streams. The individual properties would then be rehabilitated to an appropriate extent for resale to offset the costs of any new material required for construction of the new design. With the consideration that the primary value of the property is in the land itself and not the buildings situated on it, clearing and rehabilitating these existing sites intends to promote new development in the neighbourhood, ideally with buildings that also incorporate design for disassembly principles. Although it is possible to estimate the amount of materials for recycling and waste diversion, or property values through respective calculations, the primary scope of this thesis is on the salvage quantity of structural framing members and cladding for reuse.

Referencing property real estate data with aerial imaging, the dates of original construction provided a starting point for determining typical assembly specifications of the time period. Various literatures were used to digitally recreate the primary structures on each property for estimated material quantification. These include archived National Building Code requirements for typical residential construction and publications from the Canadian Mortgage and Housing Corporation (CMHC). As the national housing agency, the CMHC served as a primary source of sizing and spans for wood-frame house construction, and how innovation in house technology developed in the decades following World War 2. ${ }^{111}$ This was a necessary investigation as an interior analysis of existing structures was not possible to determine their exact construction specifications and structural framing.

111 Clayton Research Associates Ltd. and D.G. Wetherell and Associated Ltd, Two Decades of Innovation in Housing Technology: 1946-1965 (Ottawa: Canada Mortgage and Housing Corporation, 1994). 
The restricted scope unavoidably results in certain assumptions to conduct estimated material calculations. The assumptions on construction methods and framing members provided in part by the $\mathrm{CMHC}$ are reflected in the following digital models and resulting material schedule counts and totals. However, these values alone would assume the ideal scenario of absolute material reclamation. As mentioned previously, BIM scheduling parameters have been created that calculate counts of length of lumber rounding down to the nearest two-foot length section. This also reflects how actual salvaged materials may be categorized or trimmed to modular dimensions due to damage or decay. These counts of individual pieces can be requantified to provide a revised total combined length for more accurate salvage quantites. Initial results from this amount to $92 \%$ of the original total, meaning there is theorecially $8 \%$ of cut-off material. In addition, a $2 \%$ deduction to total amounts will be applied for digital scaling discrepancies as a result of the modelling process. Therefore a total deduction to total combined lumber lengths of $10 \%$ will be applied to salvage statistics generated in BIM schedules.

As noted in the Riverdale Village case study statistics, material reclamation figures are much less than perfect and some elements may be spoiled for reuse due to unforeseen decay or poor labour techniques from removal and processing. The deconstruction study of the 2,000 square foot building reported a brick recovery rate of $38 \%$ and also calculated the quantity of framing lumber to be 603 pieces, with 397 , or $66 \%$, being of higher quality (see Table 6). ${ }^{112}$ For realistic structural feasibility, the highest quality of lumber is most likely to be certified for approval and reuse. This project therefore

112 NAHB, "The Riverdale Case Study." 
assumes and considers the same two-thirds rule for lumber quality salvaged and brick recovery rates in the proposed design project.

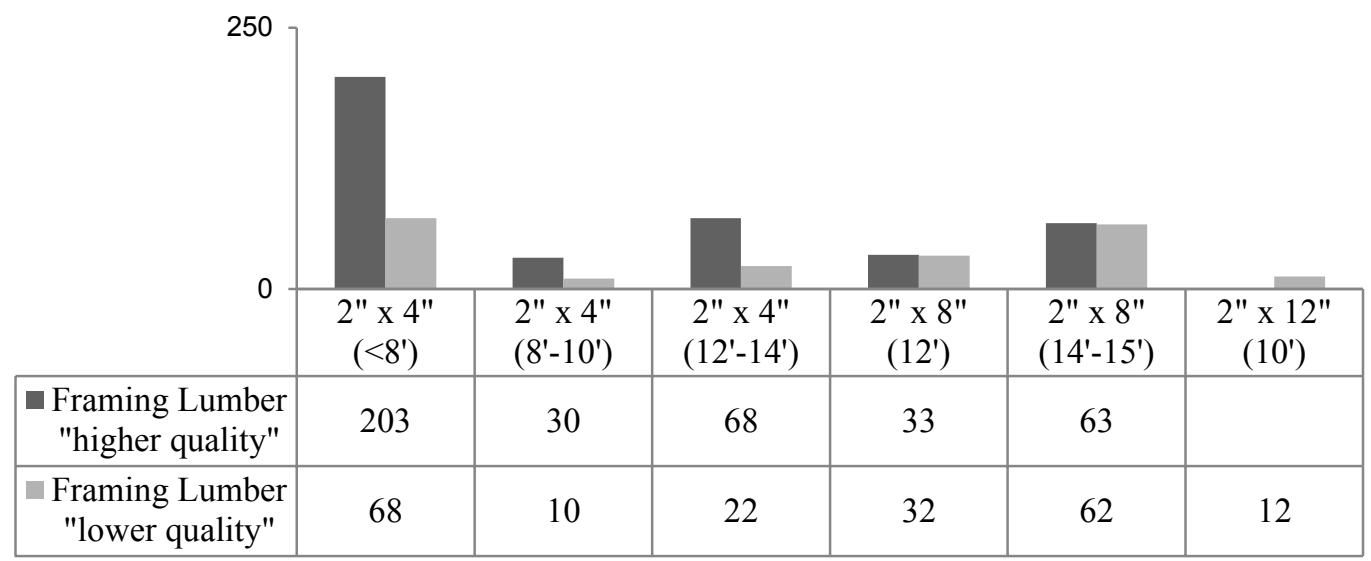

Table 5: Riverdale Case Study quantities of salvaged materials (Adapted from: NAHB, 1997)

The deductions of $10 \%$ for the combined length of framing lumber in the following property statistics are an attempt to provide conservative figures of a more realistic scenario. It is also important to note that interior layouts of buildings that had no available interior photos have been generically assumed, and could result in further discrepancies to actual conditions. In addition, types of sheathing and the layering of cladding over time make it difficult to provide estimations on exact material specifications. Ultimately, any selection of buildings will result in a wide assortment of structural material and finishes in a variety of shapes and sizes. The following pages present profiles of the subject properties and their respective statistics. 


\section{Property \#1}

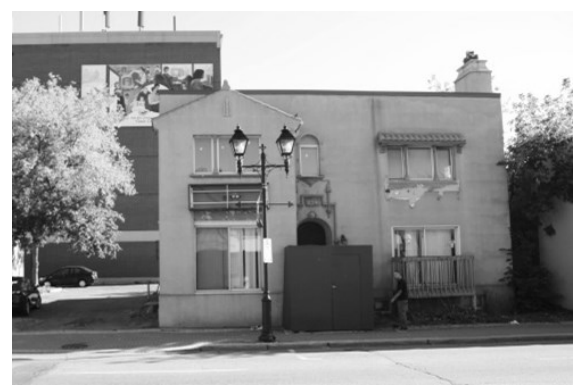

Figure 24: 234 Montreal Road.

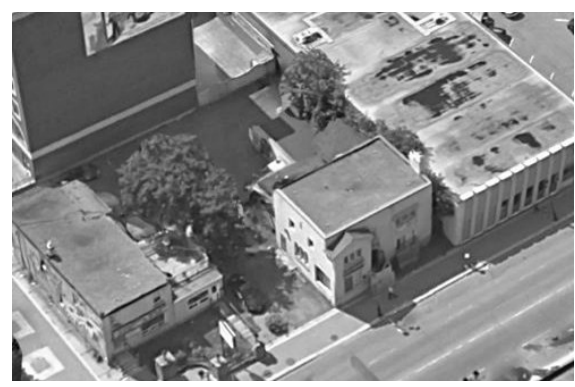

Figure 25: Property bird's eye.

Profile/Statistics

\begin{tabular}{|c|c|c|c|}
\hline Property Address: & 234 Montreal Road & Wall Area: & $\pm 7,800 \mathrm{SF}$ \\
\hline Asking Price: & $\$ 500,000$ & Lumber Length: & $\pm 7,665$ feet \\
\hline Zoning: & TM3 - Traditional Mainstreet Zone & Board Footage: & $\pm 8,150 \mathrm{BF}$ \\
\hline Lot Size: & \multicolumn{3}{|l|}{ Frontage: 71.00' / Depth: 99.00' } \\
\hline Lot Area: & \multicolumn{3}{|l|}{$7,029 \mathrm{SF}$} \\
\hline Price/Lot Area: & \multicolumn{3}{|l|}{$\$ 71.13 / \mathrm{SF}$} \\
\hline Building Area: & \multicolumn{3}{|l|}{ $\pm 4,170 \mathrm{SF}$} \\
\hline Constructed: & \multicolumn{3}{|l|}{ Pre-1965 } \\
\hline No. Stories: & \multicolumn{3}{|l|}{2 (+part basement) } \\
\hline Structure: & \multicolumn{3}{|l|}{ Timber framing, concrete foundation } \\
\hline Material Palette: & \multicolumn{3}{|c|}{$\begin{array}{l}\text { Dimensional lumber, plywood sheathing, stucco finish, brick masonry, terracotta roof tile, } \\
\text { baseboards/trim, metal flashing/eaves/soffits, steel stairs, mixed flooring, windows, doors, fixtures }\end{array}$} \\
\hline Notes: & \multicolumn{3}{|c|}{ Chimney, front deck, slab on grade rear additions, previously restaurant } \\
\hline
\end{tabular}

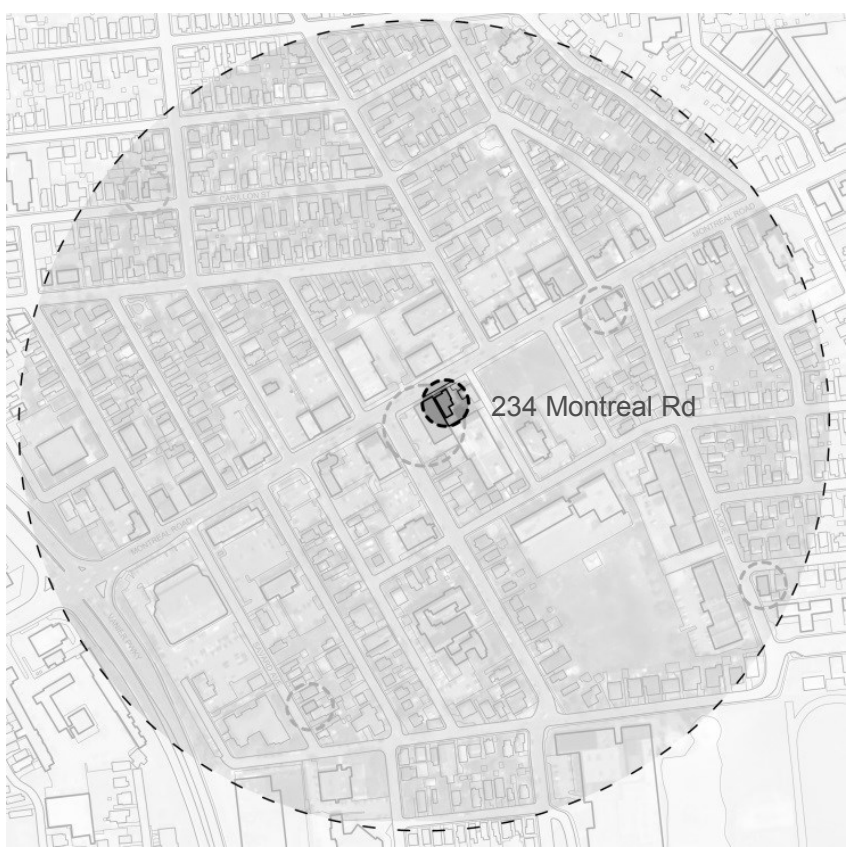

Figure 26: Context map.

\section{Salvage Estimations}
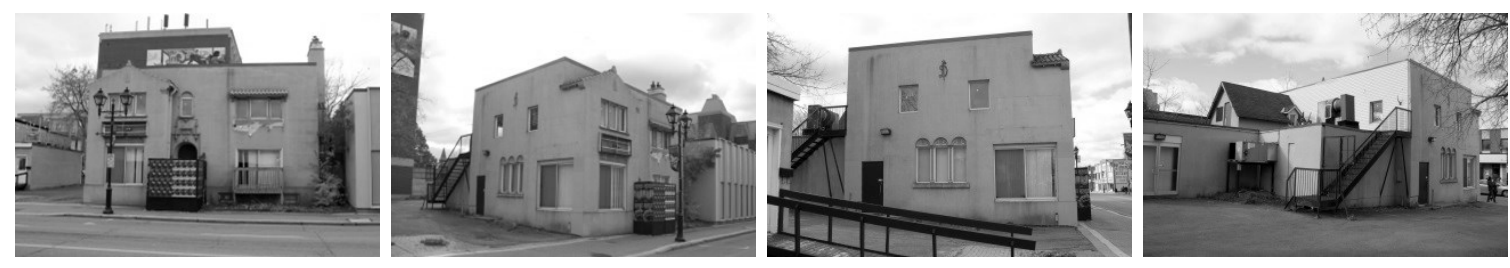

Figure 27: Selection of photos used for photogrammetry model. 


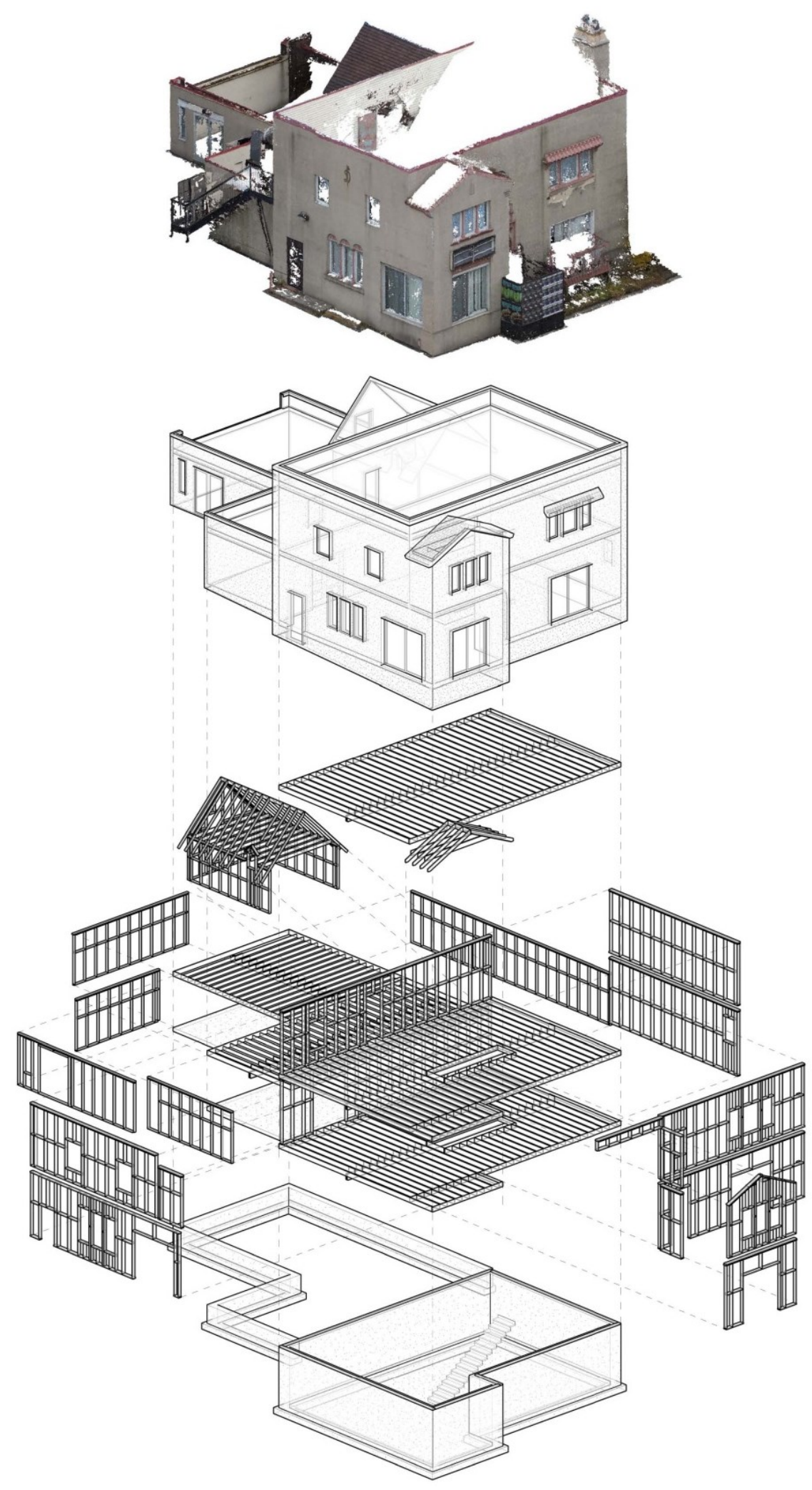

Figure 28: Exploded axonometric BIM based on point cloud from photogrammetry. 


\begin{tabular}{|c|c|c|c|c|c|c|}
\hline \multicolumn{7}{|c|}{234 Montreal Road - Structural Framing Schedule Condensed } \\
\hline Material & Type/Size & $\begin{array}{l}\text { Combined } \\
\text { Length ( } L \text { ) }\end{array}$ & $\begin{array}{l}\text { Width }(W) x \\
\text { Height }(H)\end{array}$ & $\begin{array}{c}\text { Board Feet } \\
(L x W x H)\end{array}$ & $\begin{array}{c}\text { Combined Length } \\
-10 \%\end{array}$ & $\begin{array}{c}\text { Board Feet } \\
-10 \%\end{array}$ \\
\hline M_Dimension Lumber & $38 \times 90(2 \times 4 ")$ & $2268 '-111 / 2 "$ & 8 & 1512.63 & $2042^{\prime}-01 / 2^{\prime \prime}$ & 1361.37 \\
\hline $38 \times 90(2 \times 4 "): 347$ & \multicolumn{3}{|c|}{$2268^{\prime}-11$ 1/2" } & \multicolumn{2}{|r|}{$2042^{\prime}-0$ 1/2" } & 1361.37 \\
\hline M_Dimension Lumber & $38 \times 140(2 \times 6 ")$ & $2874^{\prime}-8^{\prime \prime}$ & 12 & 2874.65 & $2587^{\prime}-21 / 2^{\prime \prime}$ & 2587.19 \\
\hline $38 \times 140(2 \times 6 "): 396$ & \multicolumn{3}{|c|}{$2874^{\prime}-8^{\prime \prime}$} & 2874.65 & \multicolumn{2}{|l|}{$2587^{\prime}-2$ 1/2" } \\
\hline M_Dimension Lumber & $38 \times 190(2 \times 8 ")$ & $2861^{\prime}-91 / 2 "$ & 16 & 3815.71 & $2575^{\prime}-7^{\prime \prime}$ & 3434.13 \\
\hline $38 \times 190$ (2x8"): 220 & \multicolumn{3}{|c|}{$2861^{\prime}-91 / 2 "$} & 3815.71 & \multicolumn{2}{|l|}{$2575^{\prime}-7^{\prime \prime}$} \\
\hline M_Dimension Lumber & $38 \times 235\left(2 \times 10^{\prime \prime}\right)$ & $510^{\prime}-3^{\prime \prime}$ & 20 & 850.42 & $459^{\prime}-21 / 2^{\prime \prime}$ & 765.38 \\
\hline $38 \times 235$ (2x10"): 15 & \multicolumn{3}{|c|}{$510^{\prime}-3^{\prime \prime}$} & 850.42 & $459^{\prime}-21 / 2^{\prime \prime}$ & 765.38 \\
\hline Grand total: 978 & \multicolumn{3}{|c|}{$8515^{\prime}-7$ 1/2" } & 9053.41 & 7664' - 1" & 8148.07 \\
\hline
\end{tabular}

Table 6: 234 Montreal Road - BIM structural framing calculations.

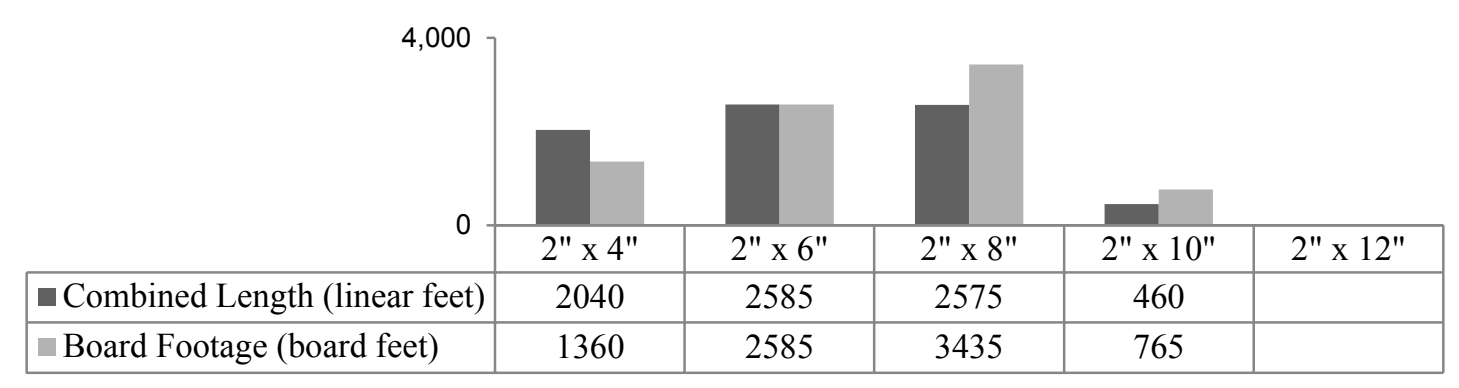

Table 7:234 Montreal Road-estimated lumber amounts per type after deductions.

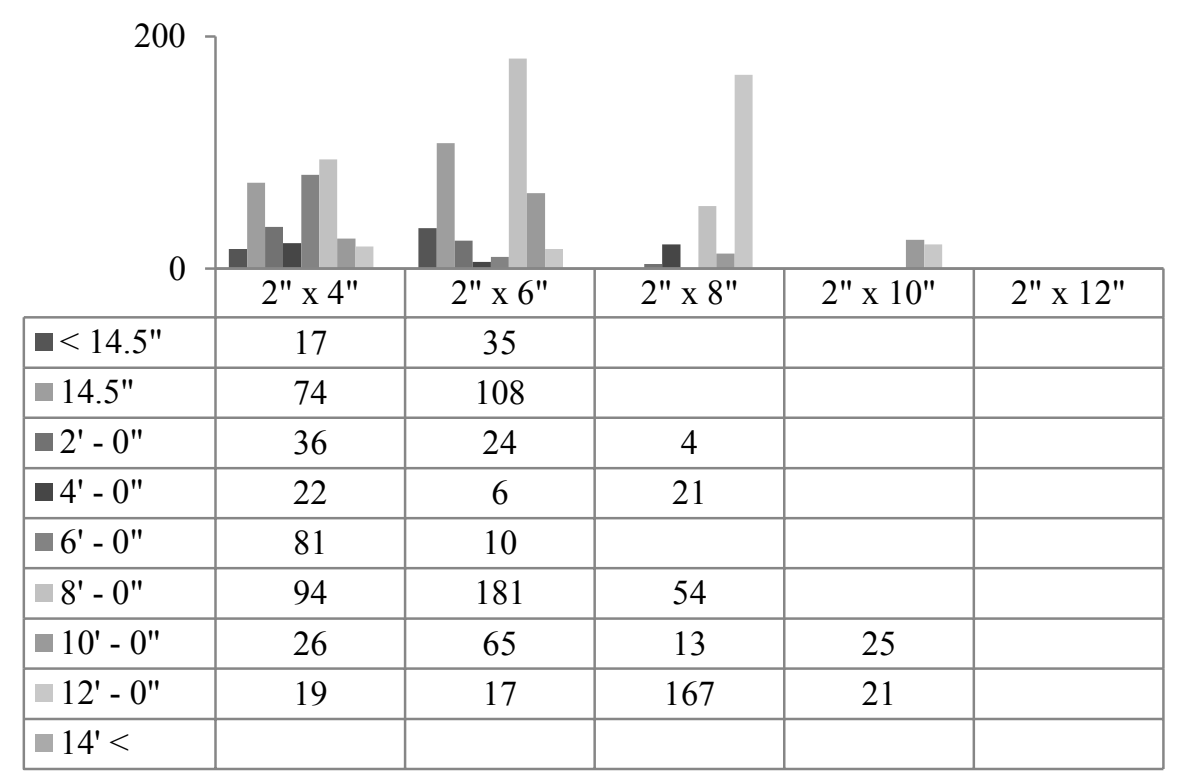

Table 8: 234 Montreal Road - estimated quantity of pieces per type by length. 


\section{Property \#2}

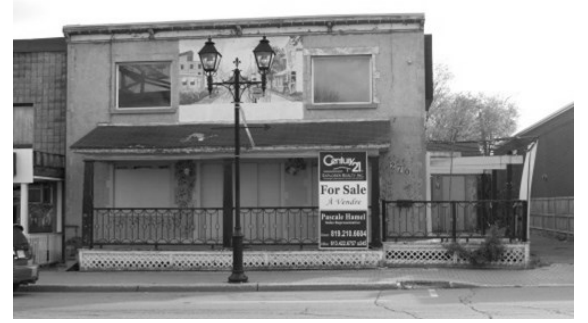

Figure 29: 270 Montreal Road.

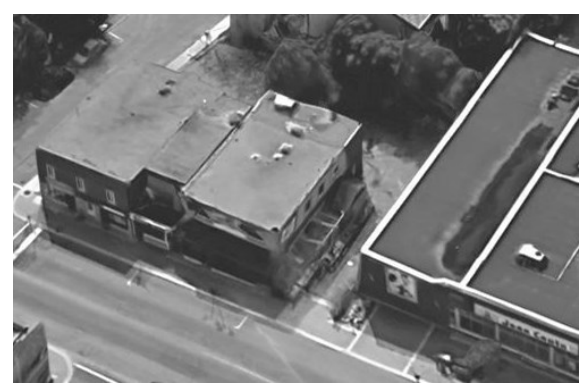

Figure 30: Property bird's eye.

\section{Profile/Statistics}

\begin{tabular}{r|lr|l} 
Property Address: & 270 Montreal Road & Wall Area: & $\pm 8,700 \mathrm{SF}$ \\
Asking Price: & $\$ 589,000$ & Lumber Length: & $\pm 12,650$ feet \\
Zoning: & TM3 - Traditional Mainstreet Zone & \\
Lot Size: & Frontage: $55.25^{\prime}$ / Depth: 99.00' & \\
Lot Area: & $5,470 \mathrm{SF}$ & $\pm 14,715 \mathrm{BF}$ \\
Price/Lot Area: & $\$ 107.68 / \mathrm{SF}$ & \\
Building Area: & $\pm 3,400 \mathrm{SF}$ & \\
Constructed: & Pre-1965 \\
No. Stories: & 2 (+part basement) \\
Structure: & Timber framing, concrete block foundation \\
Material Palette: & Dimensional lumber, plywood sheathing, brick cladding, roughcast finish, metal railings/scrap, sheet \\
& metal (hvac), flashings, glass block, windows, doors \\
Notes: & Front/side deck, rear additions, previously restaurant, presently vacant, gutted as-is
\end{tabular}

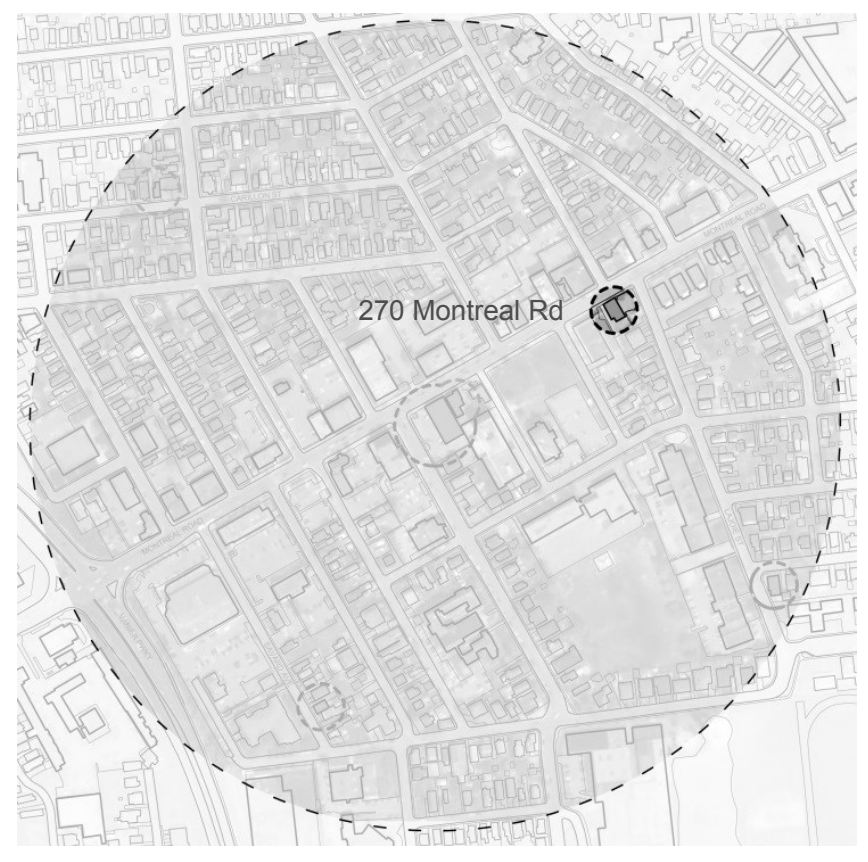

Figure 31: Context map.

\section{Salvage Estimations}
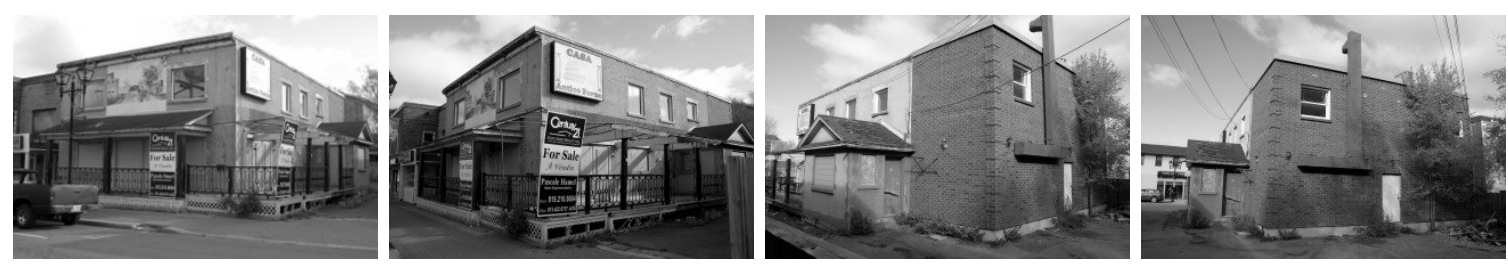

Figure 32: Selection of photos used for photogrammetry model. 


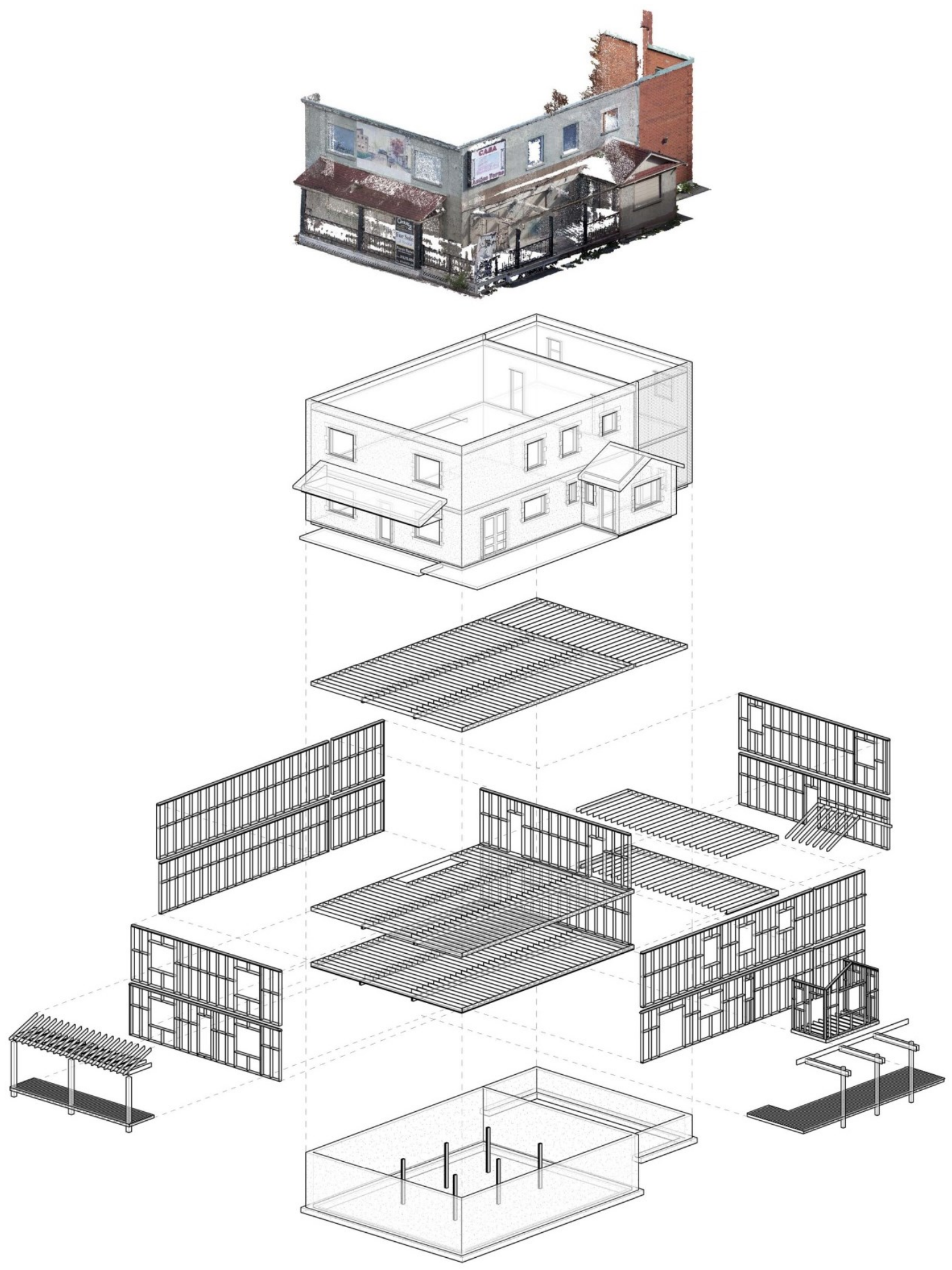

Figure 33: Exploded axonometric BIM based on point cloud from photogrammetry. 


\begin{tabular}{|c|c|c|c|c|c|c|}
\hline \multicolumn{7}{|c|}{270 Montreal Road - Structural Framing Schedule Condensed } \\
\hline Material & Type/Size & $\begin{array}{l}\text { Combined } \\
\text { Length }(L)\end{array}$ & $\begin{array}{c}\text { Width }(W) x \\
\text { Height }(H)\end{array}$ & $\begin{array}{l}\text { Board Feet } \\
(L x W x H) / 12\end{array}$ & $\begin{array}{c}\text { Combined Length } \\
-10 \%\end{array}$ & $\begin{array}{c}\text { Board Feet } \\
-10 \%\end{array}$ \\
\hline M_Dimension Lumber & $38 \times 90(2 \times 4 ")$ & $1200^{\prime}-21 / 2^{\prime \prime}$ & 8 & 800.14 & $1080^{\prime}-21 / 2^{\prime \prime}$ & 720.13 \\
\hline $38 \times 90(2 \times 4 "): 215$ & \multicolumn{3}{|c|}{$1200^{\prime}-21 / 2^{\prime \prime}$} & \multicolumn{2}{|r|}{$1080^{\prime}-21 / 2^{\prime \prime}$} & 720.13 \\
\hline M_Dimension Lumber & $38 \times 140(2 \times 6 ")$ & $7105^{\prime}-11 / 2^{\prime \prime}$ & 12 & 7105.12 & $6394^{\prime}-71 / 2^{\prime \prime}$ & 6394.61 \\
\hline $38 \times 140$ (2x6"): 866 & \multicolumn{3}{|c|}{$7105^{\prime}-1$ 1/2" } & 7105.12 & $6394^{\prime}-71 / 2^{\prime \prime}$ & 6394.61 \\
\hline M_Dimension Lumber & $38 \times 190(2 \times 8 ")$ & $3978^{\prime}-11^{\prime \prime}$ & 16 & 5305.25 & $3581^{\prime}-01 / 2 "$ & 4774.72 \\
\hline $38 \times 190$ (2x8"): 391 & \multicolumn{3}{|c|}{$3978^{\prime}-11^{\prime \prime}$} & 5305.25 & $3581^{\prime}-0$ 1/2" & 4774.72 \\
\hline M_Dimension Lumber & $38 \times 235(2 \times 10 ")$ & $1227^{\prime}-6^{\prime \prime}$ & 20 & 2045.80 & $1104^{\prime}-9^{\prime \prime}$ & 1841.22 \\
\hline $38 \times 235$ (2x10"): 162 & \multicolumn{3}{|c|}{$1227^{\prime}-6^{\prime \prime}$} & 2045.80 & $1104^{\prime}-9^{\prime \prime}$ & 1841.22 \\
\hline M_Dimension Lumber & $38 \times 285(2 \times 12 ")$ & $547^{\prime}-11 / 2^{\prime \prime}$ & 24 & 1094.21 & $492^{\prime}-41 / 2^{\prime \prime}$ & 984.79 \\
\hline $38 \times 285(2 \times 12 "): 66$ & & $547^{\prime}-11 / 2^{\prime \prime}$ & & 1094.21 & $492^{\prime}-41 / 2^{\prime \prime}$ & 984.79 \\
\hline Grand total: 1700 & & $14058^{\prime}-10^{\prime \prime}$ & & 16350.52 & 12652' - 11 1/2" & 14715.47 \\
\hline
\end{tabular}

Table 9: 270 Montreal Road - BIM structural framing calculations.

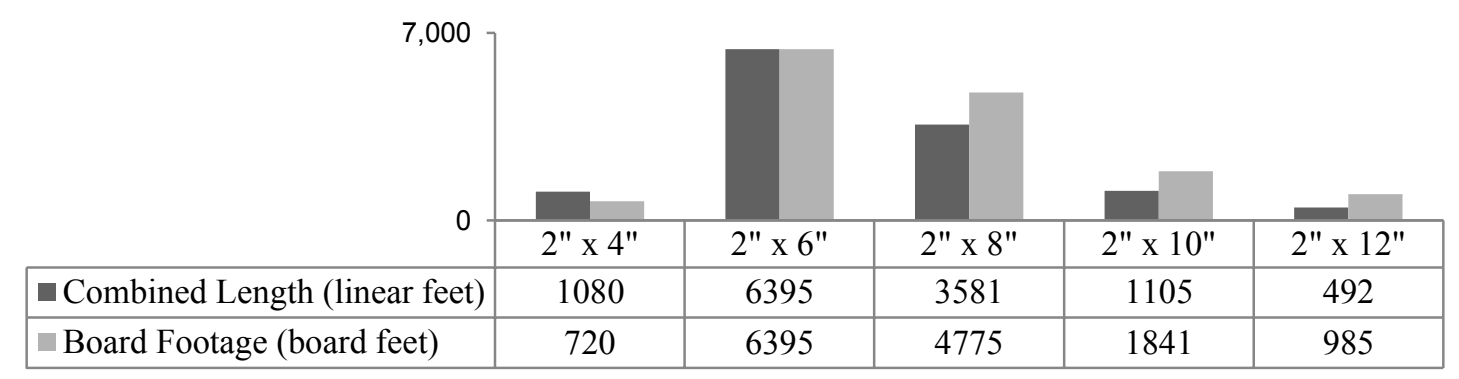

Table 10: 270 Montreal Road - estimated lumber amounts per type after deductions.

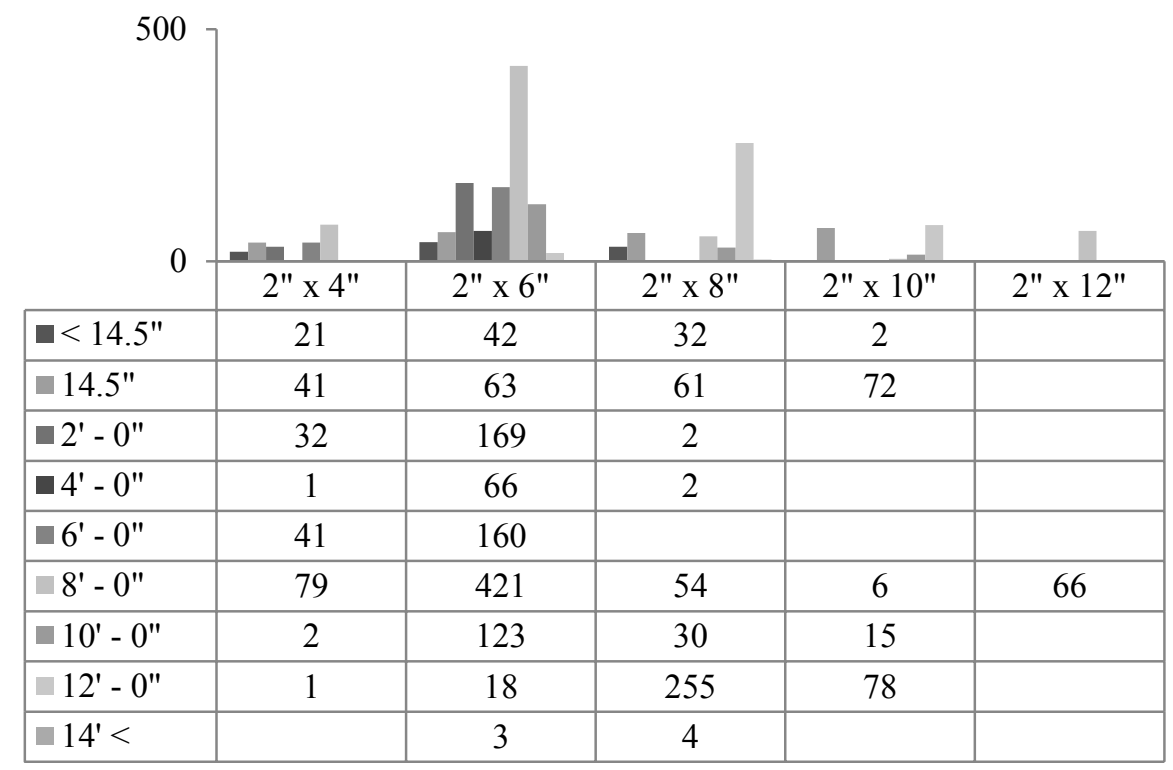

Table 11: 270 Montreal Road - estimated quantity of pieces per type by length. 


\section{Property \#3}

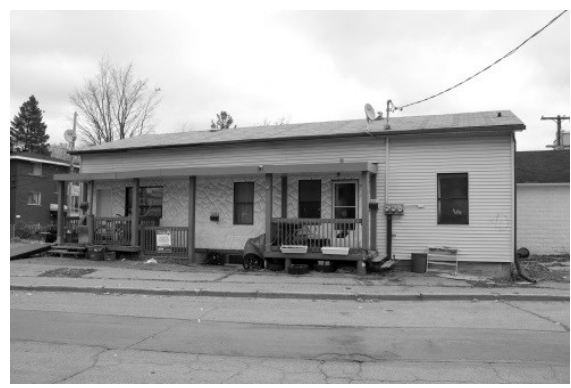

Figure 34: 329-331 Lajoie Street.

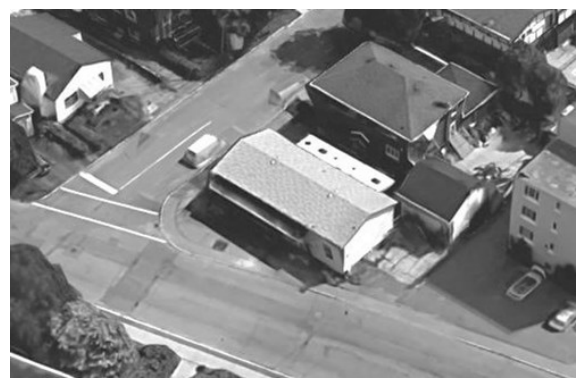

Figure 35: Property bird's eye.

Profile/Statistics

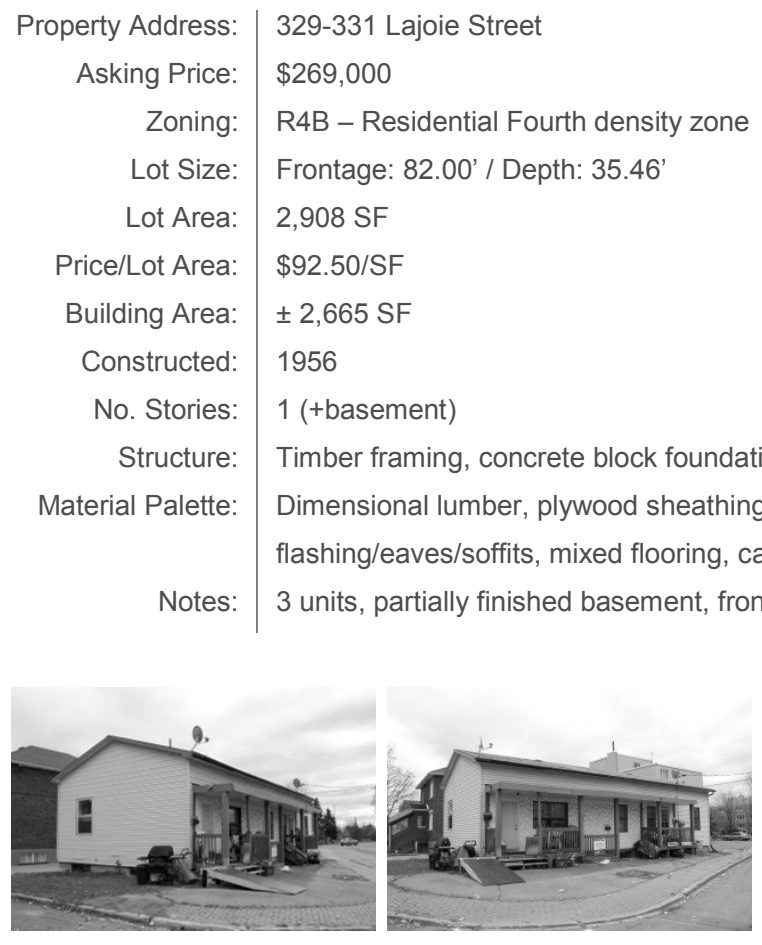

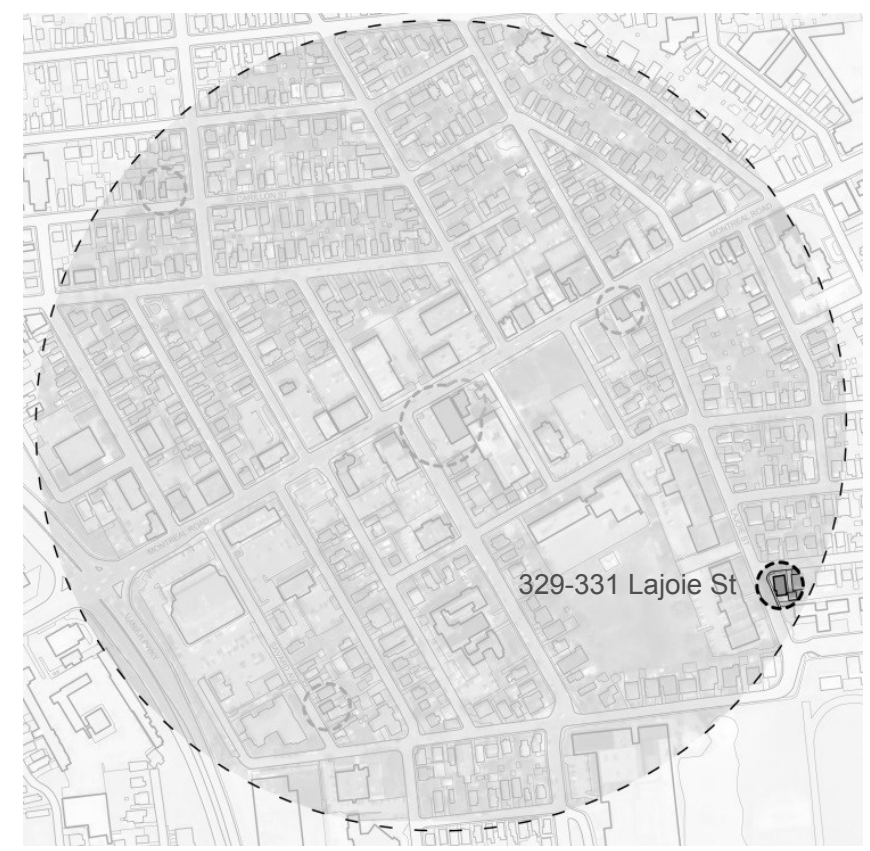

Figure 36: Context map.

\section{Salvage Estimations}

\begin{tabular}{r|l} 
Wall Area: & $\pm 7,400 \mathrm{SF}$ \\
Lumber Length: & $\pm 10,530 \mathrm{feet}$ \\
Board Footage: & $\pm 9,860 \mathrm{BF}$
\end{tabular}

Figure 37: Selection of photos used for photogrammetry model. 


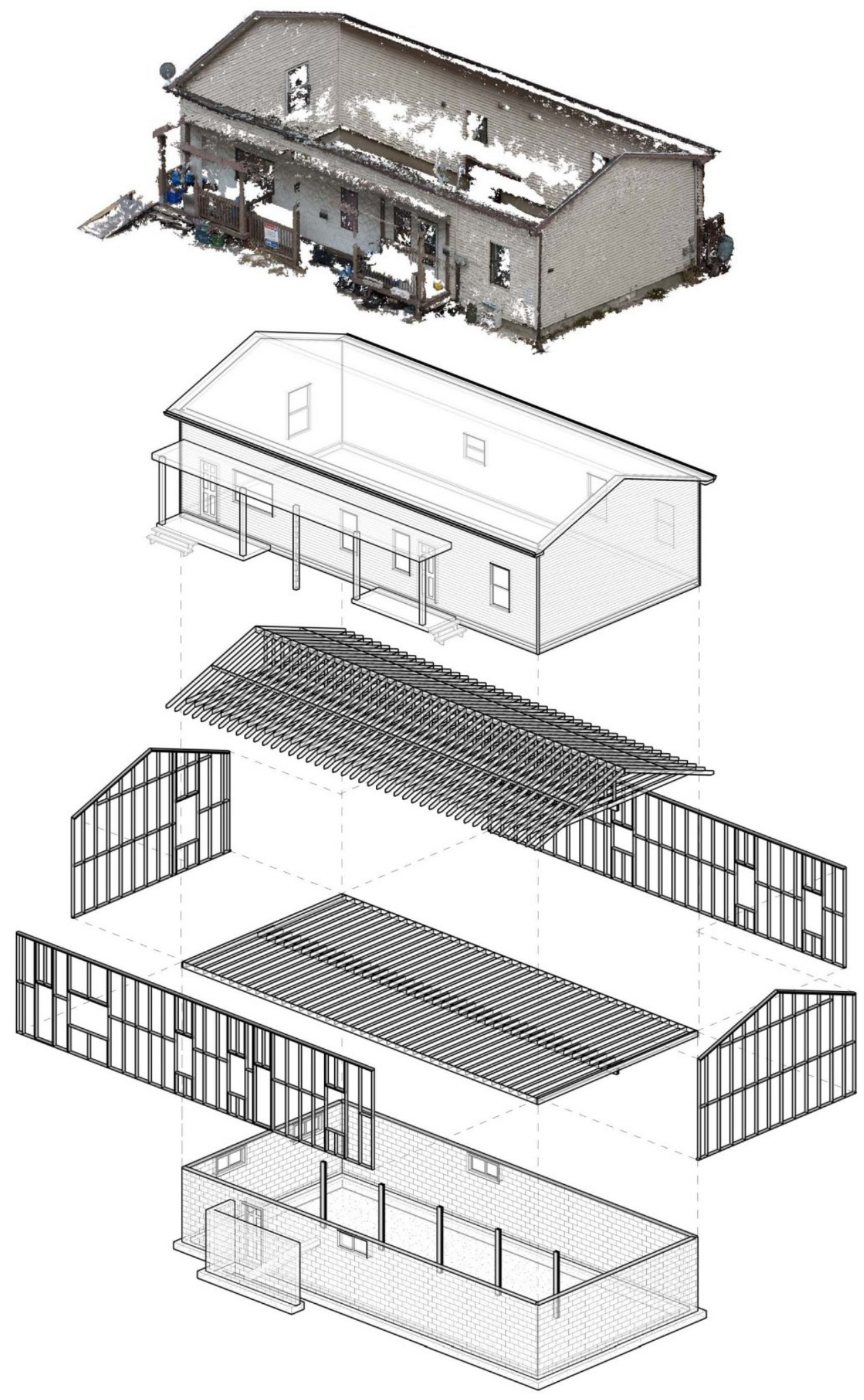

Figure 38: Exploded axonometric BIM based on point cloud from photogrammetry. 


\begin{tabular}{|c|c|c|c|c|c|c|}
\hline \multicolumn{7}{|c|}{ 329-331 Lajoie Street - Structural Framing Schedule Condensed } \\
\hline Material & Type/Size & $\begin{array}{l}\text { Combined } \\
\text { Length ( } L \text { ) }\end{array}$ & $\begin{array}{l}\text { Width }(W) x \\
\text { Height }(H)\end{array}$ & $\begin{array}{l}\text { Board Feet } \\
(L x W x H) / 12\end{array}$ & $\begin{array}{c}\text { Combined Length } \\
-10 \%\end{array}$ & $\begin{array}{c}\text { Board Feet } \\
-10 \%\end{array}$ \\
\hline M_Dimension Lumber & $38 \times 90(2 \times 4 ")$ & $6778^{\prime}-1 "$ & 8 & 4518.74 & $6100^{\prime}-31 / 2^{\prime \prime}$ & 4066.86 \\
\hline $38 \times 90(2 \times 4 "): 1094$ & \multicolumn{3}{|c|}{$6778 '-1 "$} & \multicolumn{2}{|r|}{$6100 '-31 / 2 "$} & 4066.86 \\
\hline M_Dimension Lumber & $38 \times 140(2 \times 6 ")$ & $1775^{\prime}-2^{\prime \prime}$ & 12 & 1775.16 & $1597^{\prime}-71 / 2^{\prime \prime}$ & 1597.64 \\
\hline $38 \times 140$ (2x6"): 146 & \multicolumn{3}{|c|}{$1775^{\prime}-2^{\prime \prime}$} & 1775.16 & \multicolumn{2}{|r|}{1597.64} \\
\hline M_Dimension Lumber & $38 \times 190(2 \times 8 ")$ & $1741^{\prime}-0^{\prime \prime}$ & 16 & 2321.36 & $1566^{\prime}-11^{\prime \prime}$ & 2089.22 \\
\hline $38 \times 190$ (2x8"): 124 & \multicolumn{3}{|c|}{$1741^{\prime}-0^{\prime \prime}$} & 2321.36 & 1566 - 11" & 2089.22 \\
\hline M_Dimension Lumber & $38 \times 235\left(2 \times 10^{\prime \prime}\right)$ & $1405^{\prime}-7$ 1/2" & 20 & 2342.72 & $1265^{\prime}-1^{\prime \prime}$ & 2108.44 \\
\hline $38 \times 235(2 \times 10 "): 168$ & & $1405^{\prime}-7$ 1/2" & & 2342.72 & $1265^{\prime}-1 "$ & 2108.44 \\
\hline Grand total: 1532 & & 11699' - 11" & & 10957.97 & $10529^{\prime}-11^{\prime \prime}$ & 9862.17 \\
\hline
\end{tabular}

Table 12: 329-331 Lajoie Street - BIM structural framing calculations.

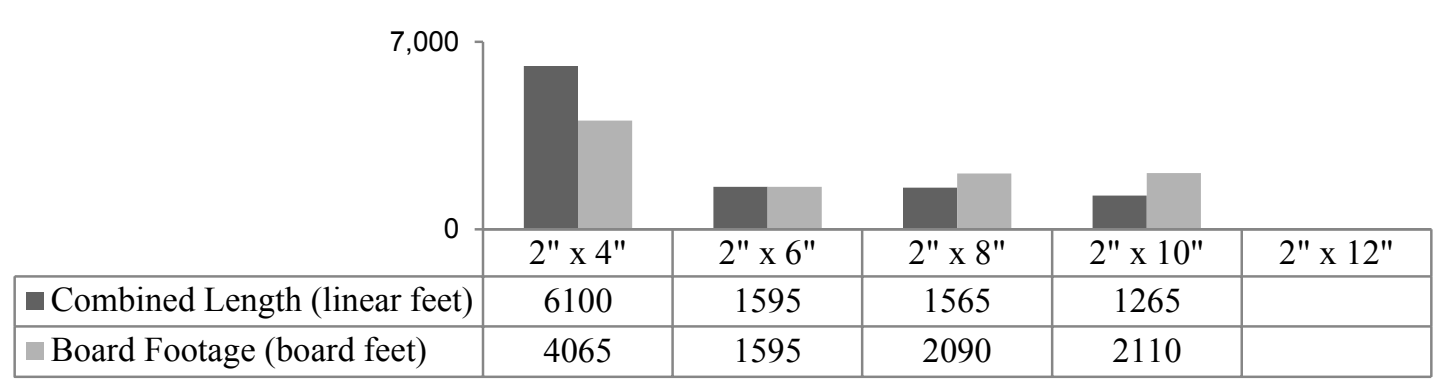

Table 13: 329-331 Lajoie Street - estimated lumber amounts per type after deductions.

\begin{tabular}{|c|c|c|c|c|c|}
\hline U & $2 "$ x 4" & $2 " \times 6 "$ & $2 "$ x 8" & $2 "$ x 10" & $2 "$ x $12^{\prime \prime}$ \\
\hline a $<14.5^{\prime \prime}$ & 17 & 35 & & & \\
\hline 14.5" & 74 & 108 & & & \\
\hline $2^{\prime}-0^{\prime \prime}$ & 36 & 24 & 4 & & \\
\hline - 4' - 0" & 22 & 6 & 21 & & \\
\hline $6^{\prime}-0^{\prime \prime}$ & 81 & 10 & & & \\
\hline $8^{\prime}-0^{\prime \prime}$ & 94 & 181 & 54 & & \\
\hline $10^{\prime}-0^{\prime \prime}$ & 26 & 65 & 13 & 25 & \\
\hline $12^{\prime}-0^{\prime \prime}$ & 19 & 17 & 167 & 21 & \\
\hline $14^{\prime}<$ & & & & & \\
\hline
\end{tabular}

Table 14: 329-331 Lajoie Street - estimated quantity of pieces per type by length. 


\section{Property \#4}

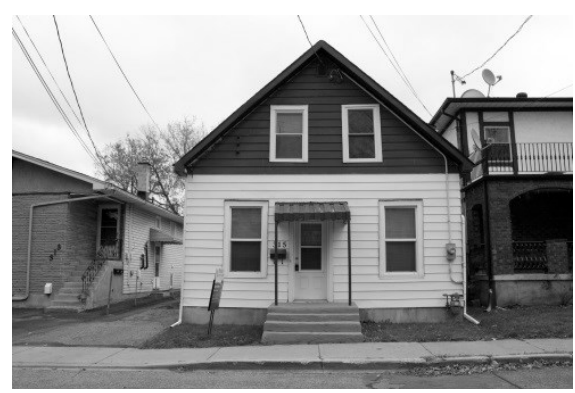

Figure 39: 315 Savard Avenue.

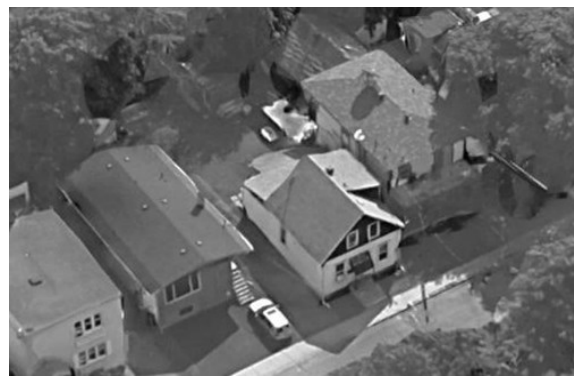

Figure 40: Property bird's eye.

Profile/Statistics

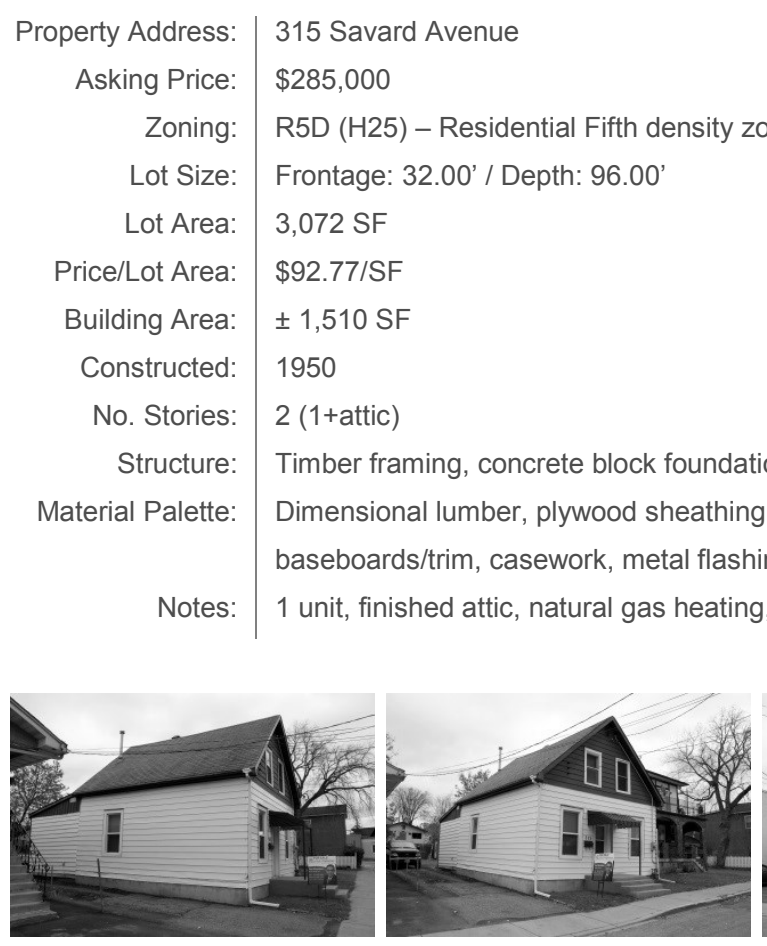

Figure 42: Selection of photos used for photogrammetry model.

\begin{tabular}{r|l} 
Price/Lot Area: & $\$ 92.77 / \mathrm{SF}$ \\
Building Area: & $\pm 1,510 \mathrm{SF}$ \\
Constructed: & 1950 \\
No. Stories: & $2(1+$ attic) \\
Structure: & Timber framing, concrete block foundation
\end{tabular}

Material Palette: Dimensional lumber, plywood sheathing, vinyl siding ( 9" width), wood siding ( 8" width), baseboards/trim, casework, metal flashing/eaves/soffits, windows, doors

Notes: 1 unit, finished attic, natural gas heating, timber fence and posts at rear, storage shed

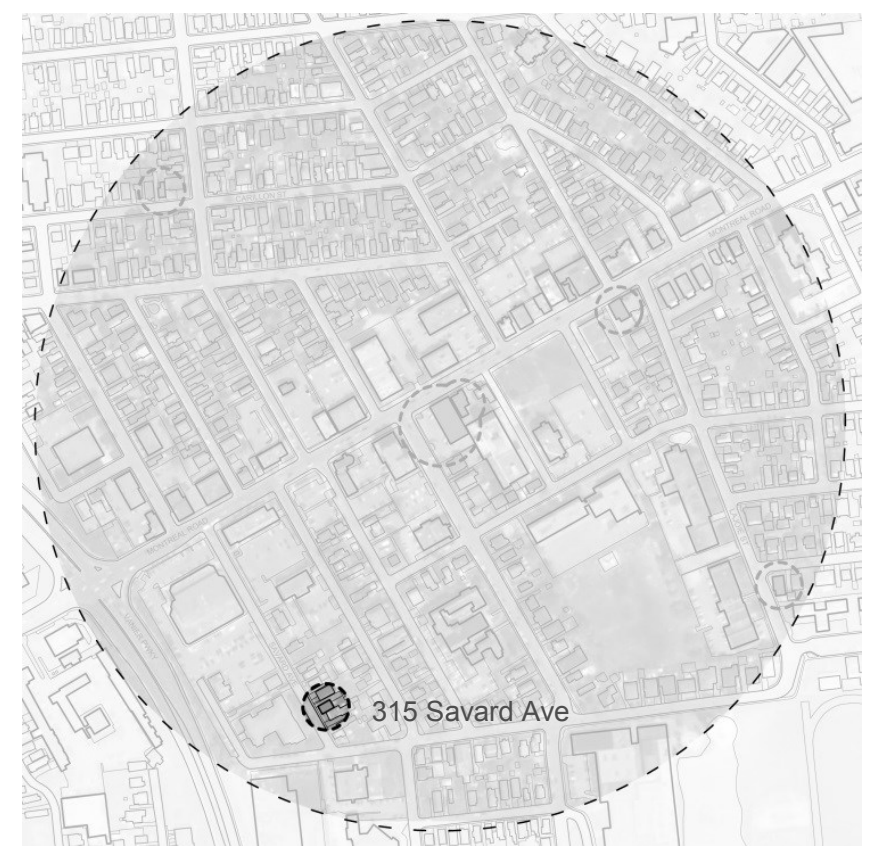

Figure 41: Context map.

\section{Salvage Estimations}

\begin{tabular}{r|l} 
Wall Area: & $\pm 6,800 \mathrm{SF}$ \\
Lumber Length: & $\pm 6,360 \mathrm{feet}$ \\
Board Footage: & $\pm 6,430 \mathrm{BF}$
\end{tabular}




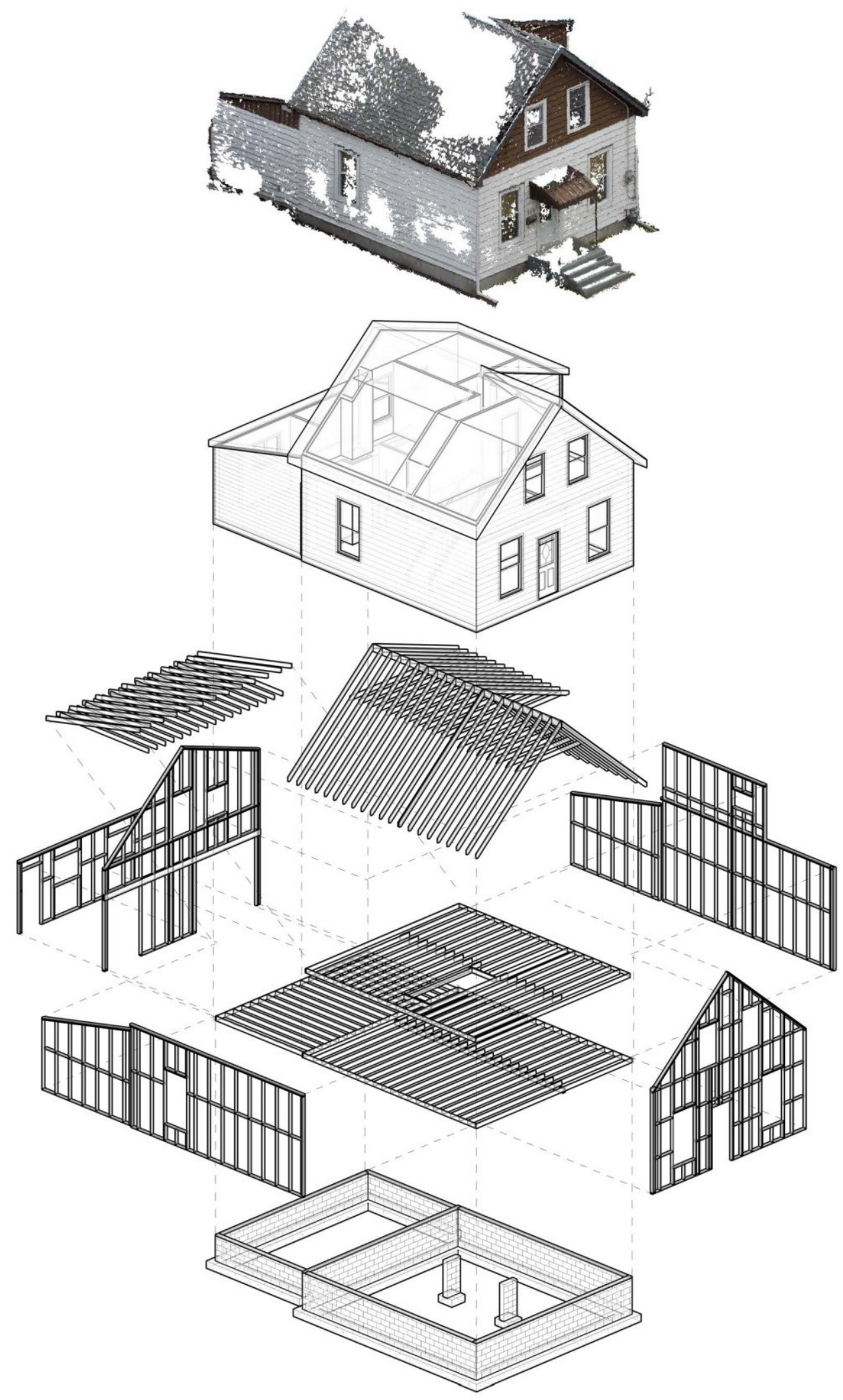

Figure 43: Exploded axonometric BIM based on point cloud from photogrammetry. 


\begin{tabular}{|c|c|c|c|c|c|c|}
\hline \multicolumn{7}{|c|}{315 Savard Avenue - Structural Framing Schedule Condensed } \\
\hline Material & Type/Size & $\begin{array}{l}\text { Combined } \\
\text { Length }(L)\end{array}$ & $\begin{array}{l}\text { Width }(W) x \\
\text { Height }(H)\end{array}$ & $\begin{array}{l}\text { Board Feet } \\
(L x W x H) / 12\end{array}$ & $\begin{array}{c}\text { Combined Length } \\
-10 \%\end{array}$ & $\begin{array}{c}\text { Board Feet } \\
-10 \%\end{array}$ \\
\hline M_Dimension Lumber & $38 \times 90(2 \times 4 ")$ & $4060^{\prime}-71 / 2^{\prime \prime}$ & 8 & 2707.10 & $3654^{\prime}-7^{\prime \prime}$ & 2436.39 \\
\hline $38 \times 90$ (2x4"): 687 & & $4060^{\prime}-7$ 1/2" & & 2707.10 & $3654^{\prime}-7^{\prime \prime}$ & 2436.39 \\
\hline M_Dimension Lumber & $38 \times 140(2 \times 6 ")$ & $329^{\prime}-1 "$ & 12 & 329.10 & $296^{\prime}-2^{\prime \prime}$ & 296.19 \\
\hline $38 \times 140(2 \times 6 "): 24$ & & $329 '-1 "$ & & 329.10 & 296 - 2" & 296.19 \\
\hline M_Dimension Lumber & $38 \times 190(2 \times 8 ")$ & $1047^{\prime}-41 / 2^{\prime \prime}$ & 16 & 1396.51 & $942^{\prime}-8^{\prime \prime}$ & 1256.86 \\
\hline $38 \times 190(2 \times 8 "): 83$ & & $1047^{\prime}-41 / 2^{\prime \prime}$ & & 1396.51 & $942^{\prime}-8 "$ & 1256.86 \\
\hline M_Dimension Lumber & $38 \times 235\left(2 \times 10^{\prime \prime}\right)$ & $1629^{\prime}-3^{\prime \prime}$ & 20 & 2715.44 & $1466^{\prime}-4^{\prime \prime}$ & 2443.89 \\
\hline $38 \times 235(2 \times 10 "): 214$ & & $1629^{\prime}-3^{\prime \prime}$ & & 2715.44 & $1466^{\prime}-4^{\prime \prime}$ & 2443.89 \\
\hline Grand total: 1008 & & $7066^{\prime}-41 / 2^{\prime \prime}$ & & 7148.14 & $6359^{\prime}-9^{\prime \prime}$ & 6433.33 \\
\hline
\end{tabular}

Table 15: 315 Savard Avenue - BIM structural framing calculations.

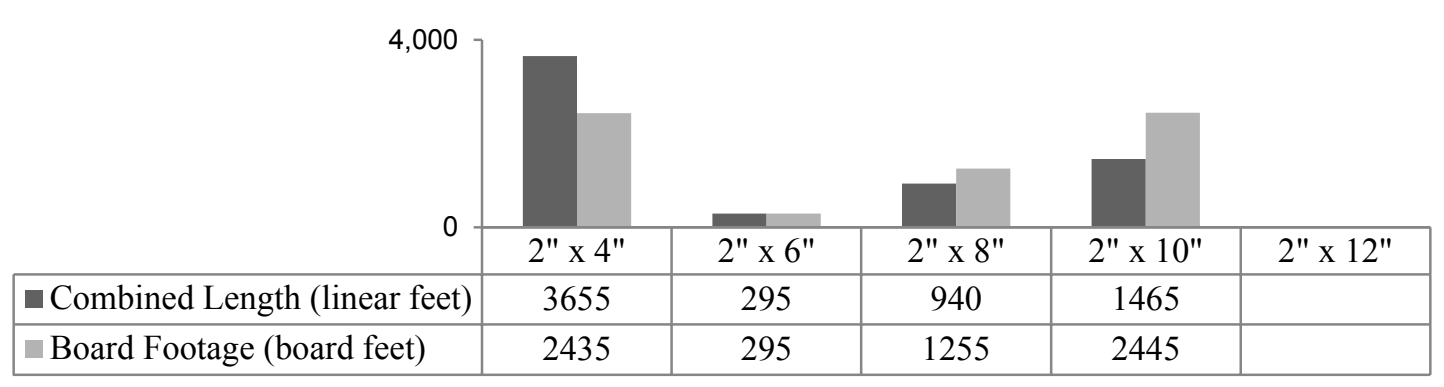

Table 16: 315 Savard Avenue - estimated lumber amounts per type after deductions.

\begin{tabular}{|c|c|c|c|c|c|}
\hline 0 & $2 " x$ 4" & $2 "$ x 6" & $2 " \times 8 "$ & $2 " \times 10^{\prime \prime}$ & $2 " \times 12^{\prime \prime}$ \\
\hline$\square<14.5^{\prime \prime}$ & 61 & & & 23 & \\
\hline 14.5" & 201 & & 16 & 72 & \\
\hline $2^{\prime}-0^{\prime \prime}$ & 88 & 4 & & 3 & \\
\hline - 4' - 0" & 24 & & 2 & & \\
\hline $6^{\prime}-0^{\prime \prime}$ & 40 & & & & \\
\hline $8^{\prime}-0^{\prime \prime}$ & 130 & 9 & 3 & 25 & \\
\hline $10^{\prime}-0^{\prime \prime}$ & 76 & 7 & 5 & 55 & \\
\hline $12^{\prime}-0^{\prime \prime}$ & 21 & 13 & 14 & 19 & \\
\hline $14^{\prime}<$ & 46 & & 45 & 38 & \\
\hline
\end{tabular}

Table 17: 315 Savard Avenue - estimated quantity of pieces per type by length. 


\section{Property \#5}

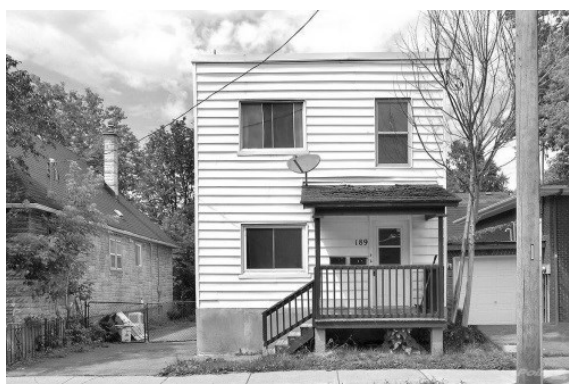

Figure 44: 189 Carillon street view.

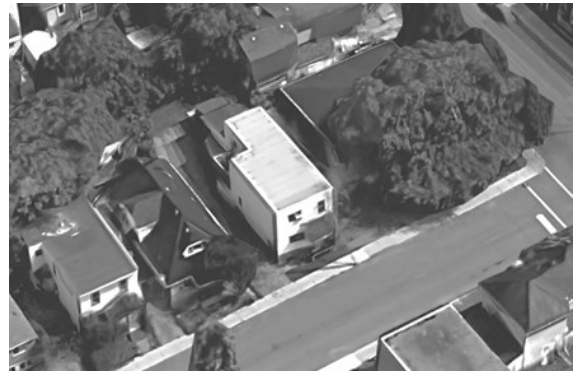

Figure 45: 189 Carillon bird's eye.

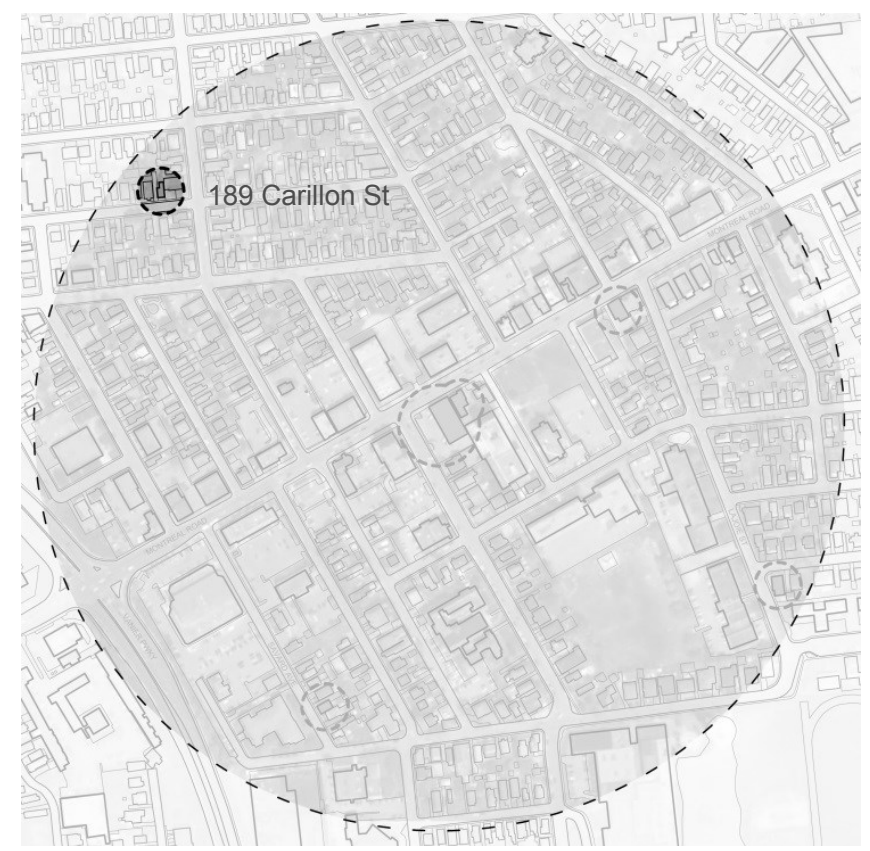

Figure 46: Context map.

\section{Profile/Statistics}

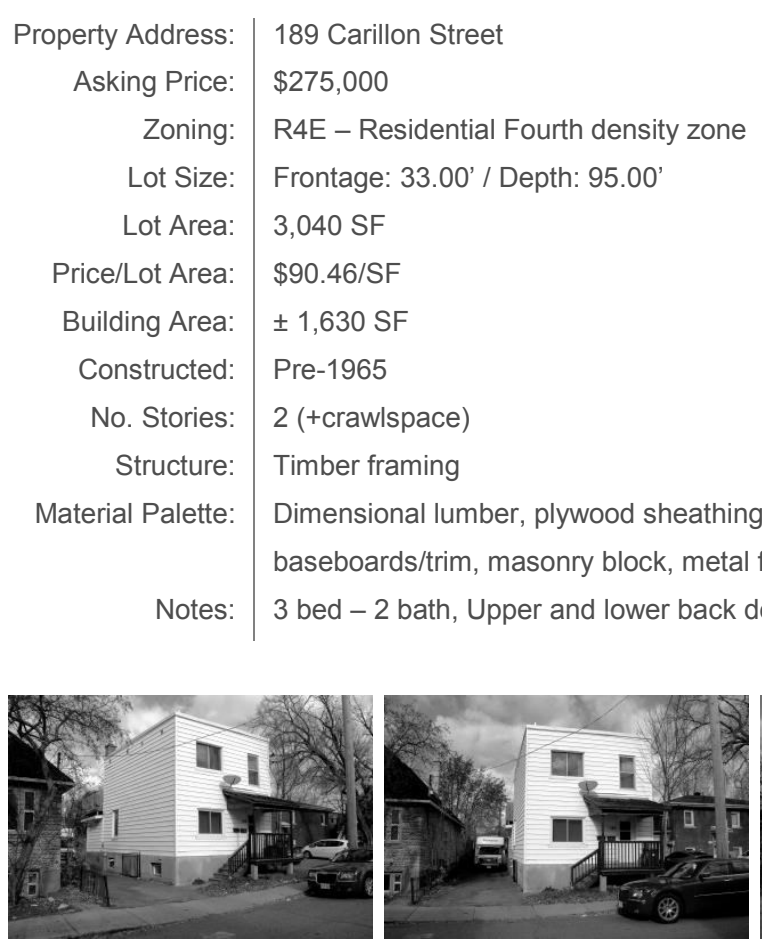

Salvage Estimations

\begin{tabular}{r|l} 
Wall Area: & $\pm 6,400 \mathrm{SF}$ \\
Lumber Length: & $\pm 7,840 \mathrm{feet}$ \\
Board Footage: & $\pm 7,100 \mathrm{BF}$
\end{tabular}

Figure 47: Selection of photos used for photogrammetry model. 


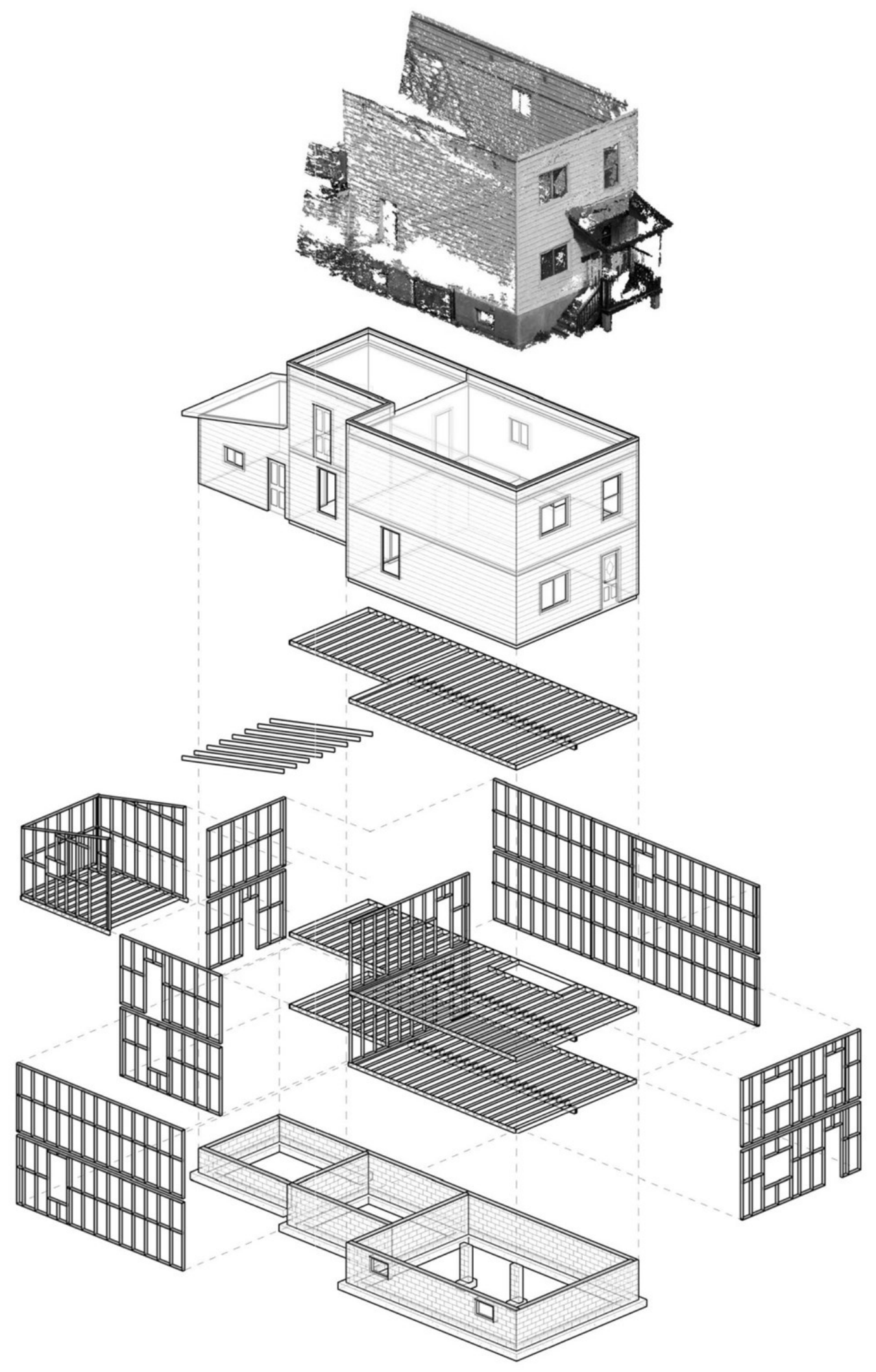

Figure 48: Exploded axonometric BIM based on point cloud from photogrammetry. 


\begin{tabular}{|c|c|c|c|c|c|c|}
\hline \multicolumn{7}{|c|}{189 Carillon Street - Structural Framing Schedule Condensed } \\
\hline Material & Type/Size & $\begin{array}{l}\text { Combined } \\
\text { Length }(L)\end{array}$ & $\begin{array}{l}\text { Width }(W) x \\
\text { Height }(H)\end{array}$ & $\begin{array}{l}\text { Board Feet } \\
(L x W x H) / 12\end{array}$ & $\begin{array}{c}\text { Combined Length } \\
-10 \%\end{array}$ & $\begin{array}{c}\text { Board Feet } \\
-10 \%\end{array}$ \\
\hline M_Dimension Lumber & $38 \times 90(2 \times 4 ")$ & $5496 '-21 / 2^{\prime \prime}$ & 8 & 3664.13 & $4946^{\prime}-7^{\prime \prime}$ & 3297.72 \\
\hline $38 \times 90$ (2x4"): 953 & \multicolumn{3}{|c|}{$5496 '-21 / 2 "$} & 3664.13 & $4946 '$ - 7" & 3297.72 \\
\hline M_Dimension Lumber & $38 \times 140(2 \times 6 ")$ & $505^{\prime}-91 / 2 "$ & 12 & 505.81 & $455^{\prime}-21 / 2^{\prime \prime}$ & 455.23 \\
\hline $38 \times 140$ (2x6"): 70 & \multicolumn{3}{|c|}{$505^{\prime}-91 / 2 "$} & 505.81 & $455^{\prime}-21 / 2^{\prime \prime}$ & 455.23 \\
\hline M_Dimension Lumber & $38 \times 190(2 \times 8 ")$ & $2382^{\prime}-31 / 2^{\prime \prime}$ & 16 & 3176.39 & $2144^{\prime}-01 / 2^{\prime \prime}$ & 2858.75 \\
\hline $38 \times 190$ (2x8"): 367 & \multicolumn{2}{|r|}{$2382^{\prime}-31 / 2^{\prime \prime}$} & \multicolumn{2}{|r|}{3176.39} & $2144^{\prime}-01 / 2 "$ & 2858.75 \\
\hline M_Dimension Lumber & $38 \times 235(2 \times 10 ")$ & $327^{\prime}-91 / 2^{\prime \prime}$ & 20 & 546.30 & $295^{\prime}-0^{\prime \prime}$ & 491.67 \\
\hline $38 \times 235(2 \times 10 "): 42$ & & $327^{\prime}-91 / 2^{\prime \prime}$ & & 546.30 & $295^{\prime}-0^{\prime \prime}$ & 491.67 \\
\hline Grand total: 1432 & & $8712^{\prime}-1 "$ & & 7892.62 & $7840^{\prime}-101 / 2^{\prime \prime}$ & 7103.36 \\
\hline
\end{tabular}

Table 18: 189 Carillon Street - BIM structural framing calculations.

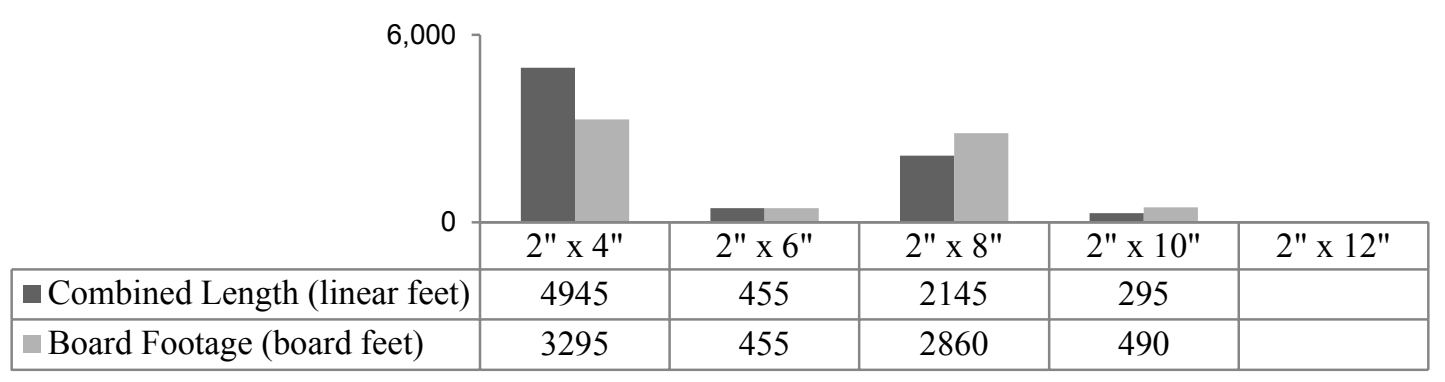

Table 19: 189 Carillon Street - estimated lumber amounts per type after deductions.

\begin{tabular}{|c|c|c|c|c|c|}
\hline U & $2 "$ x 4" & $2 " \times 6 "$ & $2^{\prime \prime} \times 8 "$ & $2 "$ x 10" & $2 "$ x $12^{\prime \prime}$ \\
\hline a $<14.5^{\prime \prime}$ & 90 & 17 & 7 & 2 & \\
\hline 14.5" & 271 & & 151 & 10 & \\
\hline$-2^{\prime}-0^{\prime \prime}$ & 88 & & 21 & & \\
\hline - 4' - 0" & 11 & 8 & 6 & & \\
\hline $6^{\prime}-0^{\prime \prime}$ & 97 & 24 & 22 & 7 & \\
\hline $8^{\prime}-0^{\prime \prime}$ & 310 & 7 & & 9 & \\
\hline $10^{\prime}-0^{\prime \prime}$ & 125 & & 108 & & \\
\hline $12^{\prime}-0^{\prime \prime}$ & 21 & & 46 & 12 & \\
\hline $14^{\prime}<$ & & 14 & 18 & 2 & \\
\hline
\end{tabular}

Table 20: 189 Carillon Street - estimated quantity of pieces per type by length. 
The recent development of software add-ons automatically generates specific structural framing according to defined parameters and presets, and can easily provide new design material take offs for pricing purposes. While these third-party add-ons were investigated, a combination of Revit's default framing tool and manual placement of members were used for this thesis exercise. As such, the total estimated lumber amounts are only as accurate as whatever was modelled digitally. Regardless, the values provide interesting observations and further comparative analysis of building and wall surface area to total lumber lengths and respective board footage totals. Combined totals of all properties amount to around 45,000 linear feet of framing members equalling 46,250 board feet (see Table 21).

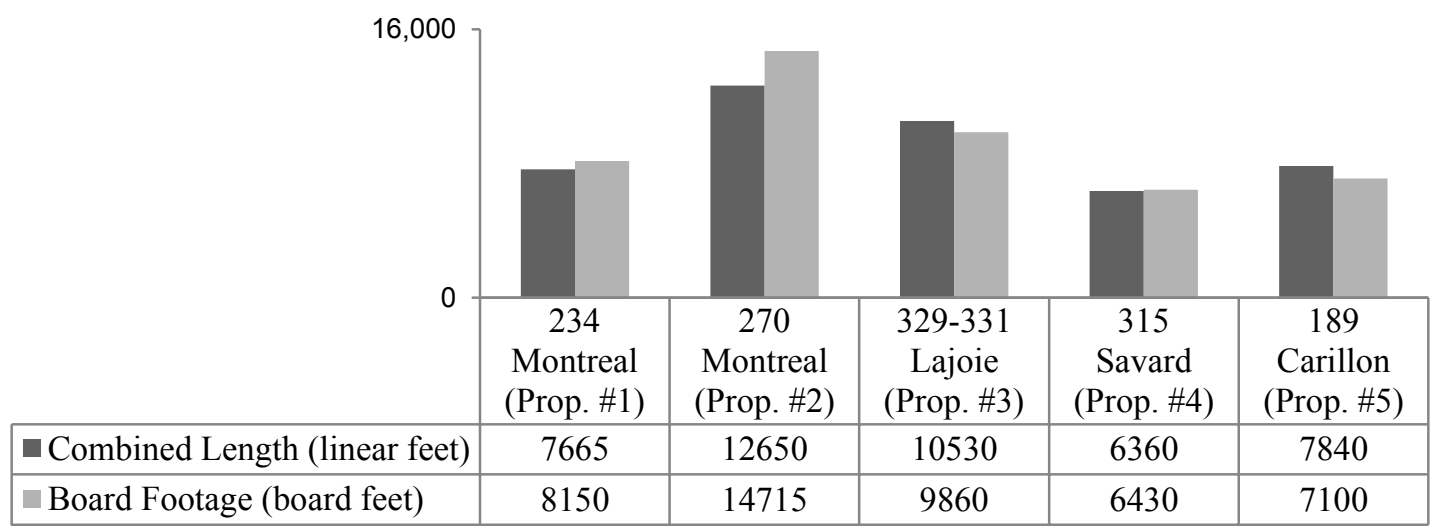

Table 21: Comparing estimated lumber amounts of subject properties.

These results of existing building area and material quantities will help inform and attempt to be reflected in the new design requirements accordingly. 


\section{[5.4] Reuse}

A major challenge for the project was reimaging ordinary salvaged materials to be reused in fresh applications or be given new life by evolving into new components. Referring to the recycling hierarchy of our built environment presented by Crowther, a recycling of materials can result in the manufacture of new components. With this in mind, the value of upcycling and reusing material not as originally intended was investigated, and led to analyzing the calculated amounts per type and quantities of individual structural members. In sum, statistical trends show many smaller, thinner pieces originating from perimeter and loadbearing walls, and longer, wider pieces originating from floor or roof joists. Questioning how to reuse these members sparked an exploration to transcend ordinary materials to have a greater value. The project therefore proposes inverting the original functions of these members into new assemblies, with the intention of using old wall studs for new floors and old floor joists for new walls.

Much of the challenge and issue in reusing salvaged material for structural purposes is in the recertification of wood products. It is not uncommon that salvaged lumber experiences wear and tear, and upon evaluation, any visual degradation in quality may not pass acceptable standards such as those outlined by the Forest Stewardship Council for sourcing pre- and post-consumer reclaimed materials in FSC products. ${ }^{113}$ In addition, the general requirements of the Ontario Building Code specify that recycled materials in buildings may only be reused if they satisfy their intended use in accordance with the

113 Forest Stewardship Council, Sourcing reclaimed material for use in FSC Product Groups or FSC Certified Projects (Bonn, Germany: Forest Stewardship Council A.C., 2011). 
provisions of referenced documents. ${ }^{114}$ If the product can undergo alternate test standards that provide comparable results to documents issued by agencies such as the Canadian Standards Association (CSA), only then may it be employed. With concern for reducing strain on our natural resources, exploring new testing methods for code equivalency of salvaged material becomes critical. This is especially the case when trying to create new types of assemblies that do not have a tested standard, which can be difficult to undertake without financial backing. Perhaps then it is the responsibility of agencies that create policy to revisit the stringent requirements for all types of salvaged materials to expand the feasibility of innovative structural assemblies. That being said, the proposed design project barely begins to explore the possibility of how these assemblies could take shape.

The existing generic retail structure of steel construction chosen for the design project qualifies as a good candidate to receive a major renovation, with much of the new addition following existing structural grids to address increased loads and viable support. The existing structure of beams, columns, and open web joists therefore established parameters for first floor height requirements and structural bay spans. Materials salvaged from the subject properties were originally cut to their buildings sizing specifications, and therefore are difficult to reuse in the exact same application. As the vast majority of salvaged stock is of timber framing with very limited steel, this prompted an investigation into clever reuse of salvage material in combination with new supporting resources. Focusing on developments and popularity with engineered wood products, the project proposes creating components which are a unification of smaller or shorter elements to achieve increased loads and greater spans. The primary elements proposed for the new

114 Ontario Building Code, O Reg. 332/12, s. 1. 
design consist of loadbearing walls and built-up columns and beams using larger, wider framing members, and trusses that combine many small, thin individual members otherwise impractical for reuse.

Joined together in triangular shapes by steel connector plates, wood trusses are engineered frames of lumber that permit long spans and flexibility from their high strength-to-weight ratio. The advantage of wood trusses are that they can accommodate complex and unusual designs, efficiently use wood, permit quick field installation, and allow for easy placement of different building services from their open web design. ${ }^{115}$

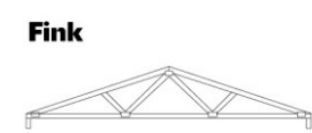

Mono

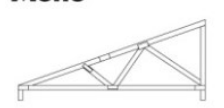

Scissors

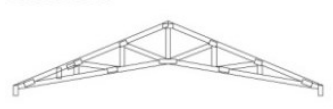

Room-in-Attic

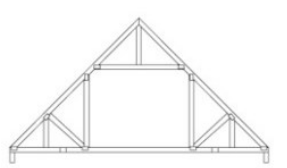

Pitched (triangular) Truss

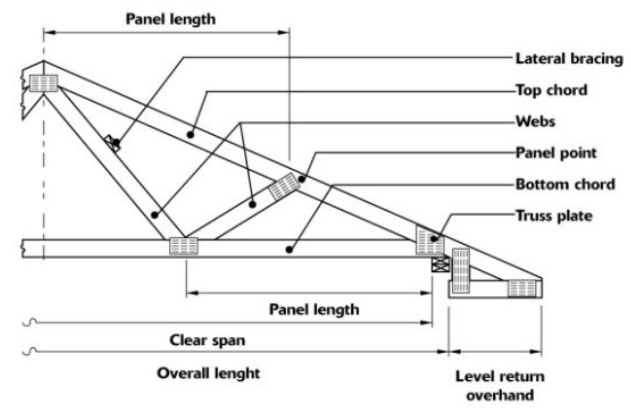

Parallel Chord (flat) Truss

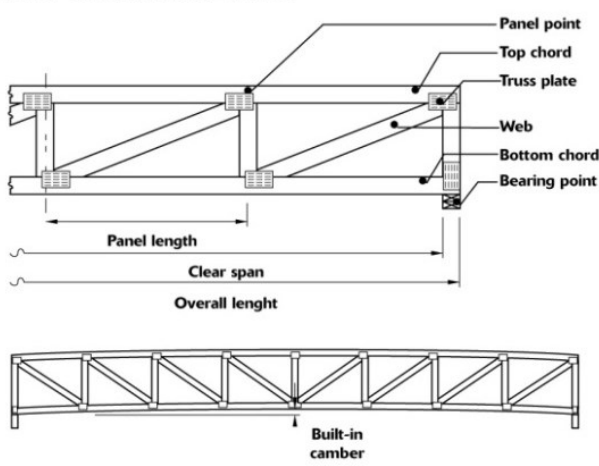

Roof Trusses:

Light trusses are manufactured to suit virtually any roof profile. Pitched or flat, they are only limited to the load arrangements and the support locations.

\section{Flat Trusses:}

Flat trusses, also known as parallel chord trusses, are an alternative to conventional wood floor joist systems and are a competitive option to open web steel joist systems.

Parallel chord floor trusses may be designed with varying chord and web arrangements and bearing support details.

Figure 49: Truss nomenclature and common truss shapes (source: Canadian Wood Council, IBS2).

Working with computer software, a truss manufacturer provides essential truss information and specification of members that are cut to size, placed to a repeated

115 Canadian Wood Council, IBS2 - Wood Trusses - Strength, Economy, Versatility, accessed February 6 , 2017, http://cwc.ca/wp-content/uploads/publications-IBS2_Wood_Trusses_SMC_v2.pdf. 
template, and secured with connector plates (see Figure 50). This type of assembly line process embodies the project idea of developing material pieces into stronger components.

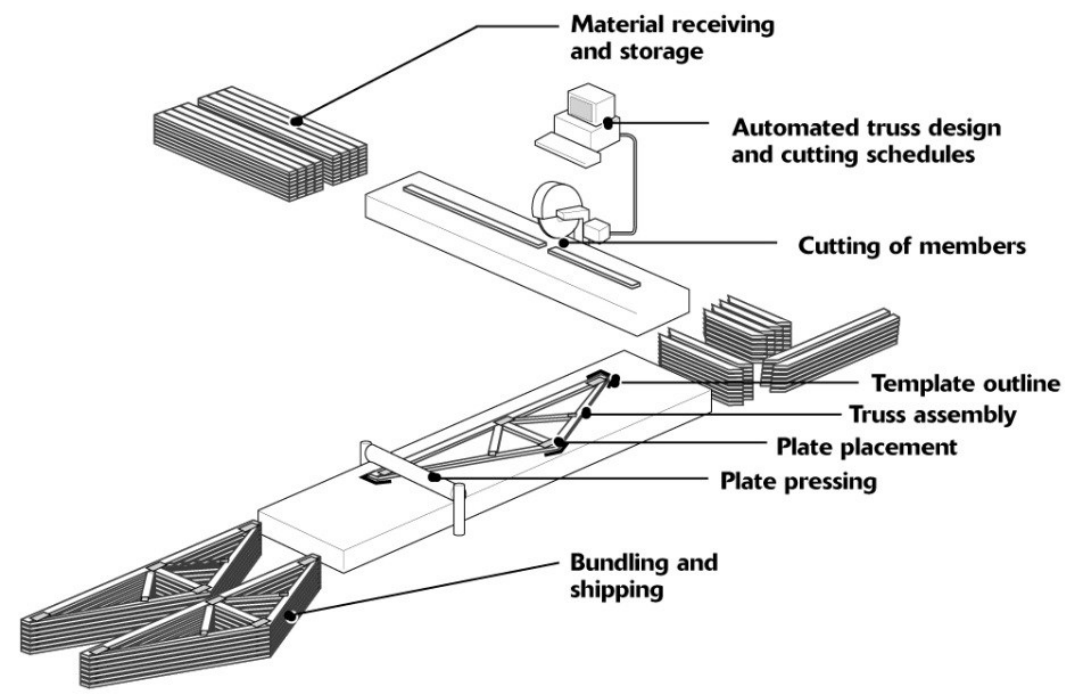

Figure 50: Manufacture of light frame trusses (source: Canadian Wood Council, IBS2).

Much of the design project focuses on the incorporation of construction detailing and techniques that facilitate disassembly. It also adopts measures of Advanced Framing techniques through optimum value engineering (OVE), which capitalizes on the use of a standard size module with minimal structural members to maximize material usage while reducing construction waste. ${ }^{116}$ As the design proposes using larger, wider framing members for walls, a 24-inch on-center framing for studs and trusses can be easily integrated along with other OVE principles to further reduce the required amount of salvaged material compared to conventional practices.

By simplifying structural systems to the existing grid to form modular or standard dimensions, the complexity and clashing of different material types is reduced. This also

116 Martin Holladay, "The Pros and Cons of Advanced Framing" Green Building Advisor, December 24, 2010, http://www.greenbuildingadvisor.com/blogs/dept/musings/pros-and-cons-advanced-framing. 
provides opportunity for standardized, repeated components and connections that are bolted or screwed as opposed to nails and adhesives. The project strives to design visually accessible, reversible connections whenever possible and reduce the amount of interior finishes to facilitate the disentanglement of different building systems and accommodate future adaptability and flexibility for different scenarios. The building addition could then be deconstructed at its end-of-life to recover its processed resources much easier and more efficiently than a building not originally designed in this way.

Other aspects of material savage analyze the results of existing building area and material quantities that become translated into new design specifications. It also endeavours to determine and compare quantities of individual pieces required for truss dimensions and their structural spans. While the new design is influenced by the structural framing members salvaged from existing properties, it is not strictly limited by them, and providing some materials such as insulation, sheathing, and cladding from new sources will almost always prove necessary.

\section{[5.5] Program}

The project proposal seeks to generate mixed-use activity as appealed by City of Ottawa and in accordance with the revised Official Plan, with intentions to develop and revitalize the immediate vicinity which for many years has known to be precarious and in need of renewal.

A major goal of the project is to demonstrate effective design for disassembly principles and strategies. This includes incorporating features that allow for flexibility and future adaptability. However, using a minimal amount of interior finishes to allow for easy 
access to building services can inhibit the ability to successfully integrate different occupancy classifications due to adjacent or superimposed fire separation requirements. It is therefore at times difficult to have both exposed building and structural systems and a mixed-use program, including the feasibility to adapt or expand in the future. For example, the combination of different occupancies requires certain fire separation ratings of wall and floor elements, and therefore certain construction details or material limitations to achieve these ratings. In the case of combustible wood construction, this primarily involves covering of structural framing elements, including trusses and the services that may run between them. While it is possible to have an exposed roof assembly that has no fire rating requirements, a floor assembly separating a different superimposed occupancy faces limitations. These sorts of barriers are reduced if the variety of program is limited.

Therefore the determination of building program becomes a lesser focus for the purposes of this analysis, and for achieving disassembly goals, including ease of maintenance and adaptability. Considering this, the opposite could be said if specific occupancy uses are desired, whereby there would become greater restrictions on wood construction and assembly detailing, primarily the sheathing and sealing of combustible members. Regardless, it is implied that fire separations would indeed occur where required for current or future uses. The proposed design seeks to provide the most positive impact on the community and a mentality that nourishes/promotes reuse and rehabilitation; however a limitation on program may not create the same ideal outcome as a richly diverse mixeduse building that encompasses a range of occupant types. 
The existing building occupies a corner lot with significant frontage off Montreal Road, and with an existing rear loading area the site lends itself well for commercial uses. Accordingly, the architectural brief primarily incorporates different types of commercial business activity as drivers for revitalization. The site would also need to become a destination that provides a missing service to the area. A review of establishments in Vanier discovered that the nearest hardware store serving the neighbourhood burnt down in 2011. ${ }^{117}$ As this thesis is very much about tools and equipment involved with deconstruction, the first part of the building program will incorporate a new storefront hardware store selling building tools and supplies.

Following strategies of scenario planning, the design offers alternate cases of occupancy and identifies the code restrictions related to their fire separation. Scenario one proposes residential live and work units that would ideally target artists as studios, in combination with open space layouts for offices or small businesses services. Scenario two removes the living component of the studio spaces to change the occupancy grouping to allow for more industrial uses of workshop spaces for material processing and use for business or artists in-house.

If this proposal were to actually undertake practical deconstruction activities, a critical requirement is a dedicated location to stock and warehouse salvaged material.

Coincidently, the existing steel structure reflects the higher average height that is typical of one-storey commercial buildings, and provides adequate interior clearance for feasibility as warehouse. Combined with new outdoor storage provisions, the rear half of

117 "Ottawa blaze leaves 2 dozen homeless," CBC/Radio-Canada, March 16, 2011 , http://www.cbc.ca/news/canada/ottawa/ottawa-blaze-leaves-2-dozen-homeless-1.1101441. 
the existing floor area is a logical choice for a place to store a variety of reclaimed materials and finishes. Appropriately then, the store can also act to sell the salvaged material acquired from deconstruction activities and that are not reused for this, or future projects.

From a practical perspective, an opportunity presents itself that the site incorporate flexible, open space office layouts for potential businesses, including for the entity owning the site and the salvaged materials from deconstructing surrounding properties. As the actual proprietor proposing the subsequent project redevelopment and performing deconstruction activities, necessities of any business are required and considered for administration, operations, employees, and amenities. As part of these business operations, and as a mandate to promote reuse and rehabilitation, scenario two proposes that a workshop be integrated in the design to provide businesses or the public with an opportunity to repair or restore different materials and architectural items.

The last program cluster proposed also aims to encourage commerce and rehabilitation by integrating Low Road ${ }^{118}$ units. These flexible spaces offer a blank palette for imagination and would be ideally target artists as places of business or live and work studios. In scenario two, the tenants would then have the option to use the workshop facilities located in the building. It also endeavours to integrate spaces for art programs and selling supplies as a catalyst for further action. Art programs and artistic events are successful in leading to renewal in areas of decline and adding quality to the urban environment. Reasons for this success are that it engages people's creativity and problem solving,

118 Brand, How Buildings Learn, 24-33. 
offering self-expression and enabling a dialogue between people and social groups. ${ }^{119}$ Compared to large capital projects, cultural programmes can be developed quickly in response to local ideas or needs, are relatively cheap and cost-effective, thereby providing a potentially high impact and return for very low risk through public interest. It is envisioned that the experimental nature of artistic settings will provide an element of unpredictability, excitement, and fun with their potential to nourish trendy urban environments. Social quality added in the form of performances or installations support a sense of creation versus desolation, with unexpected curiosity by residents and neighbours spurring rejuvenation in areas otherwise thought to be devoid. ${ }^{120}$ Given the stated programmatic considerations, the proposed design project ultimately seeks to act as a rehabilitation hub. The community building type program with affordability in mind offers a space to conceptually rebuild greater Vanier. Dubbed the RE-HUB, the proposal takes advantage of the increased area gained from the adjacent property that was deconstructed. This increased footprint is utilized as the new vertical circulation to the upper floors, and superimposes the existing structure, creating a rich mixed-use site that would undergo rezoning. Particular design decisions were further influenced by building code requirements for safety, egress, occupancy, fire separation, loading and refuse.

119 Sheryl Boyle, "Sounding Forgotten Cityscapes" (lecture, Carleton University, Ottawa, October 17, 2016). 120 lbid. 


\section{[5.6] Drawings}

The following section presents the illustrations, drawings, and details (not to scale) for the proposed design project, followed by review and analysis of statistics for material requirements.

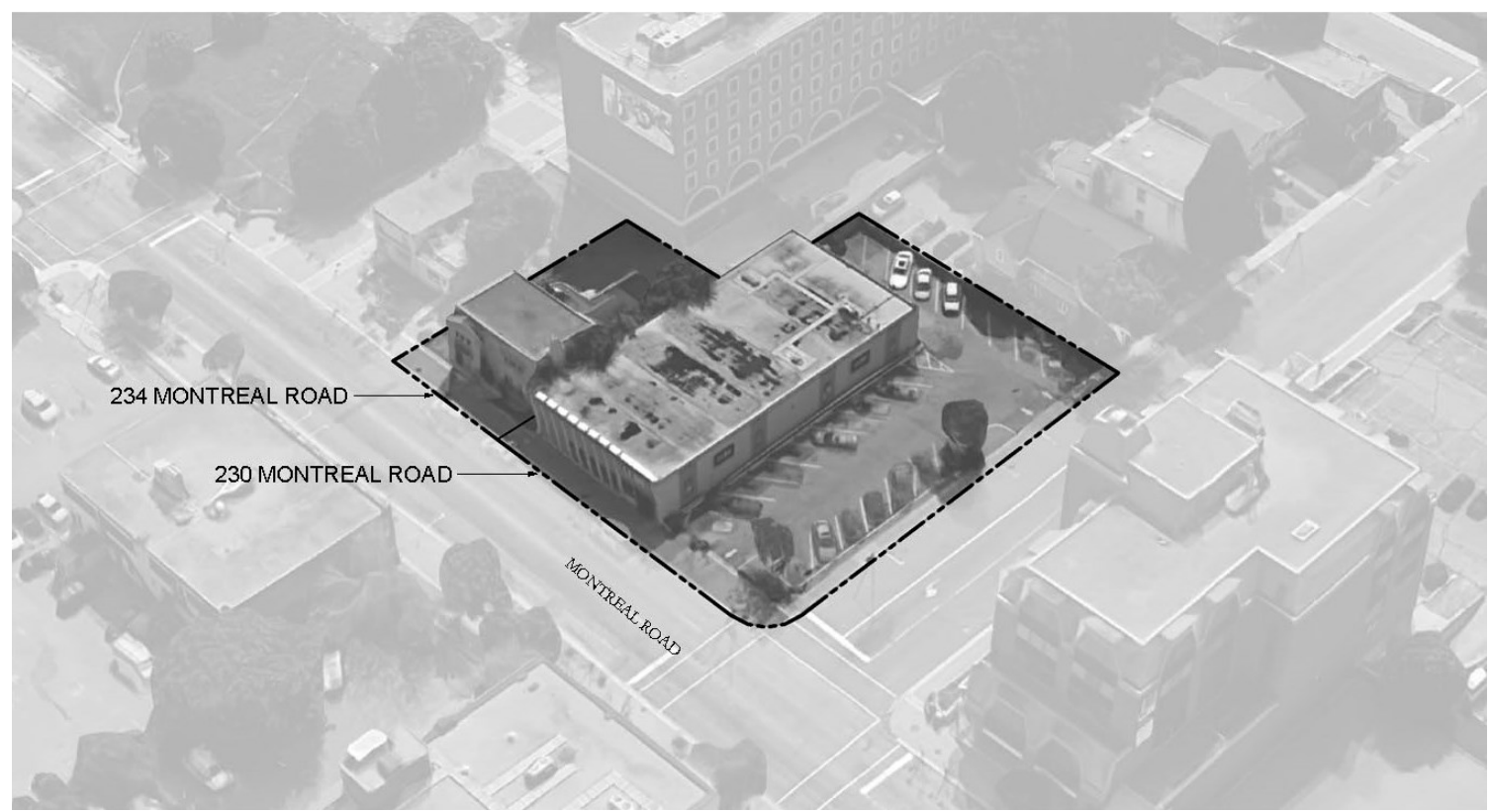

Figure 51: Bird's eye perspective of existing site conditions at 230 and 234 Montreal Road in Vanier. 

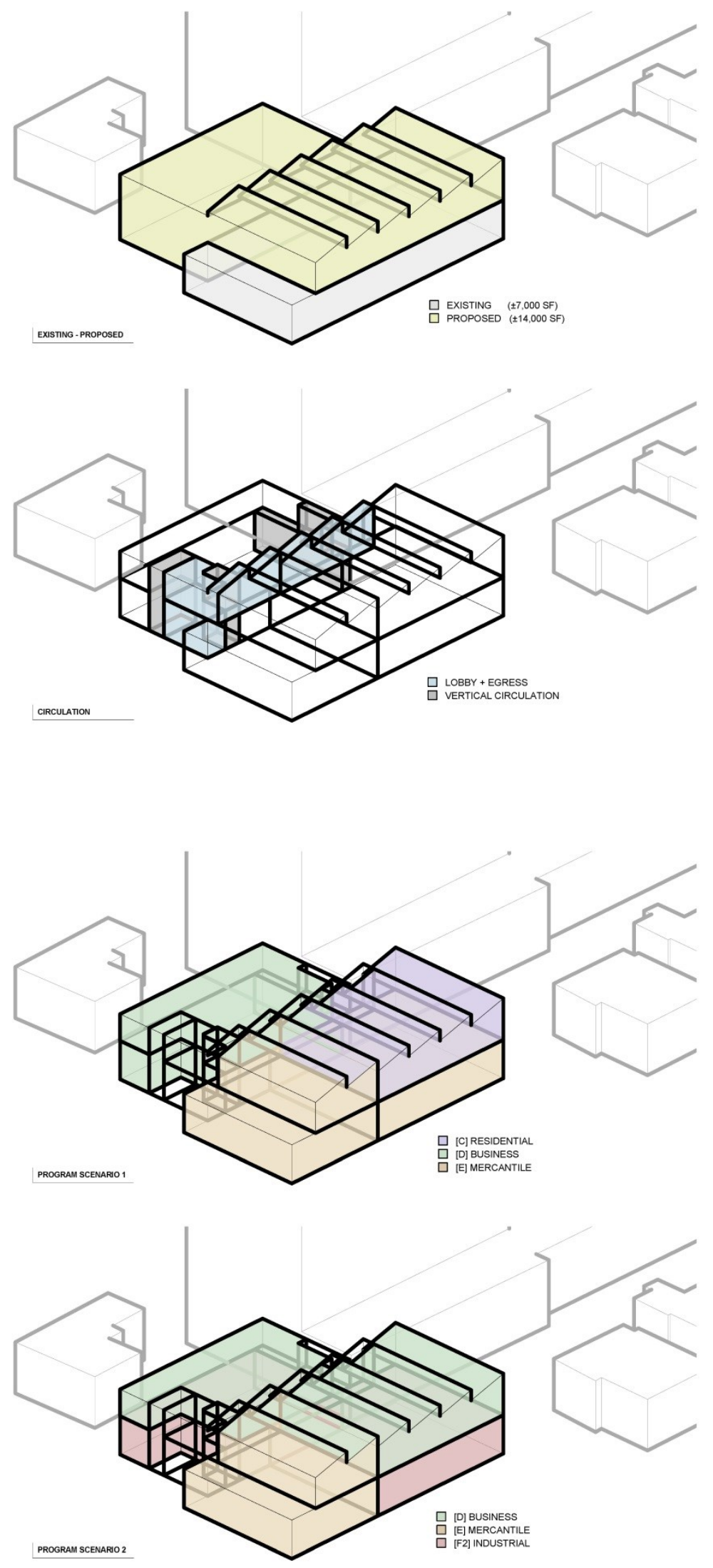


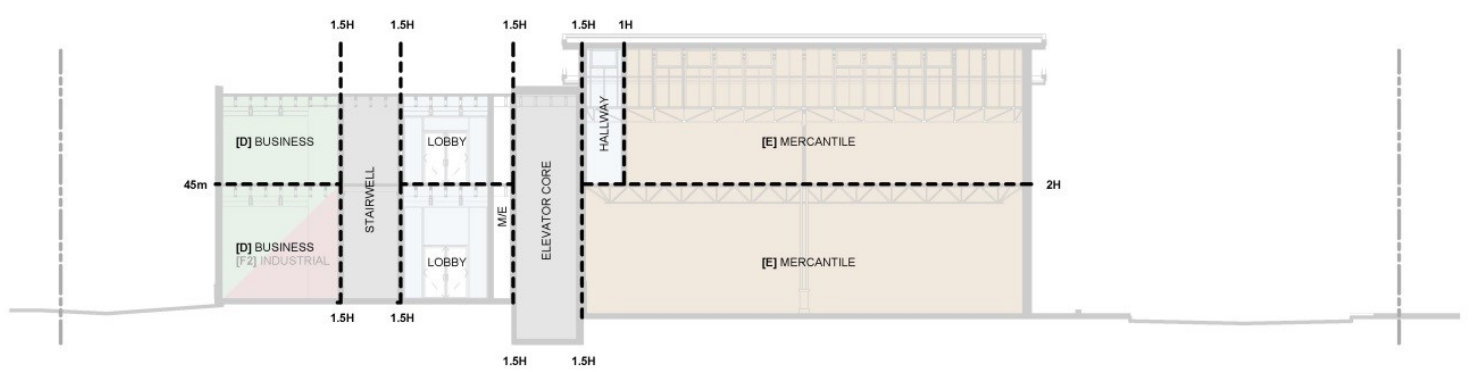

SECTION LOOKING SOUTH - FRE

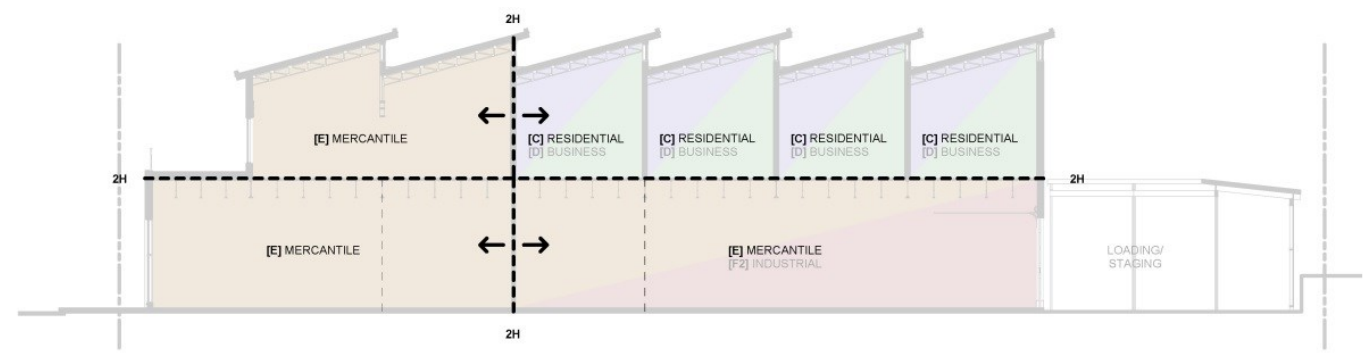

SECTION LOOKING EAST - FIRE 


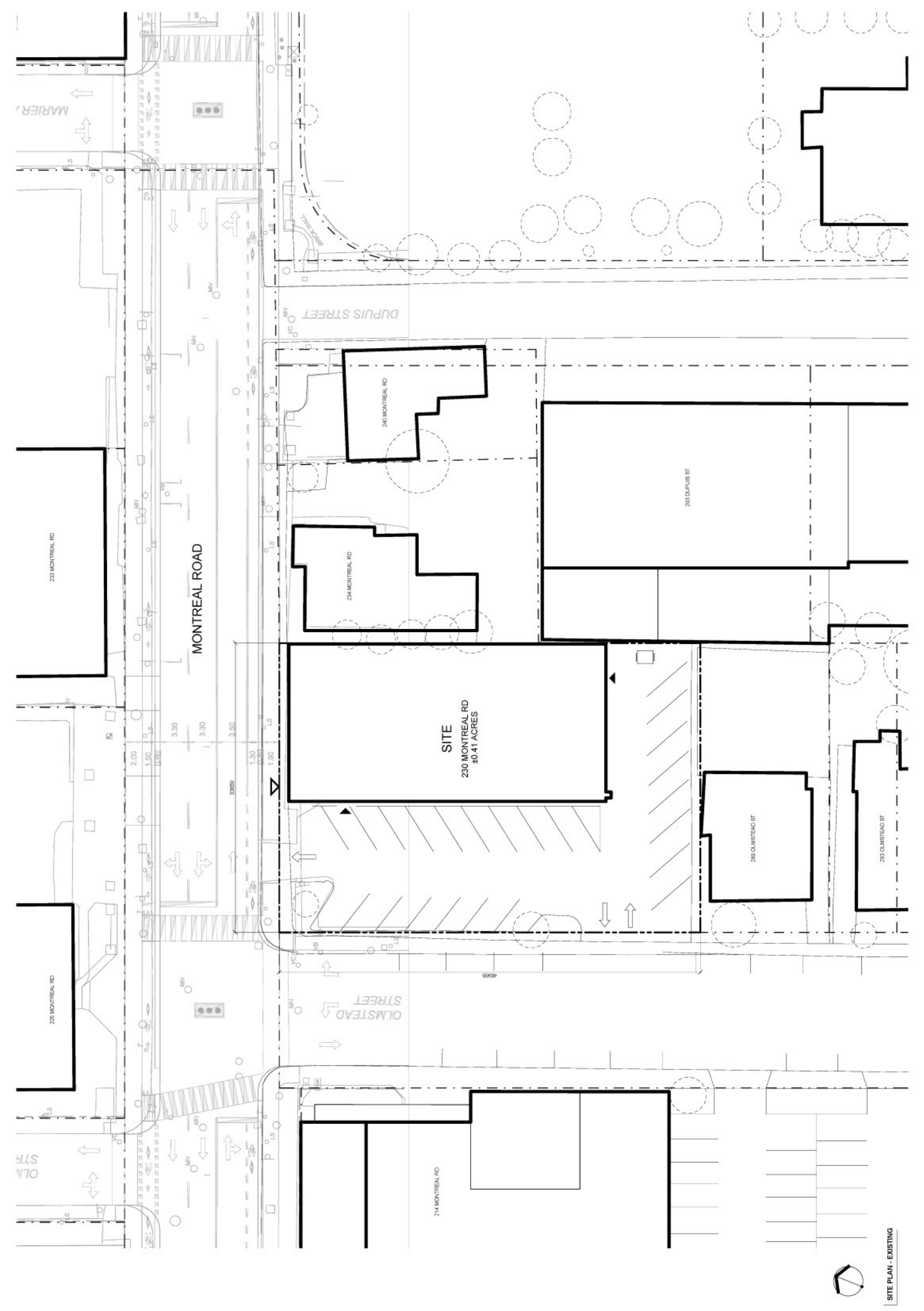




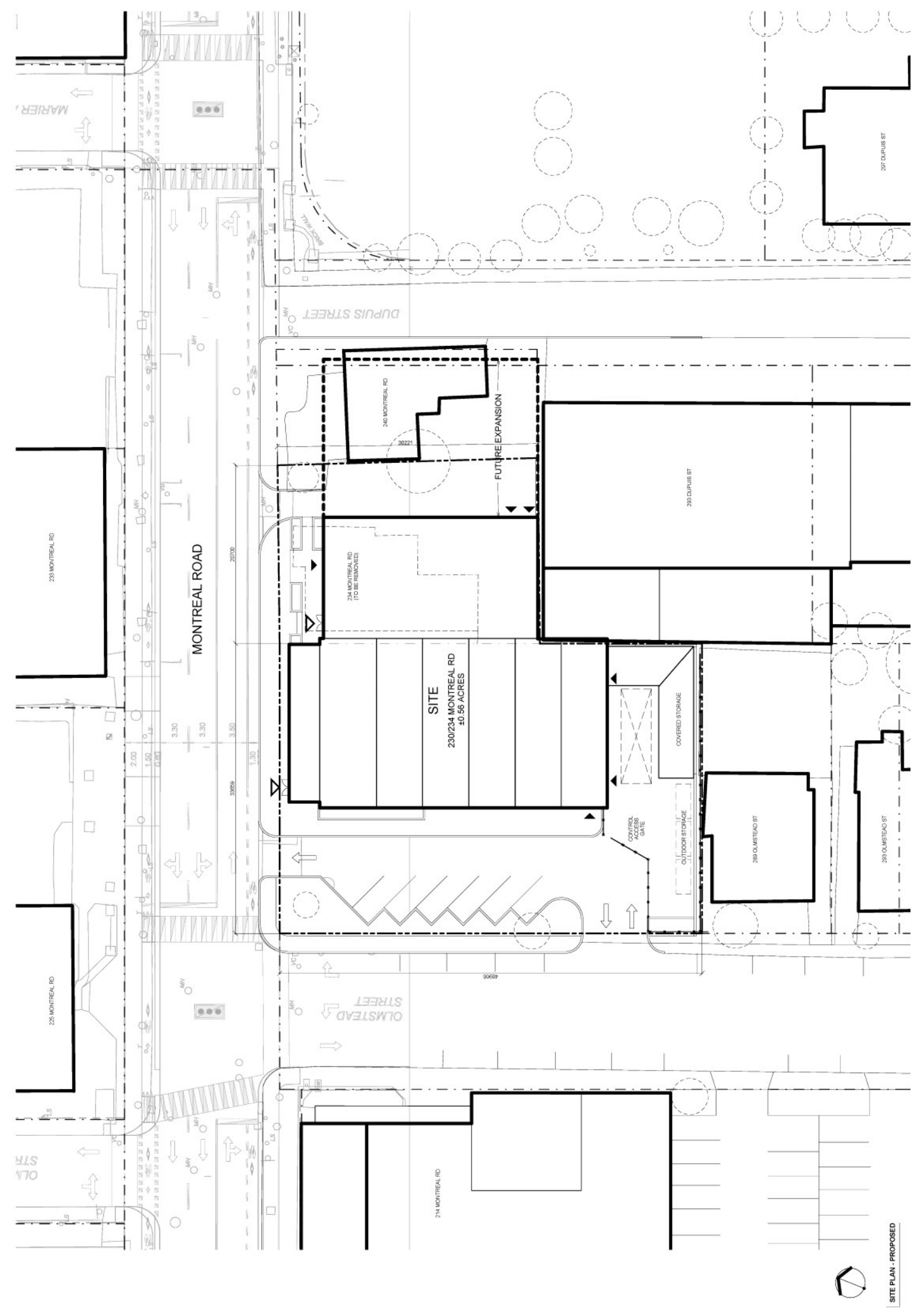




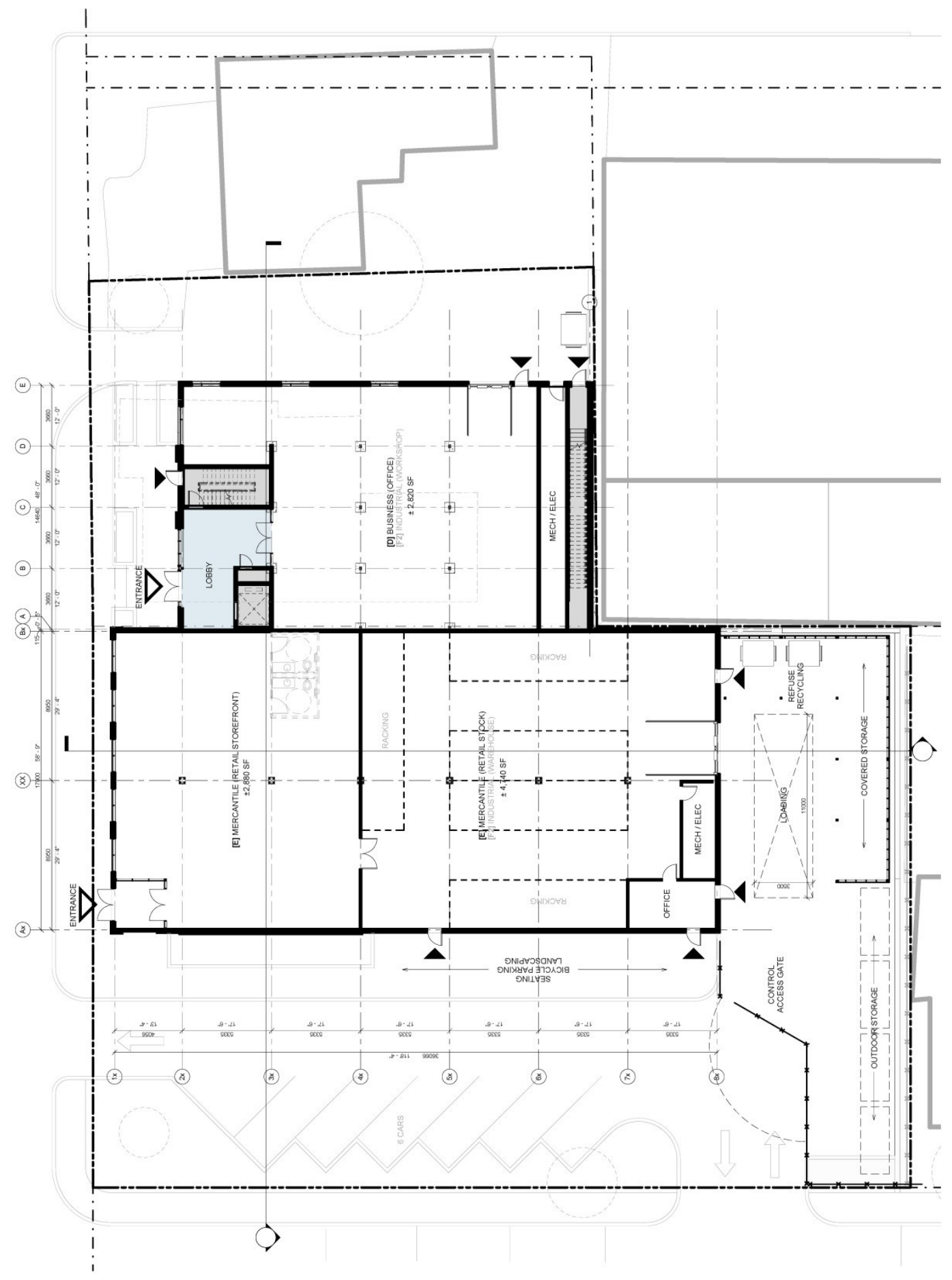

$\theta$ 


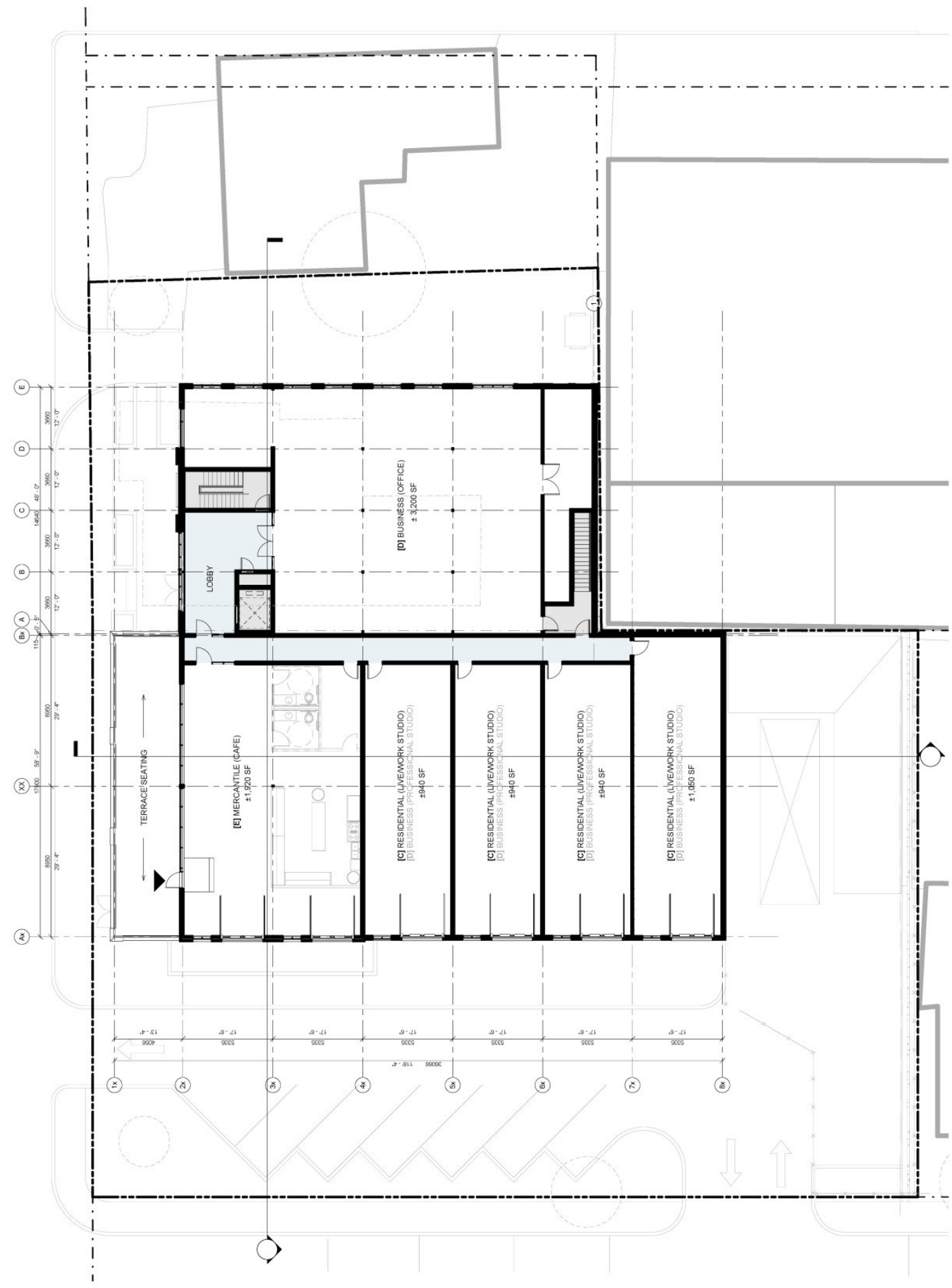

Q 


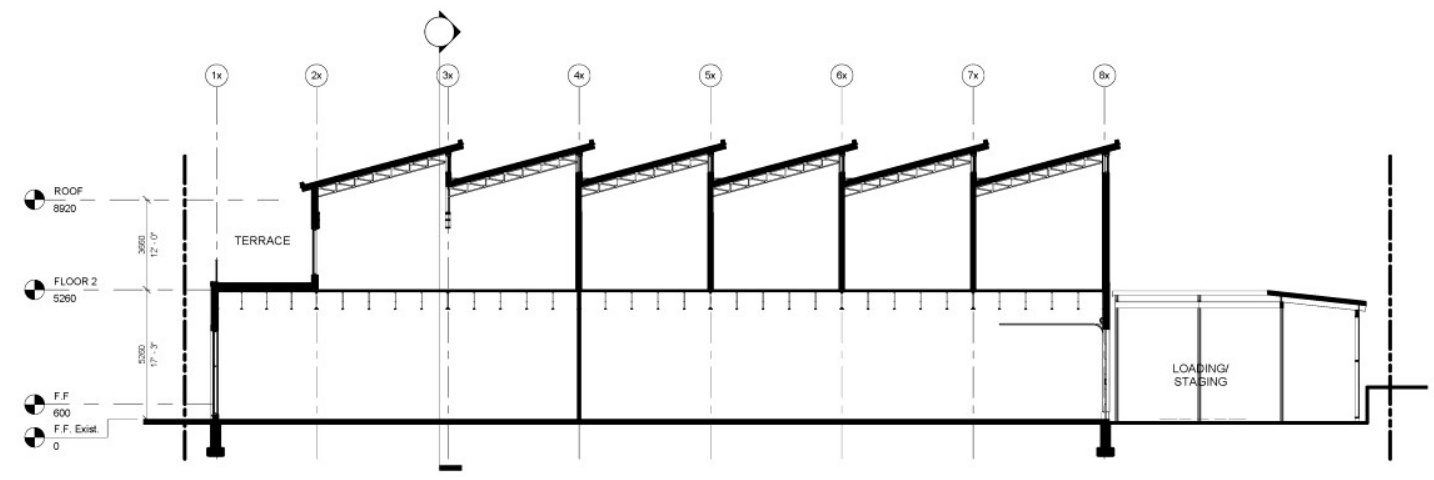

SECTION LOOKING EAST
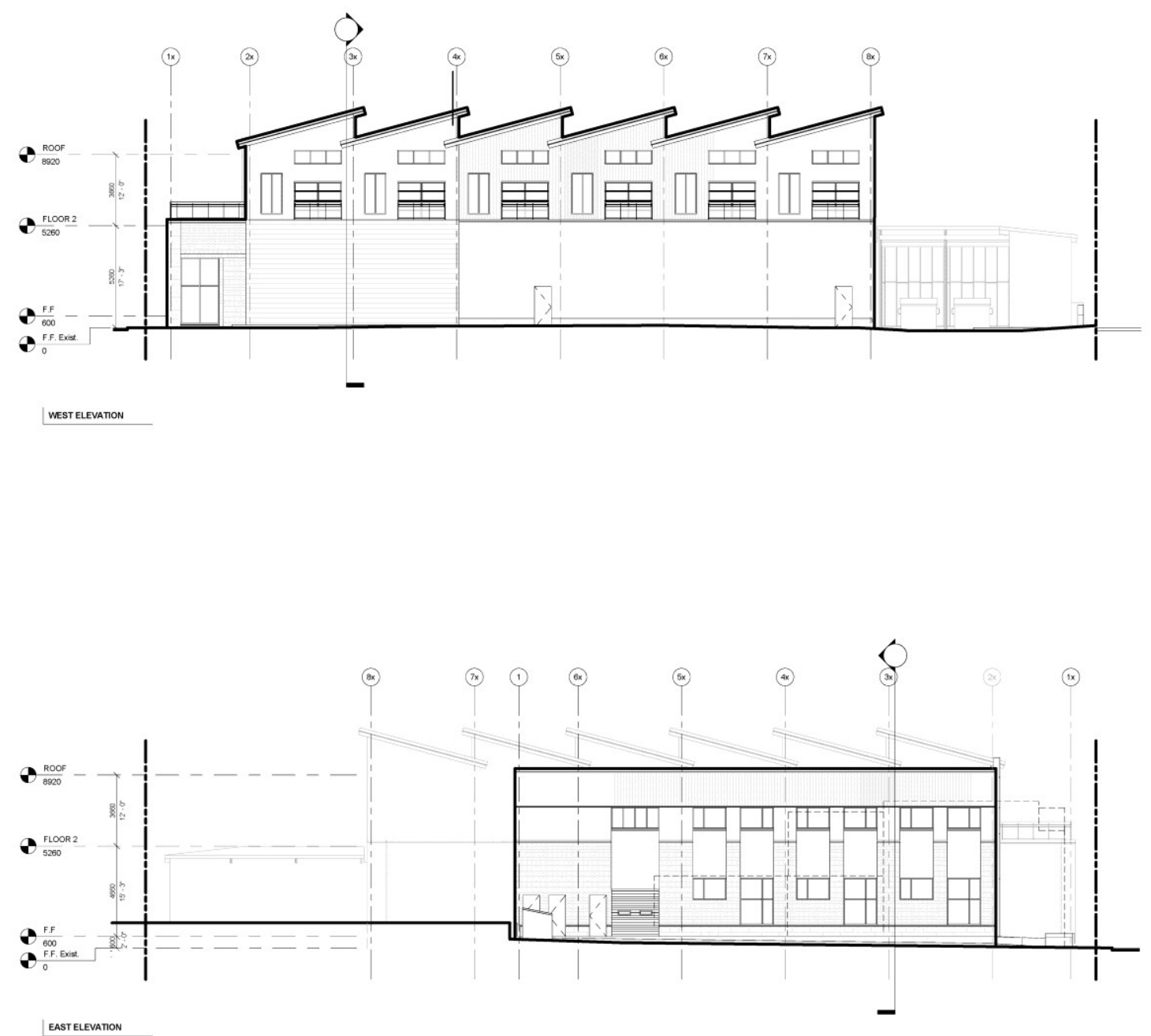


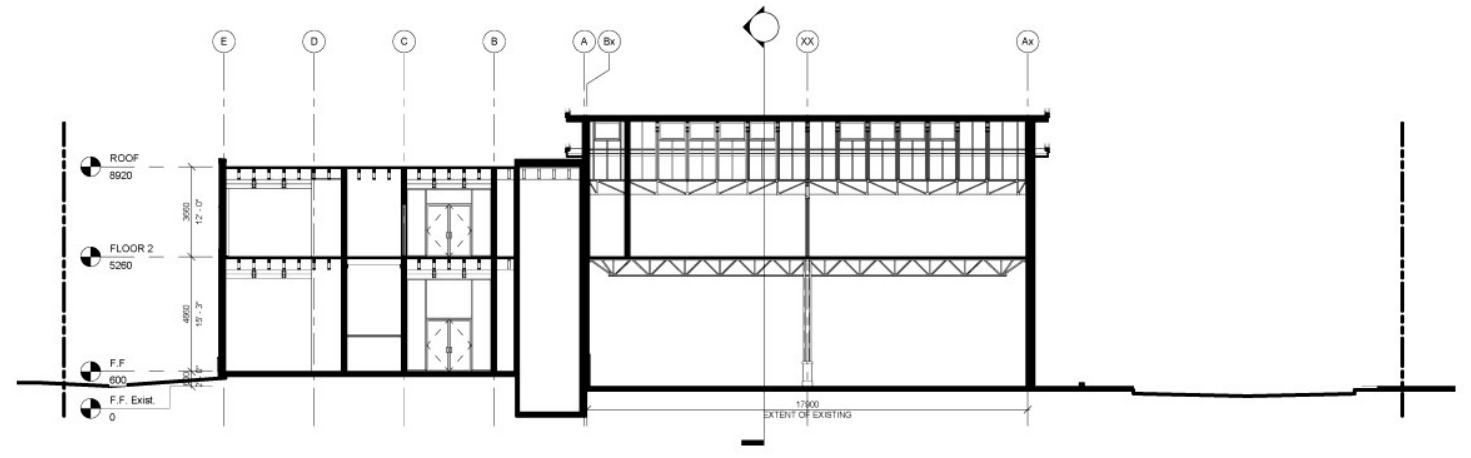

SECTON LOOKING SOUTH

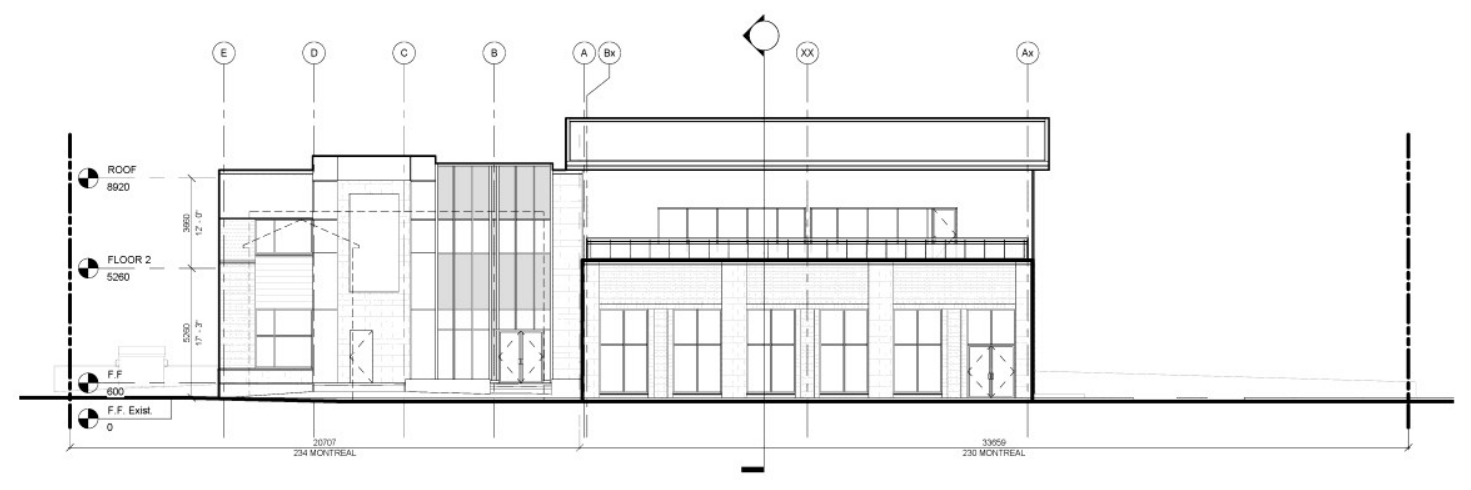

NORTH ELEVATON

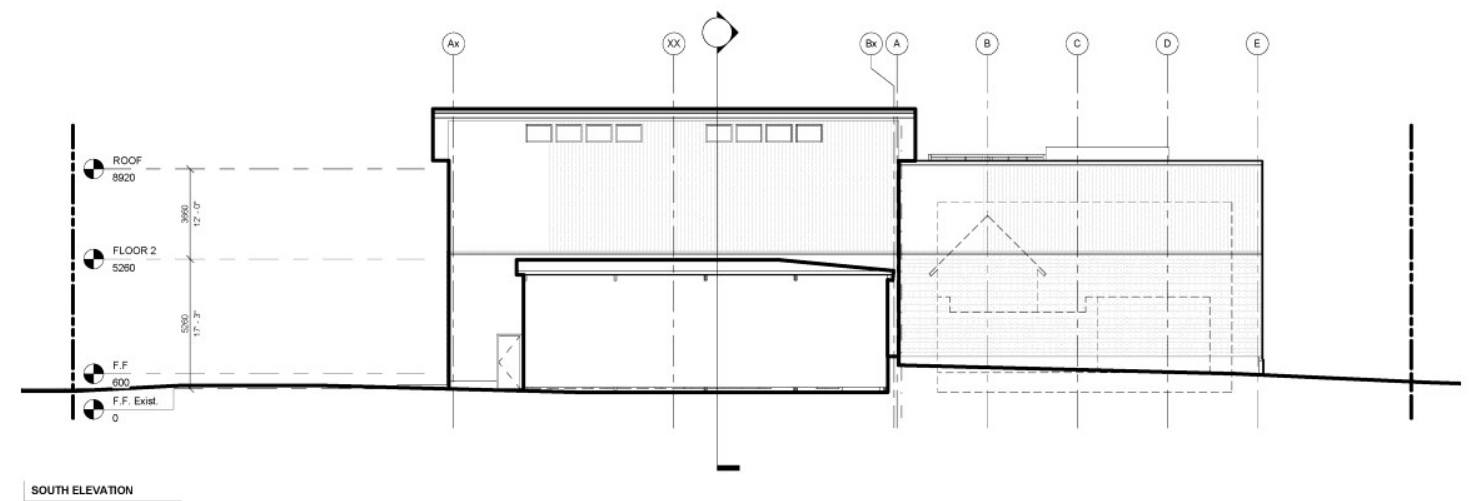



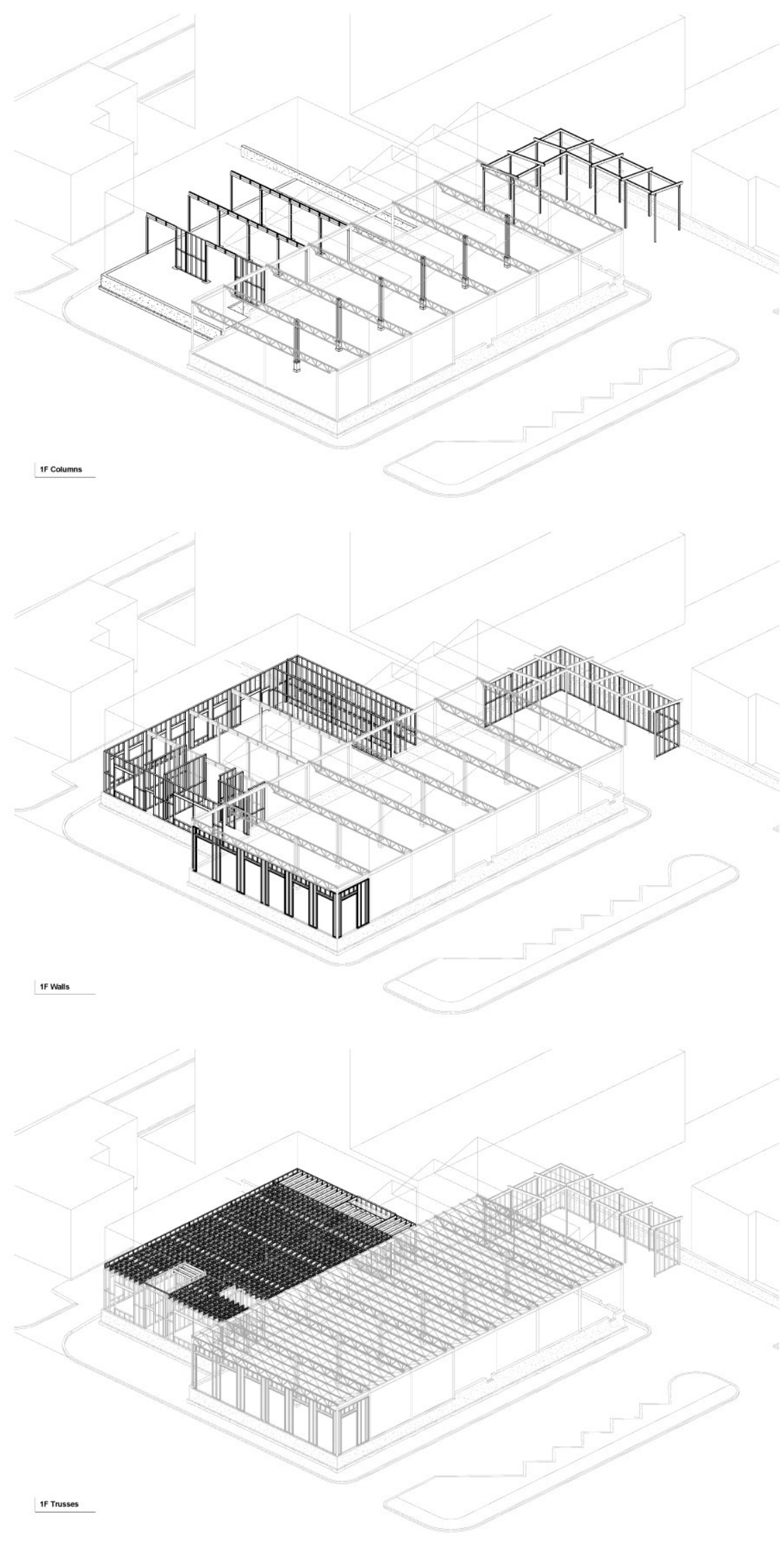

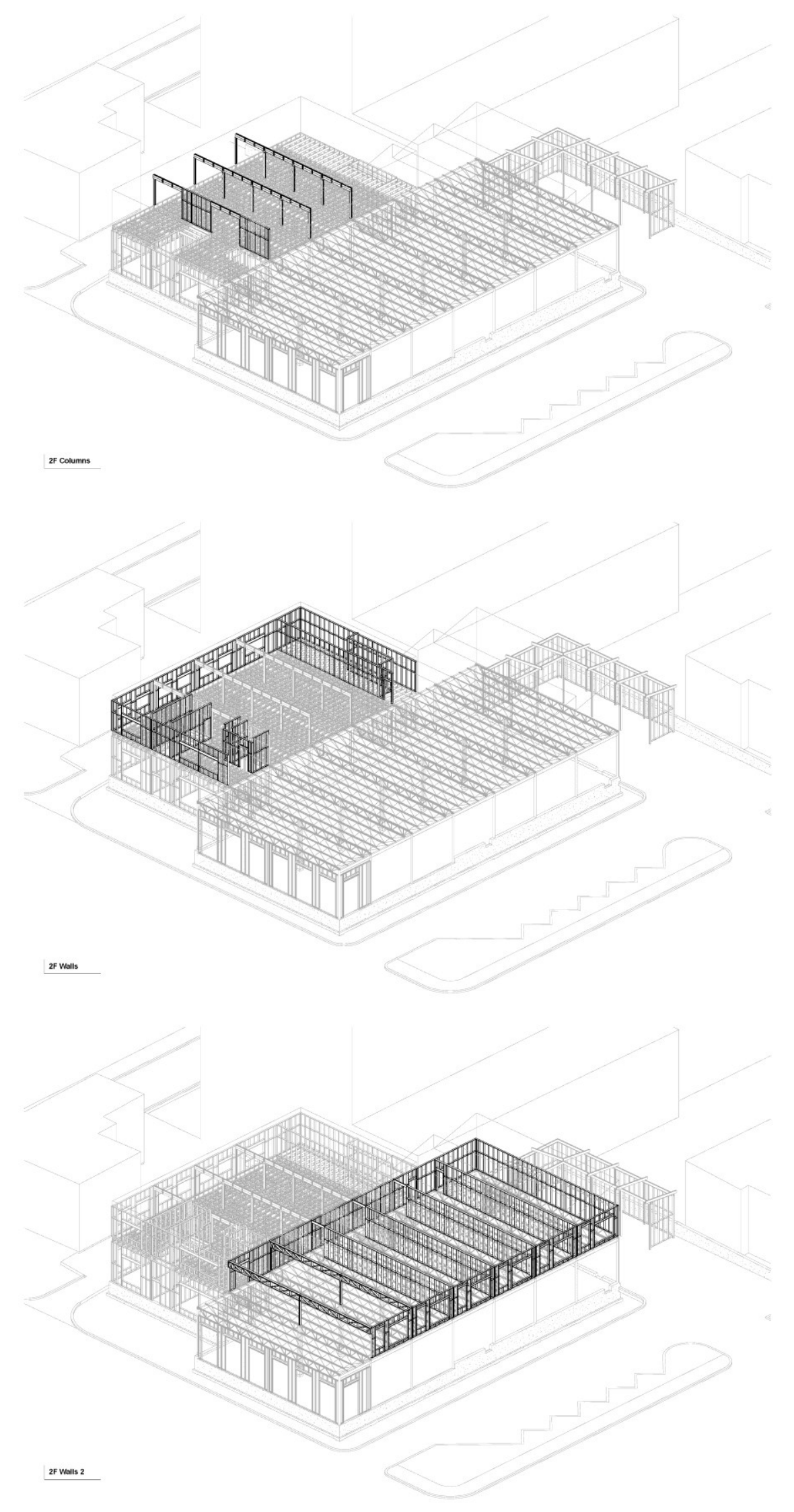

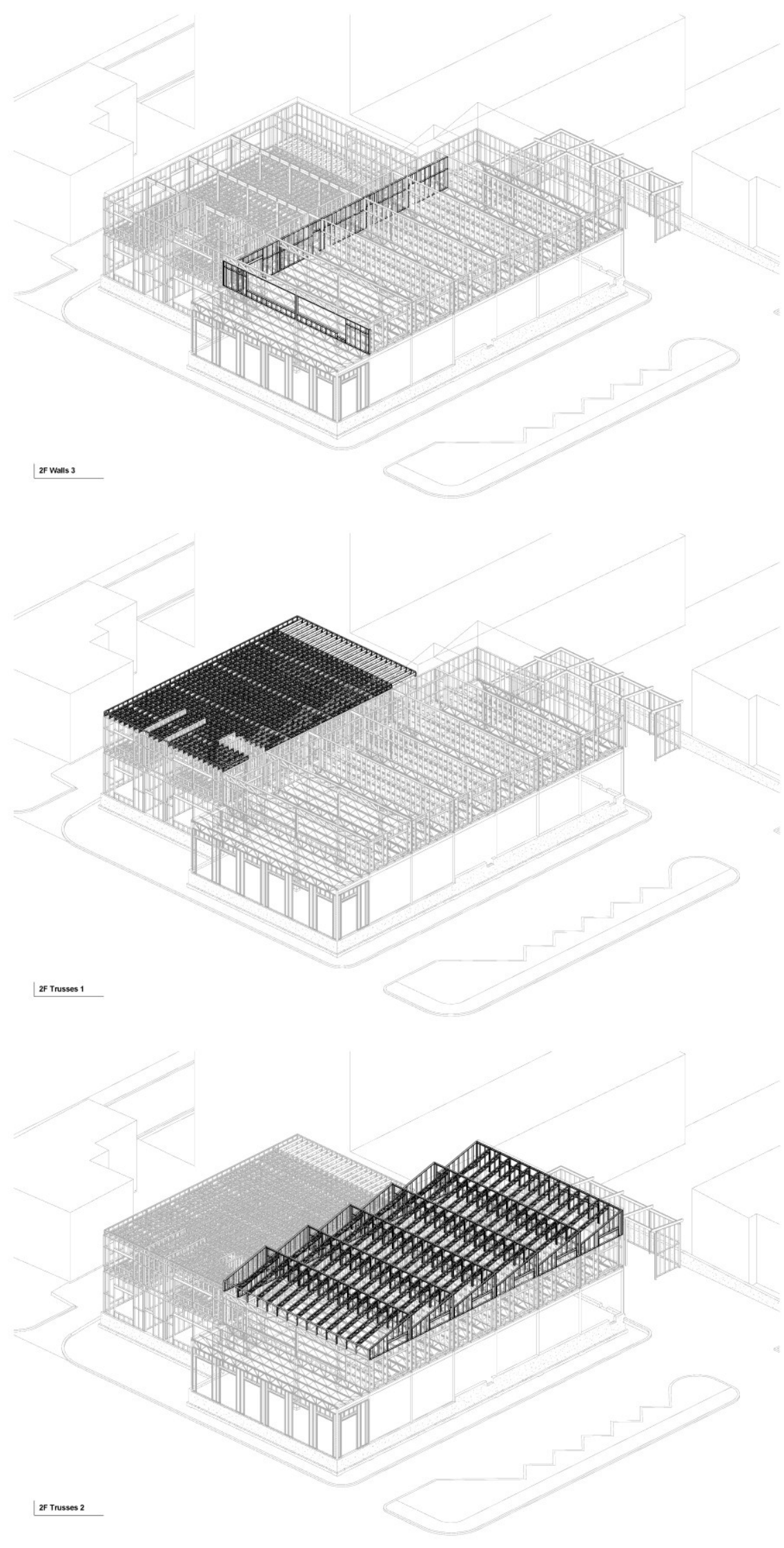


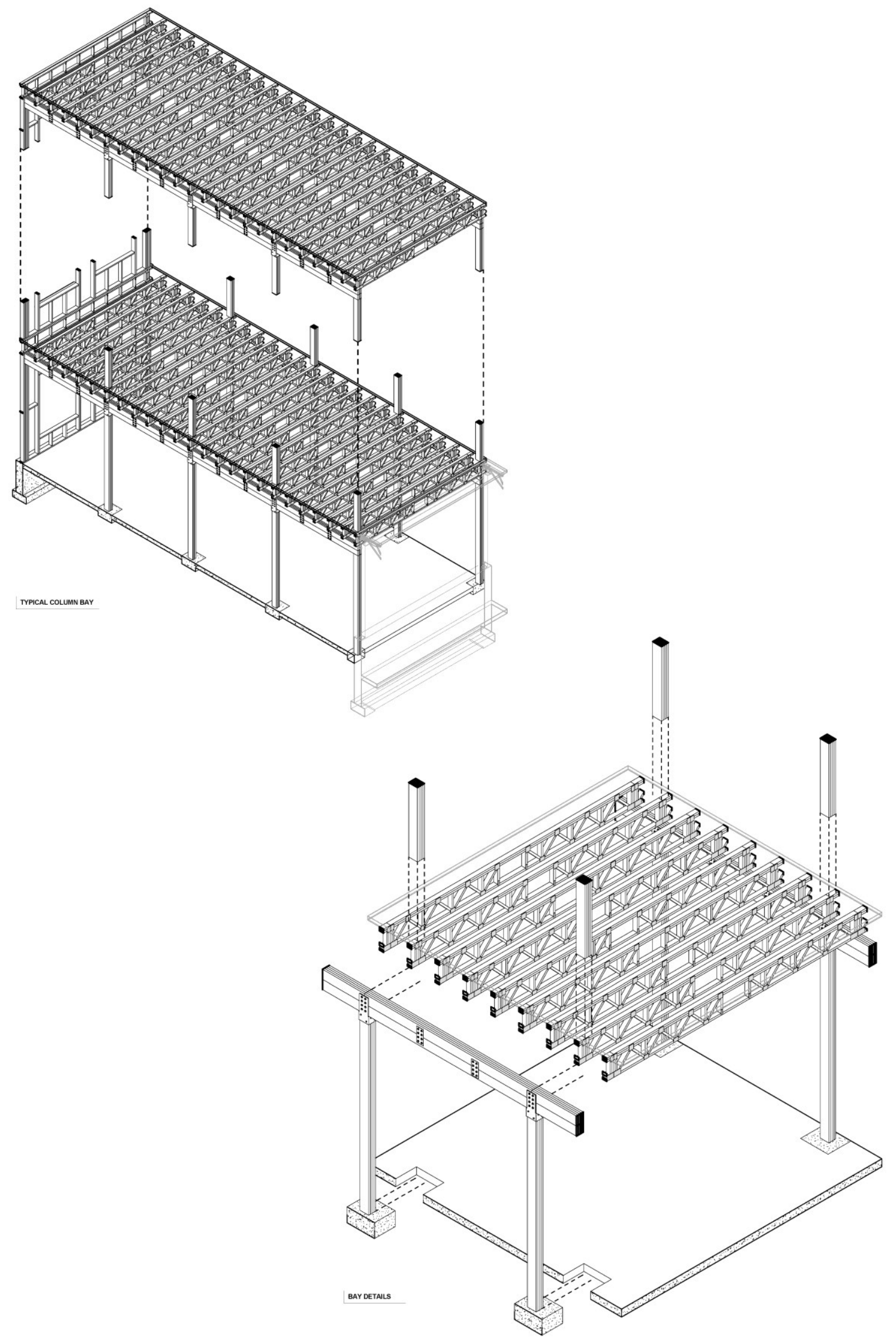




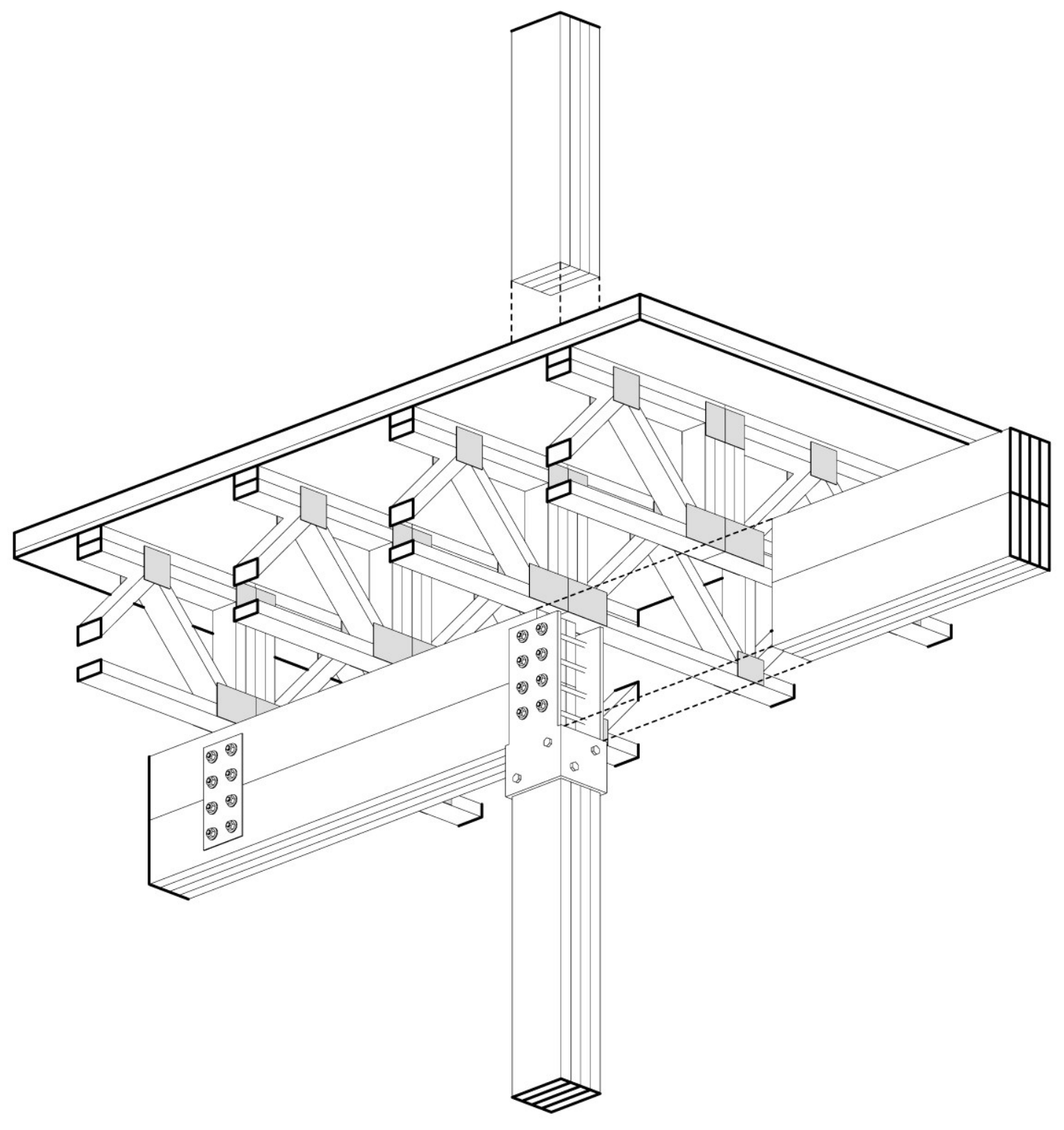

CONNECTON DETALL 

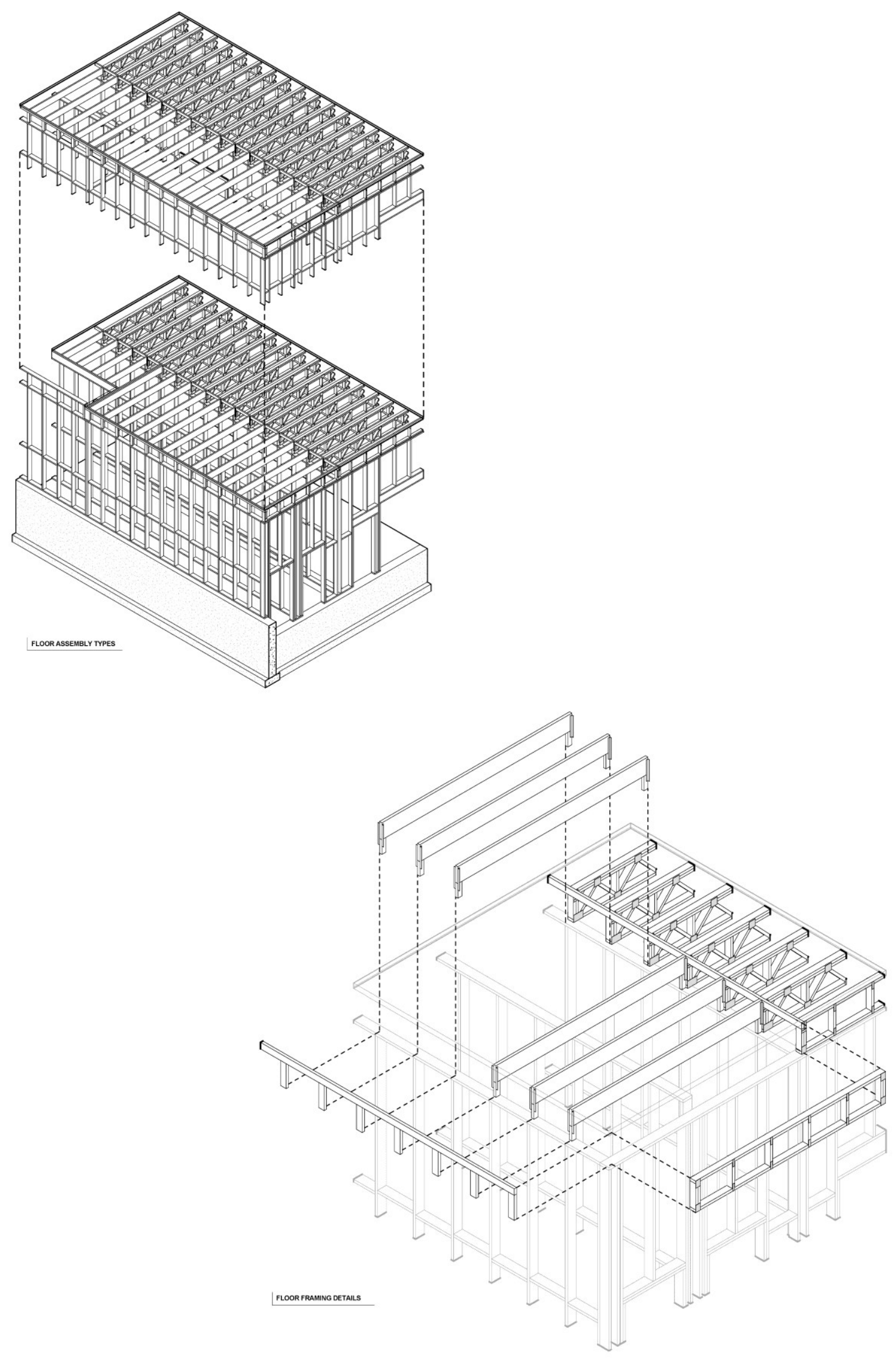


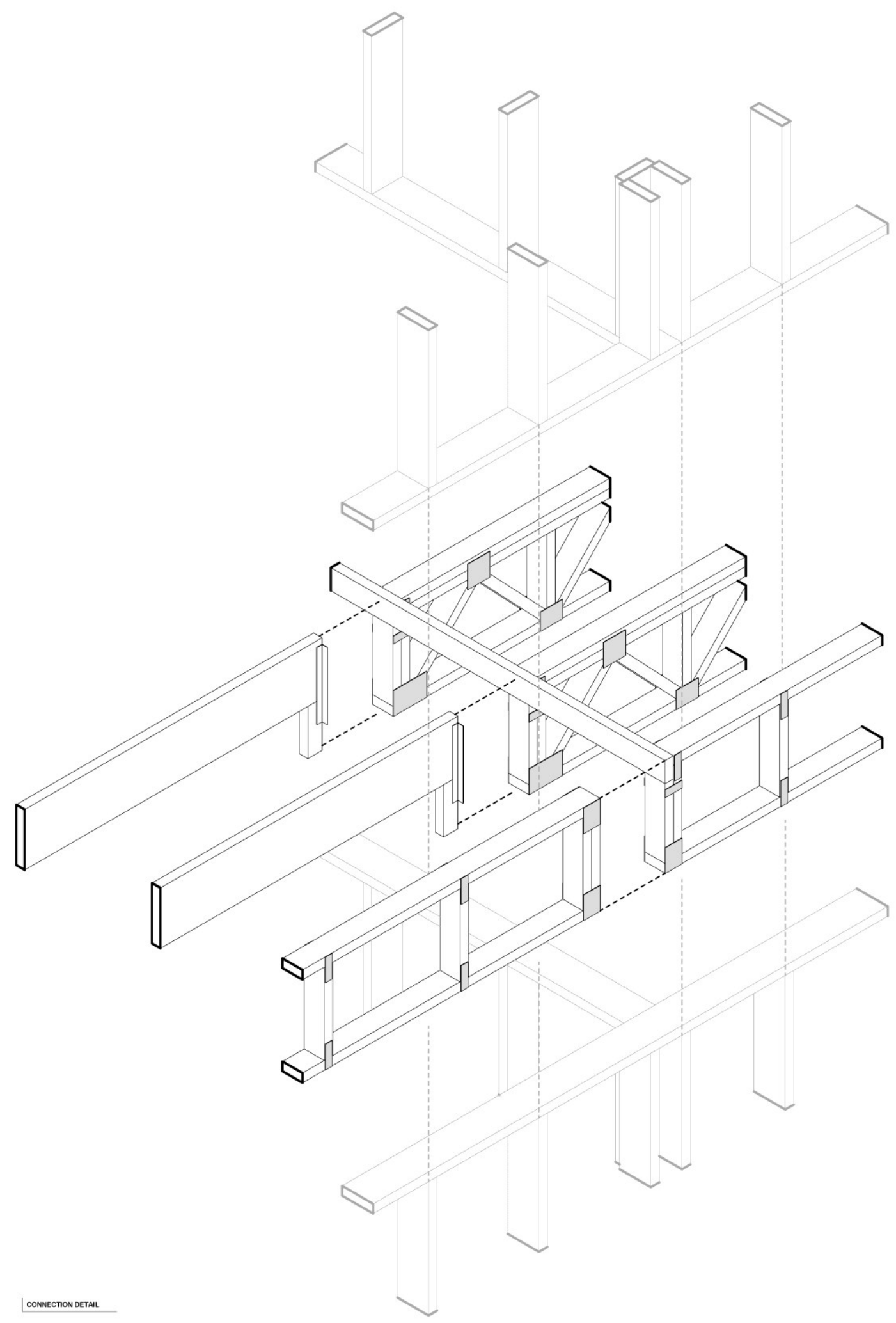



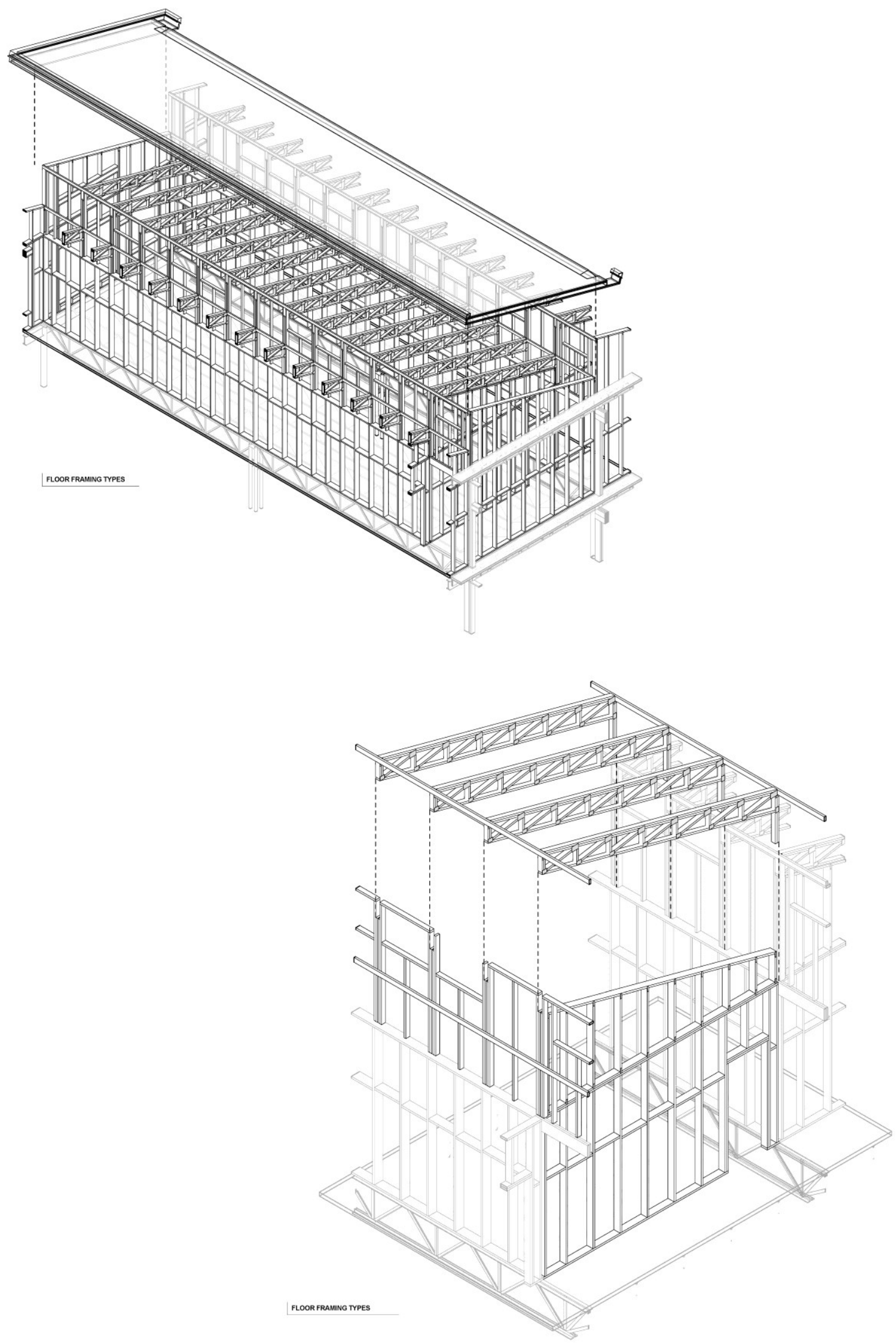


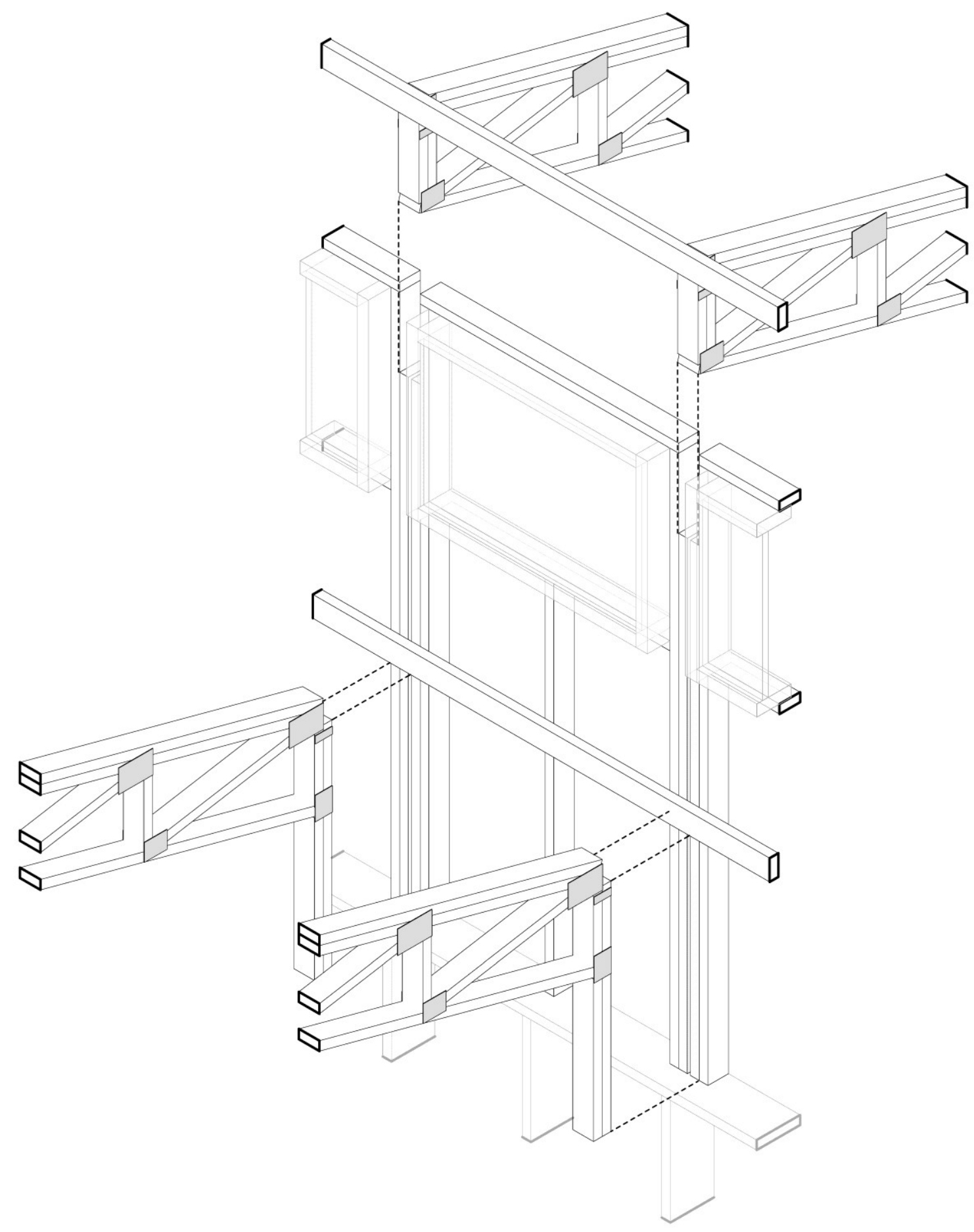

| CONNECTION DETAIL 


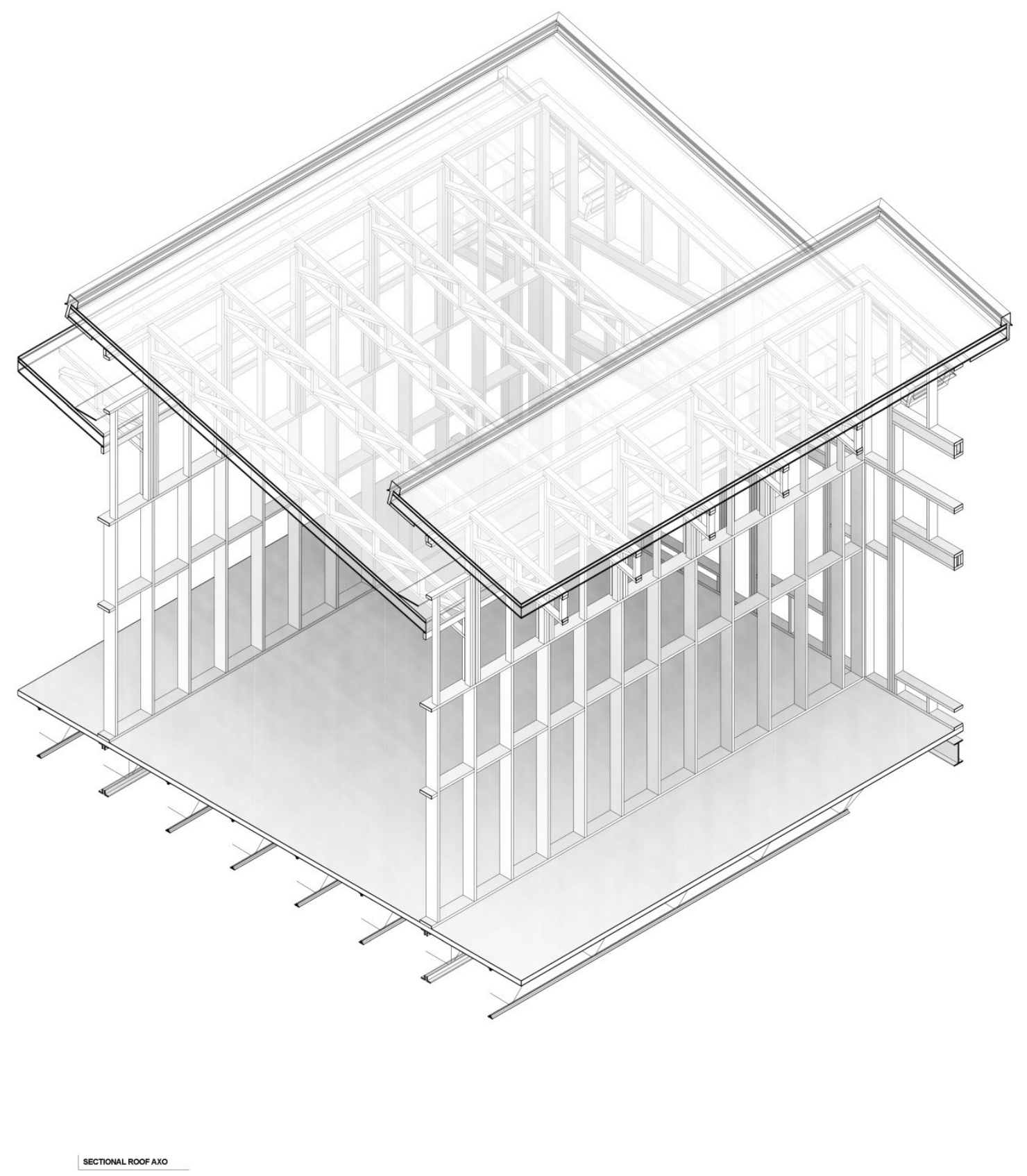




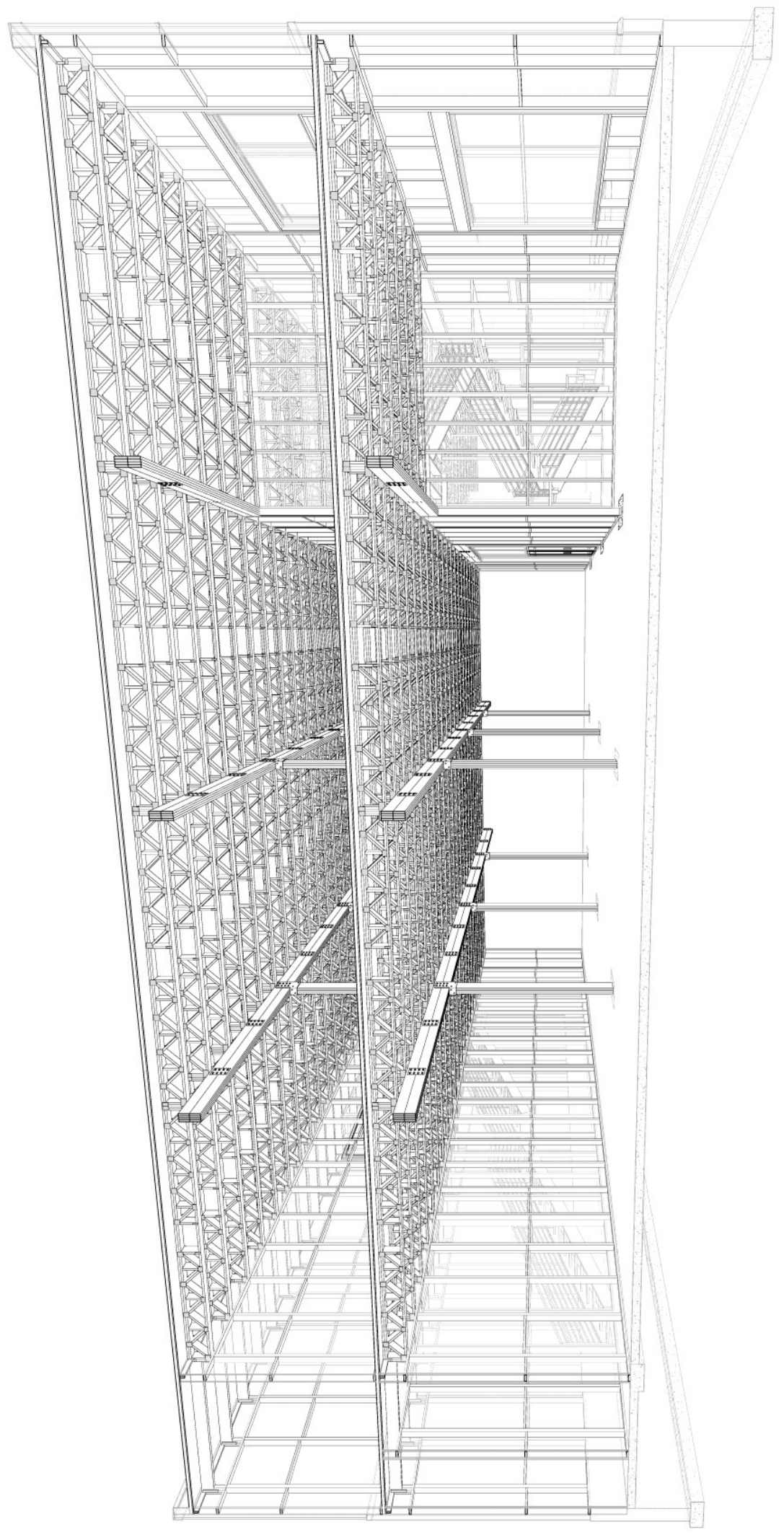




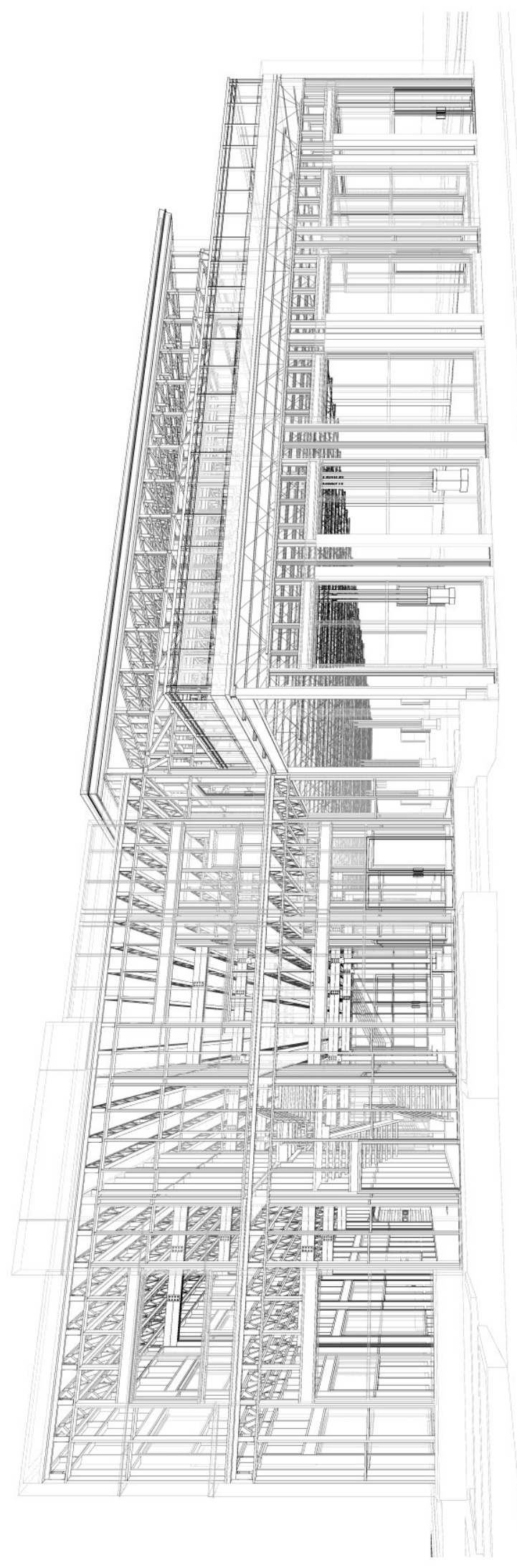




\section{CONCLUSION}

The current state of affairs in chapter one presented the implications concerning our planet if we do stay on the current path and do not change course toward a sustainableminded future. Landfills are filling up as solid waste from construction and demolition continues to grow and our finite resources are being consumed at an ever increasing rate. This research has revealed that a variety of theoretical frameworks and applied initiatives have brought forward adjustments that adopt cyclical models of reuse. Nonetheless, society will need to reduce, reuse, and recycle more than ever before.

Fortunately it was shown in chapter two that deconstruction offers a solution to our depleting resources, waste generation, and associated pollution, through untapped building material banks that provide supplies for the future. Deconstruction and material salvage can occur on a wide range of scales as a smarter method of building removal that will improve economically with time as industry adapts to progressing laws and regulations.

Chapter three expanded on why designing for disassembly and deconstruction go handin-hand. With supporting case studies, this research has highlighted that buildings designed to be taken apart are significantly easier to deconstruct than those not originally designed that way. Following key principles and strategies, design for disassembly eases environmental burdens through end-of-life recovery and reuse, but it should also integrate scenario planning and consider the different time-related building layers to become more 
versatile. All of these approaches offer a wealth of economic and environmental benefits throughout a buildings life-cycle.

Finally, digital workflows in chapter four proposed a process for undertaking either deconstruction or design for disassembly projects, utilizing technology for the benefit of documentation, team coordination, material information, and dissemination. Through exploration, this thesis informs that photogrammetry and building information modelling can be used as a viable process for estimating material quantities of existing conditions and calculating material requirements for new designs. Following this structure, the resulting requirements of the proposed design are analyzed below and compared to the salvaged property statistics. Figures such as these bring about interesting observations in comparing existing and proposed square footage to the quantity of material salvaged and required.

Combined totals for the existing properties amount to around 45,000 linear feet of wood framing members, or 46,250 board feet. The statistics of each property can be associated to their building area to establish a ratio of board feet per 100 square feet, or however else may be desired to observe and compare projects and assist in a real-world undertaking. 


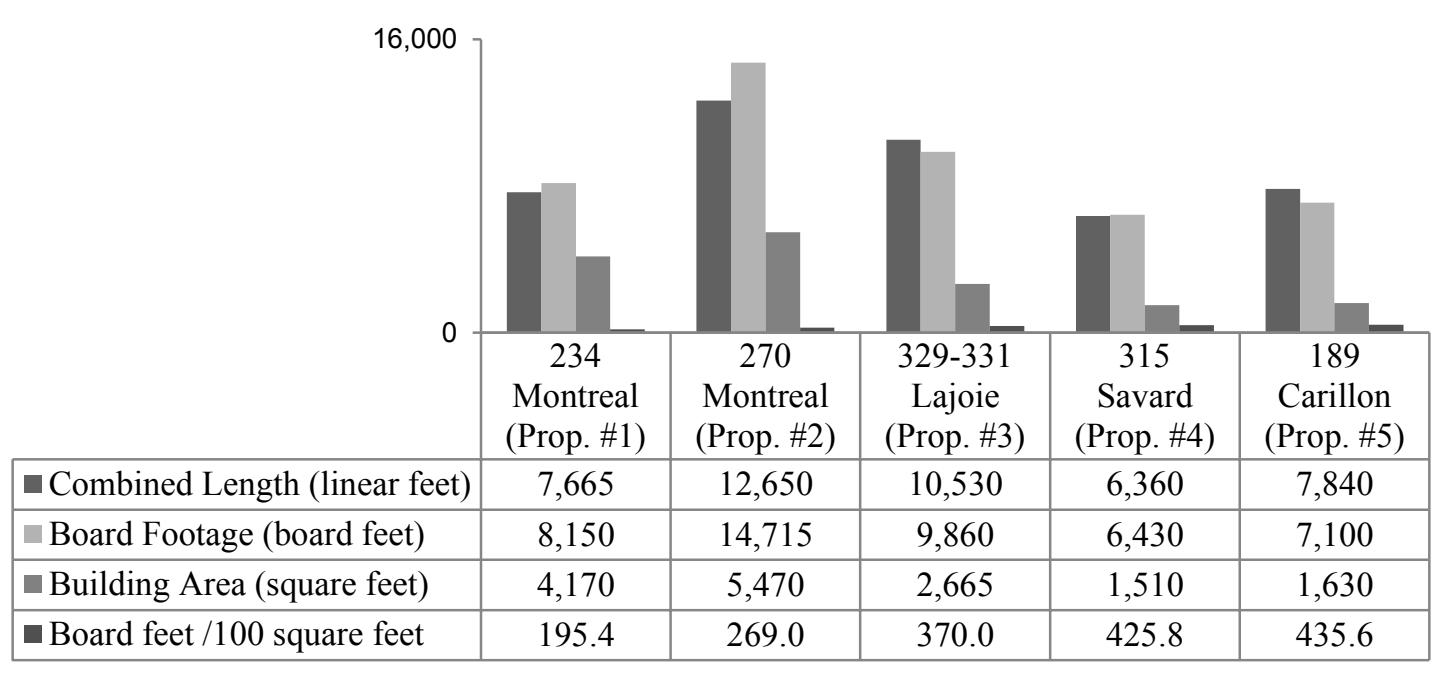

Table 22: Comparing estimated lumber quantities to building area of existing properties.

From these statistics, it is important to observe that although a large building may have larger members and greater overall quantities, a building of smaller scale may hold a higher ratio of building materials per square foot. However when modelling existing conditions, a simple difference between structural framing members inaccurately spaced 16 " or 24 " apart or sized $2 \times 4$ " versus $2 \times 6$ " in some areas may result in deceiving statistics for board footage. The schedules provided by this tool should therefore be considered as efficient estimations, with their accuracy reflected only by the thoroughness of the model and replication to verifiable existing conditions. Regardless, specific statistics that can be extracted from a BIM for analysis and comparison, such as the above, can undoubtedly assist with important decision making. 


\begin{tabular}{|c|c|c|c|c|}
\hline \multicolumn{5}{|c|}{ Proposed Design - Structural Framing Schedule Condensed } \\
\hline Material & Type/Size & $\begin{array}{l}\text { Combined } \\
\text { Length (L) }\end{array}$ & $\begin{array}{c}\text { Width }(W) x \\
\text { Height }(H)\end{array}$ & $\begin{array}{l}\text { Board Feet } \\
(L x W x H) / 12\end{array}$ \\
\hline M_Dimension Lumber & $38 \times 64(2 \times 3 ")$ & $64^{\prime}-7^{\prime \prime}$ & 6 & 32.3 \\
\hline $38 \times 64(2 \times 3 "): 97$ & \multicolumn{3}{|c|}{$64^{\prime}-7^{\prime \prime}$} & 32.3 \\
\hline M_Dimension Lumber & $38 \times 90(2 \times 4 ")$ & $27007^{\prime}-9^{\prime \prime}$ & 8 & 18005.16 \\
\hline $38 \times 90$ (2x4"): 7709 & \multicolumn{3}{|c|}{$27007^{\prime}-9^{\prime \prime}$} & 18005.16 \\
\hline M_Dimension Lumber & $38 \times 140(2 \times 6 ")$ & & 12 & 16625.16 \\
\hline $38 \times 140$ (2x6"): 2232 & \multicolumn{3}{|c|}{$16625^{\prime}-2^{\prime \prime}$} & 16625.16 \\
\hline M_Dimension Lumber & $38 \times 190(2 \times 8 ")$ & $5128^{\prime}-51 / 2 "$ & 16 & 6837.95 \\
\hline $38 \times 190$ (2x8"): 575 & \multicolumn{3}{|c|}{$5128^{\prime}-51 / 2^{\prime \prime}$} & 6837.95 \\
\hline M_Dimension Lumber & $38 \times 235(2 \times 10 ")$ & $1695^{\prime}-9^{\prime \prime}$ & 20 & 2826.27 \\
\hline $38 \times 235$ (2x10"): 184 & & $1695^{\prime}-9^{\prime \prime}$ & & 2826.27 \\
\hline Grand total: 10797 & & $50521^{\prime}-9^{\prime \prime}$ & & 44326.85 \\
\hline
\end{tabular}

Table 23: Proposed Design - BIM structural framing calculations.

For the proposed design, the total quantity of structural framing members required equal approximately 50,520 linear feet, or 44,325 board feet of dimensional lumber. This can then be compared to the total estimated quantities from the existing five properties to draw certain conclusions.

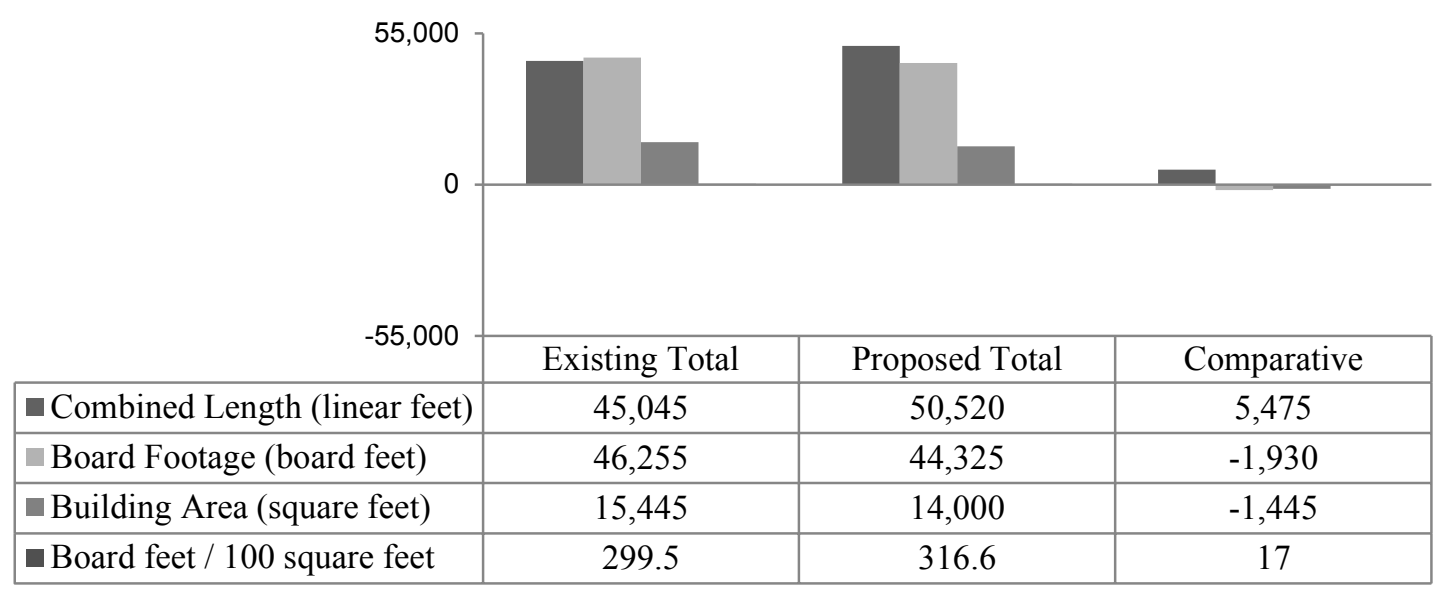

Table 24: Comparing existing and proposed building statistics.

Statistics shown here inform that while the proposed design has a lesser building area and board footage totals, it results in a slightly higher ratio of board feet required for every 100 square feet. The total combined linear length of structural members is quite higher due to the new design integrating a greater amount of smaller sized members that form the truss assemblies throughout the project, as shown in Table 22. The combined total 
length of these members end-to-end becomes greater than the existing totals, however as they are smaller sized $2 \times 4 "$ members, they result in a lesser mass per linear foot, and therefore board feet.

In further consideration of figures provided by the Riverdale case study, it is almost certain that deconstruction will result in a mix of both higher and lower quality salvaged building materials. As an example, the study found approximately two-thirds of lumber was of higher quality, and in a realistic scenario, lower quality members may not be feasible for structural reuse. Therefore this two-thirds ratio can be further applied to the total estimations for the existing properties.

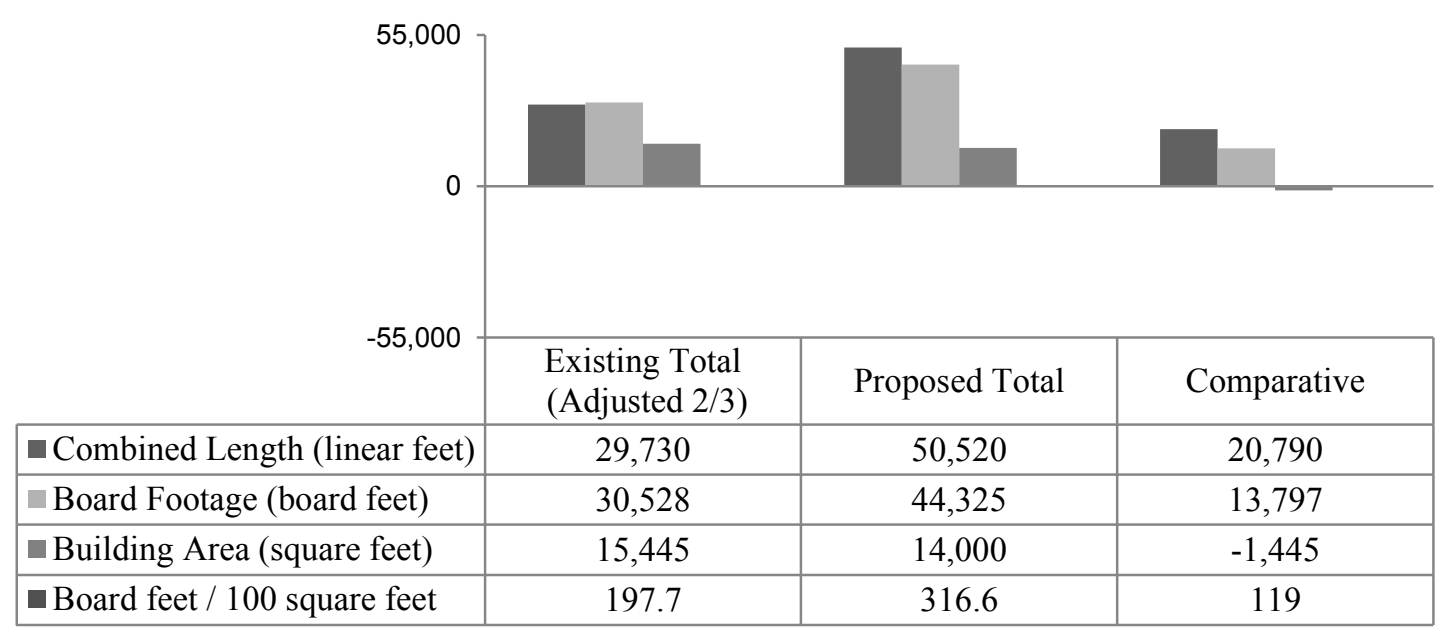

Table 25: Comparing two-thirds adjusted existing building statistics to the proposed design.

These adjusted figures immediately provide a different perspective on material requirements, where the proposed design now has a deficit of almost 13,800 board feet compared to salvage totals. If a project were to strictly adhere to reusing only salvaged materials, without new resources, then the ratio of board to square footage could be analyzed to review scaling back the proposed design. If that were to be applied in this 
case, a reduction in 13,800 board feet, at an average of 316.6 board feet per 100 square feet, results in a 4,358 square foot reduction of new building area.

There are a variety of ways this can be mediated, such as decreasing the second floor area by half, removing structural bays, using a different configuration of framing assemblies, or ultimately supplementing the proposed design with a balance of new materials to improve overall efficiency. All of these options can be quickly explored and provide immediate feedback through building information modelling. In conclusion, analyzing statistical information such as this enables different economic and environmental considerations regarding further design development in effort to match salvaged material quantities, or making informed decisions about new material investments.

This thesis has presented that a thorough understanding of deconstruction and design for disassembly must concern itself with several major issues. Increasing environmental concerns resulting from further investigations into natural resource depletion, waste generation, trends in production models, and their interrelationships will help society observe why shifting towards design for disassembly is essential. It is with hope that deconstruction will become the definitive standard for material reclamation in the coming years, as our economy shifts from being resource consumption based to adopting closed loop material cycles of reuse that minimize environmental impacts while providing resources for the future through intelligent design innovations. 


\section{BIBLIOGRAPHY}

"About Us." Salvo Ltd. Accessed March 2, 2017. http://www.salvoweb.com/aboutus.html.

"Advancing Sustainable Materials Management: Facts and Figures." United States Environmental Protection Agency. Accessed October 17, 2016. https://www.epa.gov/smm/advancingsustainable-materials-management-facts-and-figures.

Badger, Derek. Residential Deconstruction Manual. Ottawa: Canada Mortgage and Housing Corporation, 1999.

Bahamon, Alejandro, and Maria Camila Sanjines. Rematerial: From Waste to Architecture. New York: W.W. Norton \& Co, 2010.

Barkkume, Allen. "Deconstruction and Design for Disassembly." Academia. May 2008. http://www.academia.edu/178424/Deconstruction_and_Design_for_Disassembly.

Berge, Bjørn. Trans. Chris Butters and Filip Henley. The Ecology of Building Materials. Oxford, UK: Architectural Press, 2000.

Boyle, Sheryl. "Sounding Forgotten Cityscapes." Lecture. Carleton University, Ottawa, ON. October $17,2016$.

Brand, Stewart. How Buildings Learn: What Happens After They're Built. New York, NY: Viking, 1994.

"BREEAM." Building Research Establishment Ltd. Accessed January 28, 2017. http://www.breeam.com/.

Bulthuis, Mike. "Planning (and building) Vanier's mainstreets: the revised Offician Plan." VanierNow. August 18, 2013. http://vaniernow.blogspot.ca/2013/08/planning-and-buildingvaniers.html.

Burrows, John. Canadian Wood-Frame House Construction. 3rd ed, 2006. Ottawa: Canada Mortgage and Housing Corporation, 1967.

Canadian Construction Association. CCA 81-2001: A best practices guide to solid waste reduction. 2001. http://www.cca-acc.com/wp-content/uploads/2016/10/PreviewCCA81.pdf.

Canadian Wood Council. IBS2 - Wood Trusses - Strength, Economy, Versatility. Accessed February 6, 2017. http://cwc.ca/wp-content/uploads/publicationsIBS2_Wood_Trusses_SMC_v2.pdf.

Catalli, Vince. "Design for Disassembly: Early planning means an economic afterlife for buildings." Sustainable Architecture and Building Magazine, September/October 2009, 41-46. 
Catalli, Vince, and Maria Williams. "Designing for Disassembly." Canadian Architect. January 1, 2001. https://www.canadianarchitect.com/features/designing-for-disassembly/.

"C.K. Choi Building." The American Institute of Architects. Accessed October 1, 2016. http://www.aiatopten.org/node/206.

Chapman, Linda. "Mountain Equipment Co-op Store." Linda Chapman Architect. Accessed November 24, 2016. http://www.smartarchitecture.com/articles-2001spring.html.

"Chartwell." The American Institute of Architects. Accessed October 10, 2015. http://www.aiatopten.org/node/117.

City of Ottawa. 2015 Annual Development Report. April 2016. http://documents.ottawa.ca/sites/documents.ottawa.ca/files/2015_dev_rpt_en.pdf.

City of Ottawa. Montreal Road Transportation Planning and Functional Design Study. March 9, 2017.https://documents.ottawa.ca/sites/documents.ottawa.ca/files/montreal_road_pohboar ds_en.pdf.

City of Vancouver. Demolition and Abatement Reporting Requirements. Bulletin 2015-008-EV. Revised March 31, 2016. http://bulletins.vancouver.ca//2015/2015-008.pdf.

City of Vancouver. Green Demolition Program Update. November 16, 2015. http://council.vancouver.ca/20151216/documents/cfsc5.pdf.

Clayton Research Associates Ltd. and D.G. Wetherell and Associated Ltd. Two Decades of Innovation in Housing Technology: 1946-1965. Ottawa: Canada Mortgage and Housing Corporation, 1994.

Clayton Research Associates Ltd., Scanada Consultants Limited, and Marc Denhez. Three Decades of Innovation in Housing Technology: 1966-1996. Ottawa: Canada Mortgage and Housing Corporation, 2000.

Crowther, Philip. "Developing an Inclusive Model for Design for Deconstruction," in International Council for Research and Innovation in Building Construction Publication 266, edited by Abdol Chini. Wellington, New Zealand: CIB, 2001. http://eprints.qut.edu.au/2884/1/Crowther-TG39-2001.pdf.

"Design for the Environment Life-Cycle Assessments." United States Environmental Protection Agency. Accessed October 17, 2016. https://www.epa.gov/saferchoice/designenvironment-life-cycle-assessments.

"Extended Producer Responsibility." Environment and Climate Change Canada. Accessed November 17, 2016. https://www.ec.gc.ca/gdd-mw/default.asp?lang=En\&n=FB8E9973-1.

Falk, Robert H. and Brad Guy. Unbuilding: salvaging the architectural treasures of unwanted houses. Newtown, CT: Taunton, 2007. 
Forest Stewardship Council. Sourcing reclaimed material for use in FSC Product Groups or FSC Certified Projects. Bonn, Germany: Forest Stewardship Council A.C., FSC-STD-40-007 (V2-0), 2011.

Franklin Associates. Characterization of Building-Related Construction and Demolition Debris in the United States. Washington, DC: US Environmental Protection Agency, EPA 530-R-98010, June 1998.

Geggel, Laura. "US Dumps Twice as Much Trash as EPA Estimated." Live Science. September 22, 2015. http://www.livescience.com/52261-landfill-waste-underestimated.html.

Guy, Bradley, and Nicholas Ciarimboli. Design for Disassembly in the Built Environment: A Guide to Closed Loop in Design and Building. Seattle, WA: King County Solid Waste Division, accessed October 5, 2015.

http://your.kingcounty.gov/solidwaste/greenbuilding/documents/Design_for_Disassemblyguide.pdf.

Guy, Bradley, and Scott Shell. "Design for Deconstruction and Materials Reuse," in International Council for Research and Innovation in Building Construction Publication 272, edited by Abdol Chini. Karlsruhe, Germany: CIB, 2002.

https://www.iip.kit.edu/downloads/CIB_Publication_272.pdf.

Hawken, Paul, Amory Lovins and L. Hunter Lovins. Natural Capitalism: Creating the Next Industrial Revolution. New York: Little Brown and Company, 1999.

Holladay, Martin. "The Pros and Cons of Advanced Framing." Green Building Advisor. December 24, 2010. http://www.greenbuildingadvisor.com/blogs/dept/musings/pros-and-consadvanced-framing.

Kibert, Charles J., Jan Sendzimir and Brad Guy. "Construction ecology and metabolism: natural system analogues for a sustainable built environment." Construction Management \& Economics 18, no. 8 (2000): 903-916.

Knecht, Barbara. "Design for Disassembly and Deconstruction." Architectural Record, October, 2004, 181-188.

Korber, Andrea, and Brad Guy. Design for Disassembly in the Built Environment: An Atlanta Home Case Study. United States Environmental Protection Agency. December 13, 2006. http://www.lifecyclebuilding.org/docs/DfDCaseStudyHomeSummary.pdf.

Kwok, Alison G., Britni L. Jessup and Nicholas B. Rajkovich. Chartwell School Case Study. University of Oregon, June 01, 2009. http://www.aia.org/aiaucmp/groups/aia/documents/pdf/aiab080510.pdf.

Lebow, Victor. "Price competition in 1955." Journal of retailing 31, no. 1 (1955): 5-10.

Leonard, Annie. Dir. Louis Fox. Prod. Erica Priggen. "The Story of Stuff." Berkeley, California: Free Range Studios, December 2007. Video, 21:24. http://storyofstuff.org/movies/story-of-stuff/. 
Marley, Karin. "Sweden offers tax breaks to repair - not replace - broken objects." CBC/RadioCanada. October 11, 2016. http://www.cbc.ca/radio/thecurrent/the-current-for-october-122016-1.3800184/sweden-offers-tax-breaks-to-repair-not-replace-broken-objects1.3800185 .

McDonough, William. A Centennial Sermon - Design, Ecology, Ethics and the Making of Things. New York: The Cathedral of St. John The Divine, 1993.

McDonough, William. "Cradle to Cradle Design." Filmed February 2005. TED video, 20:05. https://www.ted.com/talks/william_mcdonough_on_cradle_to_cradle_design?language=en.

McDonough, William, and Michael Braungart. Cradle to Cradle: Remaking the Way We Make Things. New York: North Point, 2002.

McDonough, William, and Michael Braungart. The Upcycle: Beyond Sustainability - Designing for Abundance. New York: North Point, 2013.

NAHB Research Centre Inc. A Guide to Deconstruction. Maryland: NAHB Research Centre, Inc., February 2000. http://www3.epa.gov/epawaste/conserve/imr/cdm/pubs/decon_br.pdf.

NAHB Research Centre Inc. Deconstruction - Building Disassembly and Material Salvage: The Riverdale Case Study. Maryland: NAHB Research Centre, Inc., June 1997. http://www.lifecyclebuilding.org/docs/Riverdale\%20Case\%20Study.pdf

NAHB Research Centre Inc. Deconstruction: Building Disassembly and Material Salvage. Brochure. Accessed October 10, 2015. http://www3.epa.gov/epawaste/conserve/imr/cdm/pubs/decon_br.pdf.

National Research Council of Canada. Canadian Code for Residential Construction (Residential Standards) 1970. Ottawa: National Research Council of Canada, 1970.

Nordby, A.S. "Salvageability of building materials." PhD diss., NTNU, 2009. http://www.divaportal.org/smash/get/diva2:225736/FULLTEXT02.pdf.

Nordby, A.S. et al. "Lifetime and Demountability of Building Materials," in Proceedings of the Global Building Environment: Towards an Integrated Approach for Sustainability, edited by M. Mourshed. Preston, United Kingdom: University of Central Lancashire, 2006.

Ontario Building Code, O Reg. 332/12.

"Ottawa blaze leaves 2 dozen homeless." CBC/Radio-Canada. March 16, 2011. http://www.cbc.ca/news/canada/ottawa/ottawa-blaze-leaves-2-dozen-homeless-1.1101441.

"Overview of Greenhouse Gases." United States Environmental Protection Agency. Accessed October 17, 2016. https://www.epa.gov/ghgemissions/overview-greenhouse-gases.

Pletcher, Kenneth. "Ise Shrine." Encyclopaedia Britannica, Inc. Accessed November 4, 2016. https://www.britannica.com/topic/lse-Shrine. 
Ross, Susan. "From Salvage to De-construction of Heritage Places: Rethinking Waste Values in Canadian Cities," What Does Heritage Change? Montreal: UQAM/Association for Critical Heritage Studies (forthcoming), 2017.

Sather, Greg. "Woodward Avenue Environmental Laboratory." Sustainable Architecture and Building Magazine. Accessed September 26, 2016.

http://www.sabmagazine.com/blog/2008/10/17/wastewater-testing/.

Shell, Scott, Octavio Gutierrez and Lynn Fisher. Design for Deconstruction: The Chartwell School Case Study. United States Environmental Protection Agency. Accessed October 3, 2015. https://www.epa.gov/sites/production/files/201511/documents/designfordeconstrmanual.pdf.

"Statistics on construction activity." City of Vancouver. Accessed January 20, 2017. http://vancouver.ca/home-property-development/statistics-on-construction-activity.aspx.

"The Human Condition." National Geographic Society. Accessed December 10, 2016. http://www.nationalgeographic.com/earthpulse/human-impact.html.

Themelis, Nickolas, Rob van Haaren and Nora Goldstein. "The State of Garbage in America." BioCycle Magazine. October, 2010. https://www.biocycle.net/images/art/1010/bc101016_s.pdf.

Toffel, Michael W. "End-of-life product recovery: Drivers, prior research, and future directions" in Conference on European Electronics Take-back Legislation: Impacts on Business Strategy and Global Trade. 2002.

http://citeseerx.ist.psu.edu/viewdoc/download?doi=10.1.1.200.6612\&rep=rep1\&type=pdf.

"Training." Building Materials Reuse Association. Accessed February 08, 2017. https://bmra.org/training/.

United States Congress, Committee on Energy and Commerce. H. Rept. 113-371 - Better Buildings Act of 2014. 113 th Cong., 2d sess., 2013-2014.

https://www.congress.gov/113/crpt/hrpt371/CRPT-113hrpt371.pdf.

United States Environmental Protection Agency. Deconstruction Rapid Assessment Tool. Washington, DC: US EPA, March 2015. https://www.epa.gov/sites/production/files/201507/documents/drat-instructions.pdf

United States Environmental Protection Agency. Estimating 2003 Building-Related Construction and Demolition Material Amounts. Washington, DC: US EPA, EPA530-R-09-002, March 2009. https://www.epa.gov/sites/production/files/2015-11/documents/cd-meas.pdf.

United States Environmental Protection Agency. Municipal Solid Waste Landfills. Washington, DC: US EPA, June 2014.

https://www3.epa.gov/ttnecas1/regdata/EIAs/LandfillsNSPSProposalEIA.pdf.

United States Green Building Council. LEED Stories From Practice: Case Study - Chartwell School. Washington, DC: USGBC, 2010.

http://www.usgbc.org/Docs/Archive/General/Docs8824.pdf. 
Wagner, Lorie A. Materials in the economy, material flows, scarcity, and the environment. Vol. 1221. Geological Survey (USGS), 2002. https://pubs. usgs.gov/circ/2002/c1221/c1221508.pdf.

"Waste." Oxford University Press. Accessed October 8, 2016. https://en.oxforddictionaries.com/definition/waste.

Webster, Mark, and Daniel Costello. Designing Structural Systems for Deconstruction: How to Extend a New Building's Useful Life and Prevent It from Going to Waste When the End Finally Comes. Greenbuild Conference: Atlanta, GA, November 1, 2005.

http://www.lifecyclebuilding.org/docs/Designing\%20Structural\%20Systems\%20for\%20Dec onstruction.pdf.

"Woodward Labs." McCallum Sather Architects Inc. Accessed September 26, 2016. http://mccallumsather.com/projects/woodward-labs/.

Zimlich, Rachael. "Regional Landfill Capacity Problems Do Not Equate to a National Shortage." Waste360 Group. August 17, 2015. http://www.waste360.com/operations/regional-landfillcapacity-problems-do-not-equate-national-shortage. 


\section{APPENDICES}

\section{[A.1] Public and Private Initiatives}

Private, non-profit organizations such as the United States or Canada Green Building Council (USGBC, CAGBC) promote sustainability in the design, construction, and operation of buildings. These organizations and specialized councils have also worked with the government to help establish legislation such as the Better Buildings Act of 2014 which aims to improve the energy efficiency of commercial office buildings. ${ }^{121}$ The USGBC is best known for the development of the popular green building certification program Leadership in Energy and Environmental Design (LEED). The certification necessitates buildings to use resources more efficiently than conventional buildings built to the minimum code, and provides recognition and influence as a positive change to conventional standards through intelligent design choices. Although there may be a higher initial cost associated with the process, the reward in lower operational costs in the future offsets the difference in price.

Despite LEED's popularity in North America, the world's first and longest established process of assessing, rating, and certifying the sustainability of buildings is the Building Research Establishment Environmental Assessment Method (BREEAM). Founded in 1990, it has since been applied to masterplanning projects, infrastructure, and buildings in over 70 countries worldwide and holds a dominant share of the European market. ${ }^{122}$ Other competitive programs such as the internationally recognized Green Globes from

\footnotetext{
121 United States Congress, Committee on Energy and Commerce, H. Rept. 113-371 - Better Buildings Act of 2014. 113 $3^{\text {th }}$ Cong., 2d sess., 2013-2014, https://www.congress.gov/113/crpt/hrpt371/CRPT-113hrpt371.pdf.

122 "BREEAM," Building Research Establishment, accessed January 28, 2017, http://www.breeam.com/.
} 
the Green Building Initiative provide green building assessment and certification services which uses a rating and a guidance system for green building design, operation, and management. International programs such as the Living Building Challenge also advocate for advanced measures of sustainability in the built environment. All of these programs have the objective of reducing our impact on the planet by establishing guidelines for energy use, emissions, water, resources, and quality of health for building occupants.

In terms of public entities, government agencies and legislation have the greatest ability to influence change and establish leadership to provide the foundation for public following. In Canada, a broad range of post-consumer products at their end-of-life are managed by "product stewardship" and "extended producer responsibility" (EPR) programs. Most often with a regulatory underpinning, EPR programs intend to reduce environmental impacts of products by shifting physical and financial responsibility of post-consumer products to producers. ${ }^{123}$ Through product stewardship programs, such as retail take-back strategies, they provide a foundation to design for extended useful life and maximize recoverable value after use. In Europe, constraints on the production of waste and pollution since the early 1990s resulted in EPR legislation such as the Directive 200/53/EC of the European Parliament on end-of-life vehicles and Germany's End-of-Life Vehicle Act of 2002. This requires manufacturers to be responsible for

123 "Extended Producer Responsibility," Environment and Climate Change Canada, accessed November 17, 2016, https://www.ec.gc.ca/gdd-mw/default.asp?lang=En\&n=FB8E9973-1. 
developing strategies to reacquire and reuse or recycle their material goods as invested assets. $^{124}$

As part of a greater strategy for introducing sustainable patterns of consumption, the Swedish government offered tax breaks beginning in 2017 to repair — not replacebroken objects. ${ }^{125}$ Similar regulations in Scandinavia focus on the concern for waste reduction as building turnover increases. Enforced in 2008, any Norwegian demolition activity requires a waste plan to document the redirection of building waste volumes with a minimum $60 \%$ source separation. ${ }^{126}$

The advocacy of stewardship and sustainability through these programs has resonated through common society and is becoming more apparent to address regarding our patterns of production and consumption. On a local scale, repair businesses in Toronto are thriving on the push to fix instead of throw out, and are experiencing some of their highest amount of work as the desire grows to be a responsible consumer. ${ }^{127}$ Initiatives happen every day because of passionate people finding value in repairing or reclaiming materials. In some cases, what may start as a hobby for hoarding, people slowly accumulate so much material that they run out of space or passionately recognize the significance of the issue and decide to take on reclamation and reuse efforts full-time.

${ }^{124}$ Michael W. Toffel, "End-of-life product recovery: Drivers, prior research, and future directions" in Conference on European Electronics Take-back Legislation: Impacts on Business Strategy and Global Trade, 2002, http://citeseerx.ist.psu.edu/viewdoc/download?doi=10.1.1.200.6612\&rep=rep1\&type=pdf. 125 Karin Marley, "Sweden offers tax breaks to repair - not replace - broken objects," CBC/Radio Canada, October 11, 2016, http://www.cbc.ca/radio/thecurrent/the-current-for-october-12-2016-1.3800184/sweden-offers-taxbreaks-to-repair-not-replace-broken-objects-1.3800185.

${ }^{126}$ Nordby, Salvageability, 9.

127 Marley, "Sweden." 